\title{
DIEGO GELMÍREZ, LAS RAÍCES DEL LIBER SANCTI JACOBI Y EL CÓDICE CALIXTINO
}

Fernando López Alsina

Universidad de Santiago de Compostela 

Al dar cuenta de los avatares del pleito por diversos arciprestazgos y antes reproducir el acuerdo alcanzado en 1122 por el arzobispo Diego Gelmírez y el obispo Munio Alfonso de Mondońedo y sus respectivos cabildos, el maestro Giraldo califica a la sede jacobea como columna de la justicia y la presenta como la iglesia más apoyada por el poder eclesiástico y el temporal: "Compostellana ecclesia, columna iustitie et ecclesiastica atque seculari potentia magis suffulta» ${ }^{1}$.

Giraldo escribía hacia 1123-1124. Desde 1119 ocupaba el solio pontificio Calixto II, tío del rey Alfonso Raimúndez, que deseaba apoyar a su sobrino en sus aspiraciones al reinado exclusivo en el reino leonés. En 1120 el papa concedía a Gelmírez la transferencia de la metrópoli de Mérida y la condición de legado pontificio para las provincias de Mérida y Braga. El respaldo de los reyes asturleoneses a la sede apostólica compostelana había sido constante desde el siglo IX. No así, en cambio, la postura del papado.

Desde la segunda mitad del siglo XI, la organización eclesiástica del reino y la posición de cada sede episcopal en el seno de la iglesia universal pasó a depender de forma creciente de la autoridad pontificia. La sede compostelana estaba persuadida de la justicia que le asistía en sus planteamientos, fundamentados en el concepto de sede apostólica. León IX rechazó en 1049 este fundamento. Compostela entendía que era de justicia que se reconociese la primacía que le correspondía como sede apostólica. No le faltaba el apoyo regio, pero precisaba atraerse el pontificio. Para ello nada más oportuno que exponer con claridad los alegatos. El cambio progresivo en las relaciones de la iglesia compostelana con el papado entre $1049 \mathrm{y}$ la mitad del siglo XII está estrechamente relacionado con un singular conjunto de monumentos literarios, que toman cuerpo a lo largo de la carrera del primer arzobispo compostelano. En ellos se exponen los argumentos que esgrime Compostela para justificar el rango que debe corresponder a la sede. El propósito de este trabajo es insertar una obra tan compleja como es el Liber Sancti Jacobi en el contexto más amplio que le da su pleno significado y mostrar así su estrecha relación con la sede compostelana, en la cual se gestó, creció y alcanzó su forma definitiva² ${ }^{2}$.

1 Historia Compostellana II, 56.1, ed. Emma Falque Rey, Turnhout 1988 (Corpus Christianorum. Continuatio Medievalis 70), p. 329 (en lo sucesivo HC).

2 Manuel C. Díaz y Díaz (El Códice Calixtino de la Catedral de Santiago. Estudio codicológico y de contenido, Santiago de Compostela, 1988, p. 309-314) propone la posibilidad de que, bajo falsas atribuciones, se oculte una compilación de materiales diversos realizada en la ciudad de Santiago. 
Diego Gelmírez no tenía ninguna duda de la eficacia de la acción del apóstol Santiago en la Iglesia universal. Era de justicia para el Apóstol y su iglesia compostelana que fuese la propia Iglesia universal la que admitiese este papel, empezando por el sumo pontífice. De ahí la ficción de atribuir el Libro de Santiago a Calixto II y presentarlo como la compilación de unos materiales elaborados con el concurso de aquella misma cristiandad que reconocía y se beneficiaba de la acción apostólica de Santiago el Mayor.

\section{DIEGO GELMÍREZ ANTES DEL ACCESO AL EPISCOPADO: LA NUEVA LITURGIA, LA HISTORIA DE LA SEDE DE IRIA-COMPOS- TELA Y EL RELATO DE LA EXPEDICIÓN HISPÁNICA DE CARLO- MAGNO}

En 1049, poco antes del nacimiento de Diego Gelmírez, el mismo año en que era consagrado papa, León IX censuraba abiertamente al obispo Cresconio de Iria por emplear el título de obispo de la sede apostólica. La rapidez con la que actúa el primer papa del movimiento reformista sugiere que ya como obispo Bruno de Toul conocía perfectamente las implicaciones de la situación eclesiástica del reino de Fernando i de León. El culto al apóstol Santiago en Compostela se había hecho notorio en todo Occidente a través de la pujante peregrinación a su sepulcro.

Cresconio fue un adalid de la reforma eclesiástica de la iglesia peninsular. $\mathrm{Su}$ papel de inspirador del concilio de Coyanza de 1055 queda patente a la luz de la posterior celebración de los concilios de Compostela de 1059 y 1063, que profundizan en los acuerdos de Coyanza sobre el derecho episcopal y en la vida canónica en las sedes, dentro del respeto a las tradiciones de la Hispana. Consciente de su papel, el obispo, con el respaldo de Fernando i, nunca renunció al título de apostólico ${ }^{3}$. Sin embargo, como prelado reformista, comprendió la necesidad de coordinarse con el papado y explicar ante Roma sus puntos de vista.

Las fuentes compostelanas posteriores corren un velo de silencio sobre todas las relaciones de la sede con el papado reformista anteriores a 1095. Aun así, tanto

3 Como se desprende de Pilar Blanco Lozano, Colección diplomática de Fernando I (1307-1065), León, 1987. 
Munio Alfonso como Giraldo de Beauvais hacen una críptica referencia a un episodio de excepcional importancia para reconstruir una parte de las primeras relaciones con Roma. Las versiones de uno y otro son ligeramente distintas, pero coinciden en lo esencial. En la iglesia romana se mantenía vivo el recuerdo de una afrenta hecha por un obispo compostelano a un legado papal.

En efecto, en cierta ocasión, siempre antes del cambio litúrgico, es decir, antes de ca. 1080, un cardenal romano, legado pontificio, que ya se hallaba en Galicia, anunció por medio de sus acompañantes su inmediata llegada a Compostela ${ }^{4}$. El obispo, que se negó a recibirlo con las formalidades preceptivas, justificó la afrenta con el argumento de que tampoco su enviado había sido bien recibido en Roma, en particular por el mismo cardenal que entonces llegaba a Compostela como legado. Los dos autores de la Historia Compostellana silencian el nombre del obispo y el nombre del legado. La precisión de que se trataba de un cardenal romano conviene a Hugo Cándido, legado de Alejandro II (1061-1073), y, en consecuencia, al obispo Cresconio, pero valdría también para Ricardo de Marsella, legado de Gregorio vir, lo que apuntaría a una fecha posterior y al obispo Diego Peláez. Pero lo que merece especial atención es el hecho de que el obispo previamente había enviado a Roma a un tesorero de su iglesia. Es la única embajada compostelana a Roma anterior al pontificado de Urbano II, que se menciona en la Historia Compostellana. El objetivo no es informar de un contacto entre Santiago y Roma, sino explicar el motivo de la animosidad hacia Compostela. No parece que los legados compostelanos de las primeras décadas del siglo XII tuviesen noticia del episodio, que les era recordado al llegar a la curia pontificia. El desconocimiento previo de los legados compostelanos se explica tanto mejor cuanto mayor sea la antigüedad del episodio. En caso de que Diego Peláez hubiese sido el protagonista del episodio, siempre antes de su deposición en 1088, es mucho más difícil que con un cabildo de veinticuatro canónigos ya se hubiese perdido la memoria poco después del año 1100 .

Personalmente me inclino a pensar que la datación del episodio en tiempos del obispo Cresconio y del rey Fernando i aclara mejor el olvido a principios del siglo XII y otras cuestiones. Cresconio contaba con un reducido cabildo de siete

4 Se aborda en la HC I, 16.6, en la narración de Munio Alfonso (Falque Rey, p. 39) y II, 1, en la de Giraldo (Falque Rey, p. 220-221). 
canónigos. Como prelado reformista pudo perfectamente dar el paso de enviar un primer legado al papado de la reforma, antes de la legacía de Hugo Cándido. La censura pontificia de 1049 no lo pudo dejar indiferente. El envío a Roma de un tesorero de su iglesia podría entenderse como un gesto conciliador, que tendría como finalidad exponer ante la curia el alcance de su título apostólico y su aspiración a seguir usándolo, como realmente hizo hasta su muerte. Nótese que el tesorero tenía entre sus competencias la custodia de los documentos de la catedral compostelana, que, sin duda, serían relevantes para respaldar las posiciones de Cresconio. Un testimonio de vital importancia sería una carta, atribuida ahora a un papa León, que daba cuenta del traslado del cuerpo de Santiago desde Jerusalén a Galicia, llevado a cabo por siete discípulos del Apóstol.

Como demuestra el cisma de 1054 con el patriarca Miguel Cerulario, Roma veía con gran preocupación las consecuencias que podía tener para la unidad de la Iglesia el uso del título apostólico por parte de Cresconio.

No consta la fecha de la embajada del tesorero compostelano, pero sí el rechazo del papado a las pretensiones del obispo. Entra dentro de lo previsible que, en estas circunstancias, los asuntos hispánicos fuesen estudiados e informados por alguno de los cardenales de la curia. Lo sugiere la identidad entre el cardenal romano, al que se atribuye la desconsideración con el tesorero compostelano, y el cardenal romano enviado posteriormente a Compostela como legado.

Ante el anuncio de la llegada del legado a Compostela, el obispo de Santiago invitó a sus canónigos a dispensarle una recepción tan poco decorosa, como la que se había dispensado en Roma al tesorero. Semejante reacción se comprende mucho mejor si entendemos que la protagoniza el mismo obispo que había enviado al tesorero a Roma. La frustración de Cresconio era doble: la censura de 1049 y el rechazo a las pretensiones comunicadas por su legado.

La preocupación pontificia por la iglesia leonesa, manifestada en 1049, se agravó todavía más con el fracaso del entendimiento con Cresconio y su legado. Sin duda, lo delicado de la situación aconsejó a Alejandro in el envío de un legado pontificio. Resulta impensable que el envío del primer legado del papado reformista no tuviese nada que ver con la sede compostelana. Ese legado fue un cardenal romano, el cardenal Hugo Cándido, sin duda buen conocedor de los problemas que su legacía tendría que abordar. 
Por el relato de la Historia Compostellana comprendemos que Hugo Cándido fue el cardenal que más directamente llevó los asuntos suscitados por el tesorero enviado a Roma por Cresconio. En calidad de experto en los asuntos hispánicos, fue enviado como legado por Alejandro II. Como no podía ser menos, entre sus objetivos estaba resolver el espinoso asunto de la sede apostólica compostelana, para lo cual era imprescindible visitar Compostela. Hugo Cándido llegó a Galicia y envió sus emisarios a la iglesia compostelana, lo que provocó la reacción airada del obispo Cresconio. Todo parece indicar que, ante la afrenta recibida, Hugo Cándido desistió de visitar Compostela. Así se explica mejor que el legado romano no haya sido capaz de celebrar un concilio legatino con los obispos del reino leonés. Alejandro iI y sus sucesores recordarán este fracaso de la legacía como una consecuencia de la afrenta hecha por el obispo de Santiago.

Tras la muerte del obispo, el corto episcopado de su sucesor Gudesteo, que pertenecía a la misma familia de la nobleza gallega que su tío Cresconio, acabó dramáticamente con su asesinato a principios de 1069. Diego Peláez (ca. 1071-1088) rigió la sede de Santiago durante una parte del pontificado de Gregorio vir. En su nombramiento fue decisivo el rey Sancho de Castilla. Una parte del clero castellano había asistido al concilio legatino de Hugo Cándido. Peláez no tenía conexiones con Galicia, como demuestra el hecho de que, tras la pérdida del obispado compostelano, se exilió y buscó refugio fuera del reino, entre sus parientes y allegados, y siempre gozó del apoyo del rey de Aragón-Pamplona. Desde esta perspectiva, el perfil de Peláez lo hacía adecuado para propiciar el camino del entendimiento de la sede compostelana con Roma. De hecho, a diferencia de Cresconio, Peláez aceptó las tesis pontificias y reconoció a los legados pontificios. Sin embargo, desde 1072 el obispo se encontró con que el reino lo gobernaría Alfonso vi, un rey que no había tenido parte alguna en su promoción a la sede compostelana.

Gregorio vil seguía cuestionando el estatuto apostólico de la sede compostelana, la predicación del apóstol Santiago en Occidente, la presencia de su cuerpo en Compostela y la vigencia de la liturgia hispánica y deseaba la plena integración de Hispania en una Cristiandad occidental, colocada bajo la plena jurisdicción pontificia y de sus legados apostólicos. También reclamaba la península 
como patrimonio de san Pedro ${ }^{5}$. Alfonso vi no cedió ante esta reivindicación y Diego Peláez pudo iniciar en Compostela la nueva catedral románica en 1075 , ampliar de siete a veinticuatro el número de canónigos, organizar el servicio de hebdomarios en el altar, asumir la autoría papal de la epístola del Pseudo-León sobre el traslado del cuerpo del Apóstol a Compostela y mantener la titulación de sede apostólica. Todo ello sin perjuicio de aceptar la nueva liturgia romana, como quería Gregorio viI.

El joven Diego Gelmírez no conoció directamente el episcopado de Cresconio, pero vivió durante una parte del episcopado de Diego Peláez en el seno de la iglesia compostelana y desde una posición privilegiada. Por encargo del obispo, su padre Gelmirio gobernó durante muchos años la parte más occidental del señorío de Santiago — comprendido entre el Tambre y el Ulla, con Iria, Torres de Oeste, la Mahía y Postmarcos. Diego Gelmírez, hijo de este caballero, fue ordenado clérigo en la iglesia de Santiago a temprana edad por el mismo obispo Peláez. Se educó con provecho en la escuela catedralicia, donde adquirió amplios conocimientos de latín, lengua en la que, siendo ya prelado, pronunció sermones en ocasiones relevantes, y pasó a formar parte del grupo de veinticuatro canónigos. Hasta el encarcelamiento de Peláez en 1087, Gelmírez fue uno de los contados canónigos que formaba parte de la curia episcopal, órgano de gobierno del prelado, al que sin duda pertenecía también su padre Gelmirio ${ }^{6}$.

Como estrecho colaborador del obispo, hemos de suponer que el joven Gelmírez estaba al corriente de las vicisitudes por las que atravesaba la sede episcopal durante los años 80 y, en particular, en lo referente al tránsito del rito hispano al romano.

Hasta el año 1080 en la Catedral de Santiago, que acogía una liturgia heredera de la hispana, no había ninguna fiesta de un santo particular dotada de oficio propio para los días de la octava, ni siquiera la fiesta de Santiago el Mayor, que

5 Frente a la asociación de los varones apostólicos con Santiago el Mayor, la carta de Gregorio viI de 7 de marzo de 1074 (Gregorii VII Registrum, ed. Erich Caspar, MGH Epp. Sel. II, 1, Berlín, 1920, p. 91-94), afirma que los introductores del cristianismo en España habían sido sí los varones apostólicos, pero discípulos de Pedro y Pablo.

6 Sobre el período previo al episcopado puede verse Richard A. Fletcher, Saint James's Catapult: The Life and Times of Diego Gelmirez of Santiago de Compostela, Oxford, 1984, p. 102-116 (traducción gallega de Henrique Monteagudo y María Xesús Lama, A vida e o tempo de Diego Xelmírez, Vigo, 1992). Me apoyo en este trabajo para la mayor parte de los datos referentes a Gelmírez. 
desde el siglo viII se había venido celebrando el día 30 de diciembre en el reino astur-leonés. Sin duda alguna Gelmírez fue testigo en la Catedral de Santiago de las últimas celebraciones de la fiesta de Santiago en el día 30 de diciembre según su forma tradicional, en cuya liturgia tenían un papel destacado el Himno o Dei Verbum y la Passio Magna?.

La severidad con que Gregorio vir se había pronunciado sobre la formulación de las pretensiones apostólicas de la iglesia de Santiago obligó a Diego Peláez y a sus colaboradores a proceder con cautela. La liturgia que en torno a 1080 se introducía en Compostela, y en las sedes episcopales del reino de Alfonso vi, celebraba también una única festividad de Santiago el Mayor, pero en otra fecha, el día 25 de julio, la única difundida hasta entonces en el resto de las iglesias de Occidente.

Esta coyuntura litúrgica es especialmente importante para buscar en Compostela las raíces del Liber Sancti Jacobi. Como veremos enseguida, en el Liber se constata la coexistencia de una fiesta de verano, el martirio de Santiago, celebrada el 25 de julio, con otra de invierno, celebrada el día 30 de diciembre. Ninguna iglesia de Occidente de liturgia romana, incluido el monasterio de Cluny, había incorporado la fiesta hispánica del 30 de diciembre junto a la del 25 julio y, desde luego, no lo iban hacer después de 1080, tras la supresión de la liturgia hispánica y la solemnidad del 30 de diciembre. Con el cambio de rito, la pasión de Santiago dejaría de celebrarse el 30 de diciembre en las iglesias del reino leonés. La fiesta sería sustituida por la del 25 de julio. De todas las sedes episcopales leonesas, la Catedral de Santiago era ciertamente la más interesada en que no desapareciera definitivamente la festividad del 30 de diciembre.

Al obispo Diego Peláez se le debe el haber mantenido la antigua singularidad de la iglesia leonesa, lo que implicaba incorporar a la liturgia romana de la Catedral de Santiago la vieja fiesta del 30 de diciembre. Para ello fue preciso darle un contenido nuevo, aceptable para Roma, y seleccionar los textos apropiados. Se inauguraba así en la catedral compostelana la nueva fase de liturgia romana, con una singularidad sin parangón en las iglesias de Occidente: la celebración de dos fiestas anuales dedicadas al apóstol Santiago, la vieja celebración de invierno y la nueva de verano.

7 Justo Pérez de Urbel, «El Antifonario de León y el culto de Santiago el mayor en la liturgia mozárabe», Revista de la Universidad de Madrid, 3 (1954), p. 5-24. 
En este nuevo contexto, la Passio Magna de los siglos v/vi era totalmente inadecuada. Igual de inapropiado era el himno O Dei Verbum, en último término basado en la teoría de la predicación de Santiago en Hispania. En el himno se presenta a un apóstol Santiago que "gobierna» (regens) Hispaniam. A propósito de la petición hecha a Jesús por María Salomé, madre de los Zebedeos, de que sus hijos se sentasen en el cielo uno a su derecha y otro a su izquierda, el autor del himno afirma que, en cumplimiento de la promesa, Santiago y Juan gobiernan efectivamente en la Iglesia, uno a la derecha y el otro a la izquierda, Juan desde Éfeso y Santiago desde Hispania. El himno había sido compuesto entre los años 783 y 788, antes del descubrimiento del sepulcro. Se comprende fácilmente que en el contexto del pontificado de Gregorio viI, la iglesia compostelana se viese obligada a eliminarlo del oficio divino del día 30 de diciembre.

Las huellas de esta peculiar reforma litúrgica, tal como se llevó a cabo en Compostela hacia 1080, y de otras posteriores se aprecian perfectamente en el Liber Sancti Jacobi, lo que constituye una prueba clave a favor del origen compostelano de la compilación ${ }^{8}$. La fiesta del 30 de diciembre recibió en Compostela un nuevo contenido: la conmemoración de la vocación apostólica de Santiago el Mayor? Para el oficio divino se eligió el pasaje del Evangelio de San Mateo referente a la vocación de Pedro y de Andrés (4, 18-22) y, como lectura, se tomó a la letra la correspondiente homilía Audistis, fratres, escrita por el papa Gregorio Magno en honor de san Andrés ${ }^{10}$. Sobre ella se llevaron a cabo las necesarias adaptaciones: se sustituye el nombre de Andrés por el de Santiago y se modifica la terminación para introducir la referencia a la celebración de la fiesta de Santiago.

Para la vigilia del 24 de julio (CC I, 1, p. 11-13) se acude al comienzo de la Epístola de Santiago (Jac. 1,1-14), porque se pensaba en Santiago el Mayor como su autor, y el sermón Quoniam Beati de Beda el Venerable, tomado del comen-

8 Sobre la parte litúrgica del Códice Calixtino véase Elisardo Temperán Villaverde, La liturgia propia de Santiago en el Códice Calixtino, Santiago, 1997. La relación con la liturgia concreta vigente en la Catedral de Santiago es una cuestión diferente.

9 Liber Sancti Jacobi. Codex Calixtinus, I, 18, ed. Klaus Herbers / Manuel Santos Noia, Santiago de Compostela, 1998, p. 105-106 (en lo sucesivo cc). Se trata de la mejor edición latina disponible.

10 Jacques Paul Migne, Patrologia cursus completus. Series latina, 76, París, 1857, col. 1093-1095 (en lo sucesivo PL). 
tario a esta epístola, con las pertinentes adaptaciones, como la referencia a la festividad de la "vigilia de Santiago» ${ }^{11}$.

Para el 25 de julio (CC I, 8, p. 55-59) se eligió el pasaje del Evangelio de Mateo sobre la petición de María Salomé (Mt 20, 20-23), texto muy apropiado para la fiesta del martirio de Santiago puesto que anuncia el martirio de los dos hermanos. Es el mismo episodio que, como vimos, había inspirado en el siglo viII al autor del himno O Dei Verbum, para relacionar la predicación de Santiago en Hispania y los lugares occidentales con su posición de gobierno en Hispania, frente a la posición de gobierno de Juan en Éfeso ${ }^{12}$. Para subrayar mejor el nuevo sentido que Compostela aceptaba darle ahora a este pasaje, se acudió a la homilía Dominus conditor, tomada de las estivales de los santos compuestas por Beda el Venerable ${ }^{13}$. En su texto Beda afirma que «está sentado a la diestra del Salvador el que en la bienaventuranza celestial goza de su visión real», mientras que «está sentado a la izquierda el que en esta peregrinación está al frente de su santa Iglesia con la dirección sacerdotal $»^{14}$. Precisa más adelante que Santiago y Juan «estaban sentados a la izquierda de Cristo, cuando estaban al frente de los fieles para regirlos en esta vida por derecho apostólico» ${ }^{15}$. Estas frases de Beda, escritas en el siglo viII, se leían en la liturgia de una Compostela que a finales del siglo xI buscaba congraciarse con Roma. Nada recuerda en ellas la interpretación que Roma acababa de censurar. El derecho apostólico de Santiago se ejerció cuando regía a los fieles «en esta vida».

Los dos sermones de Beda y el de Gregorio Magno, universalmente conocidos, eran anteriores a la fundación del culto sepulcral en la Galicia del siglo Ix. El Dominus conditor neutraliza la teoría de las dos sedes de Oriente y Occidente, Éfeso y Santiago, tan embarazosa ante Gregorio viI.

\footnotetext{
11 La pieza Quoniam beati, sobre la epístola de Jac. 1, 1 ss., en PL 93, col. 9-14; véase Liber Sancti Jacobi "Codex Calixtinus». Traducción por los profesores A. Moralejo / C. Torres / J. Feo, reed. Xosé Carro Otero, Santiago, 1992, p. 11, n. 6.

12 Véase Robert Plötz, «Der Apostel Jacobus in Spanien bis zum 9. Jahrhundert», en Spanische Forschungen der Görresgesellschaft, 1. Reihe, Gesammelte Aufsätze zur Kulturgeschichte Spaniens 30 (Münster, 1982), p. 19-145, especialmente p. 90-94.
}

13 CC I, 8, p. 56-59. Véase PL, 94, col. 228-233.

14 Herbers / Santos Noia, p. 57; Moralejo / Torres / Feo, p. 118.

15 Herbers / Santos Noia, p. 58; Moralejo / Torres / Feo, p. 119. 
Tras el encarcelamiento de Peláez de 1087, el canónigo Gelmírez, que ya debía de ser uno de los miembros destacados e influyentes del cabildo, había aprendido los entresijos de las relaciones con Roma.

Peláez debía el obispado de Santiago al rey Sancho de Castilla y carecía de conexiones familiares en Galicia. La hostilidad que le demostraría Alfonso vi puede estar en relación con la oposición al plan de conferir un estatuto primacial al cluniacense Bernardo, obispo desde 1086 de la recientemente conquistada sede de Toledo. Semejante proyecto significaba que una sede apostólica como la de Santiago quedaba subordinada a la autoridad del primado de Toledo. Si el programa se llevaba hasta sus últimas consecuencias, la sede episcopal debía ser Santa Eulalia de Iria, ni siquiera Santiago de Compostela. En el concilio legatino de Husillos (marzo/abril de 1088), el cardenal legado Ricardo ratificó su deposición y autorizó la promoción episcopal del candidato regio, el abad Pedro de Cardeña. Pocos meses después, Urbano II concedía la primacía a Bernardo de Toledo, con autoridad sobre todos aquellos obispos cuya metrópoli no hubiese sido aún restaurada (15-X-1088). Sin embargo, desautorizó a su legado por haber permitido la deposición de Peláez.

La implantación de un mapa eclesiástico inspirado en el tardo-visigodo debía beneficiar las legítimas aspiraciones metropolitanas de Pedro de Braga, aunque, sin duda, desde el punto de vista del cluniacense Bernardo, el obispo no era la figura idónea para impulsar la reforma eclesiástica. El primado consagró la Catedral de Braga (28-vini-1089), acompañado por tres obispos que serían sufragáneos de Braga, en caso de una hipotética restauración de la metrópoli: Gonzalo de Mondoñedo, Auderico de Tui y Pedro de Ourense.

Urbano II envió un nuevo legado, el cardenal Rainerio, futuro papa Pascual II, quien celebró concilio legatino en León (marzo de 1090). El obispo Pedro de Santiago fue removido de su sede. En coherencia con el paso dado al restablecer la vieja primacía toledana, Pedro de Braga solicitó el palio y la restitución de la provincia eclesiástica bracarense. Su petición fue rechazada, pero el obispo bracarense acudió al antipapa Gilberto de Rávena, de quien obtuvo el palio, y regresó a Braga como arzobispo cismático. Urbano II decidió reforzar su autoridad en la iglesia peninsular y nombró legado pontificio a Bernardo de Toledo.

La inseguridad canónica se había instalado en la iglesia compostelana. Diego Gelmírez tuvo ocasión de comprender que la continuidad de la sede en Com- 
postela y el papel que sus obispos habrían de jugar en el futuro sobre el conjunto de la iglesia hispánica tendría que ser definido necesariamente en dos instancias: la curia pontificia y la corte regia. De hecho, al vacar la sede, Alfonso vi privó a la iglesia compostelana de las temporalidades y todavía en León, en marzo de 1090, confió la administración del señorío de la iglesia de Santiago a un habitante de la ciudad, Pedro Vimáraz, que era el gobernador regio de la urbe (regius villicus), medida que no dejaría de ser bien vista por los habitantes de una ciudad de realengo, pero que resultaba nefasta para la iglesia compostelana.

El desafío de Pedro de Braga a Urbano ir y la situación eclesiástica en la que estaba llamada a ser la provincia eclesiástica bracarense debieron pesar decisivamente a la hora de concretar el poder territorial encomendado a Raimundo de Borgoña, cuñado del duque Eudes I de Borgoña, quien, a su vez, era sobrino de la reina Constanza. El conde Raimundo y su esposa, la infanta Urraca, recibieron el gobierno de Galicia, Portugal y Coimbra. Pedro de Braga fue capturado y acabó sus días en un monasterio.

Con Raimundo y Urraca, Pedro Vimáraz perdió su villicatio sobre el señorío de la iglesia compostelana. Ahora competía a Raimundo decidir. Los destinos de Gelmírez y Raimundo debieron cruzarse en ese momento. Es posible que, al organizar su gobierno en Galicia, Raimundo se asociase como colaborador de la primera hora a quien debía ser entonces uno de los canónigos más influyentes en la sede compostelana. Diego Gelmírez fue efectivamente canciller, secretario y miembro de la curia del conde Raimundo, funciones para las que el conde solo habría seleccionado a un clérigo de buena formación. Es de destacar que esta posición de Gelmírez en el entorno de Raimundo de Borgońa es paralela a la que alcanzó como arzobispo en 1127, en la curia de su hijo, como canciller de Alfonso viI.

Aun así, cuando Raimundo tuvo que pronunciarse sobre el señorío de la iglesia de Santiago, pensó en otro laico. Nombró merino a Arias Díaz y lo puso al frente de la merindad, en la que se hallaba la ciudad de Santiago, de manera que el señorío de la vacante iglesia compostelana quedó incorporado a su merindad. Pero cuando murió Arias Díaz, siguiendo probablemente los consejos de Gelmírez, estimó que la administración del señorío eclesiástico debía recaer en un clérigo, antes que en un laico, y eligió para ello a su canciller y secretario, el canónigo Diego Gelmírez, quien lo rigió desde 1093 hasta la llegada del obispo Dalmacio 
en 1094 y de nuevo, tras la muerte de este, hasta su consagración episcopal en 1101.

Hemos de situar en este momento, en los años comprendidos entre 1093 y 1095, sin duda con conocimiento de Diego Gelmírez o, incluso bajo su directa inspiración y dirección, el giro definitivamente pro romano en la sede compostelana y el comienzo de una producción de textos, de tipología muy variada, que no se completarían hasta poco después de la muerte del arzobispo en 1140, de la cual Diego Gelmírez fue siempre el principal inspirador, promotor y, en la mayor parte de los casos, autorizado supervisor.

El resultado de estas primeras iniciativas, llevadas a cabo con la sede de Braga vacante, fue la composición de una historia de la sede de Iria-Santiago y de un relato que vinculaba a Carlomagno con Santiago, germen de lo que acabará siendo el Pseudo-Turpín en el Liber Sancti Jacobi.

Urgida por Roma, Gelmírez comprendió que la sede debía replantear el fundamento de su apostolicidad, tal como se había expuesto y defendido hasta Diego Peláez. La sede episcopal era la iglesia de Santa Eulalia de Iria, sufragánea de Braga al final del siglo viI. La monarquía había promocionado desde el siglo IX la iglesia sepulcral de Compostela, donde desde 1075 se construía la nueva catedral románica, y a donde acudía la peregrinación occidental. Era preciso que el papado aceptase la transferencia de la sede y reconociese la presencia sepulcral del Apóstol en Compostela. Si Roma aceptaba la nueva realidad, la sede podría alegar que, a diferencia de Santa Eulalia de Iria, Compostela nunca había estado sujeta a la metrópoli bracarense. La posición del primado Bernardo de Toledo, legado pontificio, sería también determinante.

Compostela elaboró los primeros materiales compatibles con las exigencias romanas. Los nuevos puntos de vista se plasmaron en el llamado Chronicon Iriense, obra de un anónimo canónigo compostelano. No hay evidencias para pensar en el propio Diego Gelmírez. La crónica expresa con claridad las preocupaciones del momento y presenta una historia de la sede de Iria-Compostela que no menciona la predicación de Santiago, la intervención de varones apostólicos ni la translatio: la apostolicidad se sustenta únicamente en la presencia sepulcral, ratifi- 
cada y avalada por el argumento contemporáneo de la existencia de una poderosa peregrinación occidental en expansión ${ }^{16}$.

La crónica nos ha llegado mutilada en su parte final. La narración se acaba bruscamente en torno al año 1000, lo que no debe tomarse como indicio sobre la fecha de su composición. La obra se escribe en el contexto de la reciente concesión de la primacía a Toledo, sancionada por Urbano ir en 1088, y de la aspiración compostelana a la promoción romana de la sede compostelana. Iria-Compostela está ahora subordinada al arzobispo de Toledo, como primado y como legado pontificio, y, de aplicarse los mismos fundamentos históricos que justificaban la primacía toledana, como había pretendido Pedro de Braga, la iglesia compostelana y el obispado de Iria pasarían a ser sufragáneos de Braga.

Para proponer argumentos históricos contrarios a los del período visigodo, que resultaban favorables a Braga, la crónica se remonta a la ordenación eclesiástica del reino suevo católico en el siglo vi, antes de su anexión al reino visigodo por Leovigildo, tal como efectivamente se había llevado a cabo en un concilio, reunido probablemente en Lugo en el año 569 por el rey Teodomiro. Las disposiciones de este concilio de Lugo habían sido manejadas por Santiago y Lugo en la década de los años 60 del siglo XI, con ocasión del restablecimiento de las iglesias episcopales de Braga, Ourense y Tui ${ }^{17}$.

La fundación de la sede de Iria se presenta como primer acto del primer rey católico del primer reino suevo, en el primer concilio del reino romano-germánico, proponiendo para ello la hipotética celebración de un concilio en Lugo, no el año 569, sino antes del i de Braga del 561, cuando el rey Miro aún no había

16 Véase Fernando López Alsina, «Urbano Ir y el traslado de la sede episcopal de Iria a Compostela», en El Papado, la Iglesia leonesa y la basilica de Santiago a finales del siglo XI. El traslado de la sede episcopal de Iria a Compostela en 1095, ed. id., Santiago, 1999, p. 107-127.

17 En los 62 documentos auténticos de Fernando I están presentes como confirmantes los obispos de nueve sedes episcopales: León en 25, Oca en 18, Palencia en 17, Astorga en 14, Lugo en 9, Santiago en 8, Oviedo en 8, Mondoñedo en 4 y Oporto en 3. Cf. Bernard F. Reilly, The Kingdom of León-Castilla under King Alfonso VI. 1065-1109, Princeton, 1988, p. 16 (traducción española de Gaspar Otálora, El reino de León y Castilla bajo Alfonso VI: 1065-1109, Toledo, 1989). García de Galicia multiplica por dos el número de obispados de su reino, que pasan a ocho: Mondońedo, Lugo, Santiago, Tui, Ourense, Braga, Lamego y Porto; en el reino leonés de Alfonso se mantienen los cuatro obispados preexistentes: Oviedo, Astorga, León y Palencia. Oca es el único obispado del reino castellano de Sancho. 
anexionado el reino de Braga y, por tanto, aún no se había celebrado el primer concilio en la ciudad conquistada, que sería el del año 561.

La crónica emplea como nuevo recurso favorable a Santiago la asociación del espacio geográfico de la provincia eclesiástica bracarense del siglo viI con la apostolicidad de la sede de Santiago, a través del tratamiento que se hace del voto de Santiago ${ }^{18}$. En todo el relato se evita con esmero el uso del término de sede apostólica para referirse a Iria, incluso en el descubrimiento del sepulcro por Teodomiro en el siglo ix, que sería el lugar apropiado para introducirlo. De forma bien significativa, la crónica espera para introducir el título apostólico hasta bien entrado el siglo $\mathrm{x}$, justo en el momento de abordar la concesión del voto por el rey Ramiro II (931-951). Según la crónica, Ramiro acudió a Santiago causa orationis y prometió pagar a la iglesia apostólica un censo anual, a percibir en las tierras comprendidas entre el Pisuerga y el mar ${ }^{19}$.

El cronista sugiere una relación causa-efecto entre la promesa de otorgar el censo y la gran victoria militar posterior sobre Abderramán. El voto se ofrece en el curso de una peregrinación al sepulcro apostólico, para invocar la intercesión del Apóstol, petición que otros reyes habían hecho antes. La percepción del voto se asocia a una apostolicidad de la sede compostelana basada solo en la presencia del sepulcro y a una posición de preeminencia sobre Braga, reconocida por el derecho a percibir el censo, dentro de un espacio que se aproximaba a lo que podría entenderse en aquel momento por provincia eclesiástica bracarense, incluida la ciudad de Braga. El límite oriental del río Pisuerga, afluente del Duero, y el derecho a percibir un censo en espacios propios de otras iglesias episcopales apuntan a la pretensión de construir una provincia compuesta por iglesias sufragáneas, con la sede apostólica de Compostela como cabeza ${ }^{20}$.

18 Fernando López Alsina, La ciudad de Santiago de Compostela en la Alta Edad Media, Santiago de Compostela, 1988, p. 174-186.

19 Manuel Rubén García Álvarez, «El Cronicón Iriense», en Memorial Histórico Español, 50 (1963), p. 115: "Cuius tempore, Abdirahaman, Cordobensis rex, cum omni exercitu suo, fugatus et uictus est, qui rex antea acceserat ad beatum Iacobum causa orationis et obtulit ibidem uota usque in Pisorgam, ut singulis annis redderent censum apostolice ecclesie, et Deus magnam dedit ei victoriam».

20 En la crónica no aparece la figura del Santiago ecuestre, que el Silense asocia con la conquista de Coimbra. Véase Ángel Sicart Jiménez, «La iconografía de Santiago ecuestre en la Edad Media», Compostellanum, 27 (1982), p. 11-32. Su ausencia no significa necesariamente que no se hubiese acuñado todavía. 
Con esta reinterpretación del concepto de apostolicidad que expone la crónica, la sede de Santiago quiere cumplir las exigencias que contemporáneamente impone Roma. Tras dos siglos y medio de culto sepulcral, la peregrinación de gentes de ultra puertos avalaba la posesión del cuerpo. La crónica evita mencionar la predicación de Santiago en España, que, en último término, había justificado la fundación de la iglesia jacobea en el siglo Ix, y renuncia a una explicación histórica del traslado del cuerpo y, por tanto, a la actividad de los varones apostólicos que la habían llevado a cabo y encarnaban la idea de una primitiva comunidad cristiana apostólica, pero no romana. Por eso inicia el relato con la fundación de la sede de Iria en el siglo vi. La aceptación de los postulados de Gregorio vir explica que se soslaye cualquier relación de la sede de Iria-Compostela con los tiempos apostólicos del primer siglo de nuestra era $^{21}$.

Los esfuerzos de Peláez ante Roma no habían sido suficientes. El obispo había mantenido con poco éxito la tesis de una translatio, reforzada incluso con la identificación del autor de la carta explicativa con un papa llamado León ${ }^{22}$. En esta crónica, al prescindir de los varones apostólicos, las concesiones respecto al tema de la translatio llegan a la incoherencia puesto que, sin ellas, no se sabe cómo habría podido llegar el cuerpo a Compostela. La censura voluntaria, aunque formal y coyuntural, del tema de la misión de Santiago en Occidente obliga a la crónica a evitar también el tema de la participación de los discípulos de Santiago, agentes del traslado, y su papel en la construcción del edículo o iglesia primitiva.

La intención de subrayar explícitamente una autoría papal de la carta sobre la traslación de Santiago no está presente en el siglo Ix. Más bien hay que relacio-

21 Andrés suscribe las actas del i Concilio de Braga del 561 en primer lugar, precediendo a los otros seis obispos, entre los cuales está el propio Martín de Dumio. Antonio López Ferreiro (Historia de la Santa A. M. Iglesia de Santiago de Compostela, vol. I, Santiago, 1898, p. 374) entiende que el orden de confirmación refleja el de ordenación, lo que le sirve para sostener que Andrés fue obispo de Iria antes de la conversión de los suevos y que la sede tenía más antigüedad de la que le atribuye el Iriense. Una de las versiones sobre la misión de Santiago en España es censurada por el Códice Calixtino. Cf. Serafín Moralejo, «Idea de una exposición», en Santiago Camino de Europa. Culto y cultura en la Peregrinación a Compostela, Madrid, 1993, p. 235-241.

22 En la Concordia de Antealtares del año 1077 la autoría de la carta se atribuye explícitamente al papa León. Jesús Carro García, «La escritura de concordia entre Don Diego Peláez, obispo de Santiago, y San Fagildo, Abad del monasterio de Antealtares», Cuadernos de Estudios Gallegos, 4 (1949), p. 111-122. 
narla con una continuada preocupación de la sede compostelana, visible desde el siglo XI, por autorizar los hechos relativos al Apóstol. De un papa León autor de la carta, se pasará a una autoría del papa Calixto in del Libro de Santiago, certificada posteriormente por Inocencio II.

La última novedad de la crónica, en cuanto a la apostolicidad de la sede, se manifiesta en el tratamiento de la relación legendaria entre Carlomagno y Compostela. En una simple insinuación de sincronía con el descubrimiento, esta pieza historiográfica constituye una evidencia de que en Compostela ya se había formado la leyenda que atribuía a Carlomagno una intervención decisiva en la fundación del culto sepulcral.

El relato legendario de la campaña de Carlomagno en Espańa se ha conservado en los cinco primeros capítulos del Pseudo-Turpín del Códice Compostelano del Liber Sancti Jacobi. Hay algún indicio para pensar que su autor fue un franco, como por ejemplo la utilización del término galleciani para referirse a los gallegos, en lugar de gallaeci.

Si la historia de la sede sacrifica las espinosas cuestiones de la predicación y del traslado es porque su autor sabe perfectamente que otro relato contemporáneo las reafirmaba. Basta con recordar en la historia que la inventio del sepulcro tuvo lugar cuando reinaba Carlomagno.

En efecto, el relato de la expedición de Carlomagno se inicia con la exposición de la misión apostólica de Santiago en Galicia (CC IV, 1), es decir, con el relato del período anterior al siglo vi, que la crónica de Iria había evitado cuidadosamente. Se remonta al momento de la dispersión apostólica, con el fin de afirmar que Santiago predicó el primero en Galicia; sus discípulos trasladaron su cuerpo por mar desde Jerusalén a Galicia y en ella predicaron, aunque en algún momento posterior se borró la huella del cristianismo. Esta situación habría perdurado hasta la época de Carlomagno ${ }^{23}$.

Se trata de devolver a dominio cristiano la tierra que ha caído en manos del Islam. Es el propio apóstol Santiago el que por tres veces se le aparece en Aquis-

23Sobre este relato y su conexión con Compostela véanse Fernando López Alsina, «La prerrogativa de Santiago en España según el Pseudo-Turpín: ¿̇tradiciones compostelanas o tradiciones carolingias?», en El Pseudo-Turpin, lazo entre el culto jacobeo y el culto de Carlomagno (Actas del vI Congreso Internacional de Estudios Jacobeos), coord. Klaus Herbers, Santiago de Compostela, 2003, p. 113-129, y Santiago López Martínez-Morás, Épica y Camino de Santiago: en torno al Pseudo-Turpin, Sada, 2002. 
grán a Carlomagno para urgirle que libere su camino y su tierra y visite su basílica y sarcófago, es decir, que peregrine armado y con un gran ejército.

El Apóstol revela al emperador el significado del camino de estrellas que tanto le inquietaba a Carlomagno: desde el mar de Frisia se extendía «entre Alemania e Italia, entre la Galia y Aquitania, por Gascuña, Vasconia, Navarra y España hasta Galicia». Es el itinerario que, pasando por Aquisgrán, conduce al olvidado sepulcro de Santiago.

Claramente se reivindica el papel secular de los monarcas cristianos peninsulares en la "reconquista», frente a cualquier novedad que pudiera enfocarla desde la perspectiva de una dirección pontificia ${ }^{24}$. En el enfrentamiento con el Islam, en contra de las claves de la cruzada, es el propio apóstol Santiago quien promete a Carlomagno una corona inmortal, es decir, la indulgencia plenaria. Se quiere destacar el papel que históricamente habían tenido los reyes cristianos en la fundación de la Iglesia de Santiago, en la configuración de las vías de peregrinación y en la recuperación armada del espacio de la Cristiandad frente al Islam en una contienda de siglos. La actividad bélica frente a Al-Andalus precedía en el tiempo a las recientes iniciativas papales. En plena querella de las investiduras, el emperador Carlomagno aparece como el trasunto de ese poder temporal, que históricamente habían ostentado Alfonso II y sus sucesores hasta Alfonso vi, el emperador hispánico.

En el último tercio del siglo XI, el vigor de la peregrinación jacobea era un argumento de peso a favor de la sede compostelana. El tránsito creciente desde el siglo $\mathrm{x}$ de peregrinos ultrapirenaicos hacia Compostela se canalizó por ciertos lugares de paso tanto más frecuentados cuanto más cerca se hallaban de la meta. Poco a poco se fue esbozando una ruta en el norte peninsular y al costado norte de los puertos pirenaicos. Fueron los reyes cristianos peninsulares desde Sancho el Mayor de Navarra, no los papas, quienes prestaron atención y protección a los peregrinos que transitaban por un camino geográficamente fijado, que desde el último tercio del siglo xi empieza a ser denominado por los contemporáneos "Camino de Santiago» o "Camino francigena». Dos de las siete puertas de la

24 La reacción de los monarcas leoneses ante las pretensiones pontificias son estudiadas por Carlos de Ayala Martínez, Sacerdocio y Reino en la España Altomedieval. Iglesia y poder político en el Occidente peninsular, siglos VII-XII, Madrid, 2008, p. 324-415. 
segunda muralla de la ciudad de Santiago, construida hacia mediados del siglo XI, reflejan esta realidad. La puerta francigena o del Camino por antonomasia, la más oriental, y la puerta del Santo Peregrino, la más occidental, por la que el cuerpo del peregrino muerto en el curso de su peregrinación salía de la ciudad, para recibir sepultura en el cementerio del hospital. En 1072, Alfonso vi suprimía un peaje a la entrada de Galicia que perjudicaba a los peregrinos jacobeos, que, dice el rey, procedían de Italia, Francia y Alemania.

Lógicamente, cuanto más lejos de Compostela, menos densos podrán ser los flujos de peregrinos, más tardía será la eventual cristalización del camino y su reconocimiento específico como "Camino de Santiago» y menor la densidad de instituciones y hospitales especializados en la atención de los peregrinos jacobeos.

La peregrinación de las gentes de Occidente al sepulcro del Apóstol a finales del siglo xI solo ha sido posible gracias al esfuerzo militar por controlar el territorio por el que transita el camino. Por eso, el Apóstol promete a Carlomagno que, si vence, nunca cesará la peregrinación a su sepulcro y que, detrás de él, caminarán a Compostela todos los pueblos, de mar a mar, hasta el final de los tiempos.

La primera parte de la campańa empieza en Pamplona y, vía Santiago, concluye en Padrón, donde Carlomagno clavó su lanza en el mar, para indicar así que había conquistado todas las tierras hasta el mismo límite occidental del continente. Como cabría esperar, la toma de Pamplona, después de tres meses de inútil asedio, solo se resuelve cuando se invoca el auxilio de Santiago, que interviene milagrosamente en ayuda de los cristianos haciendo que los muros caigan de raíz. Ayuda de Santiago decisiva también para poder tomar la ciudad de Lucerna. El Iriense afirmaba también que Santiago auxiliaba a los cristianos contra los normandos y la conquista de la ciudad de Coimbra, en 1064, se acabará relacionando con otra intervención milagrosa del apóstol, si bien en el relato Santiago se le ha aparecido a Carlomagno bajo la forma de un heros, no aún como un miles. Quienes combaten bajo la protección de Santiago no precisan combatir exclusivamente bajo la protección de san Pedro.

La localización del sepulcro y la visita del mismo por Carlomagno revisten las características de una verdadera inventio regia, que contrasta con el escuetísimo tratamiento que le da contemporáneamente el Iriense. 
Si desde Pamplona a Galicia la población musulmana ha sido hecha tributaria, en los gallegos, en cambio, habitantes de la tierra donde el apóstol Santiago y sus discípulos habían predicado, procede regenerar su fe con el bautismo, administrado por el arzobispo Turpín. Nótese que aquí Turpín no es el autor del relato, sino un acompañante más de Carlomagno. El paralelismo Alfonso II/Teodomiro con Carlomagno/Turpín es más que evidente. Galicia, gracias al sepulcro de Santiago, tiene la primacía en la fe. Solo después de haber restablecido la fe apostólica en Galicia, el emperador recorre y conquista «España de mar a mar».

En toda la narración es muy significativa la oposición Galicia/resto de España, énfasis que tiene por objeto vincular la intervención de Carlomagno principalmente con Galicia y con el espacio provincial bracarense, exactamente igual que se hace en el Chronicon Iriense con el tratamiento geográfico del voto. La Iglesia de Santiago es la única basílica cristiana peninsular que merece la atención de Carlomagno. Es, sin duda, una sede apostólica, tanto por sus orígenes en la predicación apostólica y la de los discípulos, como por la presencia del cuerpo de Santiago. Los francos, adulados y bien recibidos, son los agentes de la regeneración de la primacía apostólica de la sede compostelana en Galicia, que es presentada como su provincia. En ninguno de los textos precedentes de las tradiciones jacobeas se había insistido de este modo en una relación apostólica de Santiago exclusivamente con Galicia ${ }^{25}$.

La misma oposición se hace patente al enumerar las ciudades y grandes villas que Carlomagno adquirió (cC IV, 3), de manera que nos permite verificar que la definición geográfica concreta que se propone para Galicia coincide con la de ca. 1093-1096. Las ciudades gallegas son trece: Viseo ${ }^{26}$, Lamego, Dumio, Coim-

25 El campo tradicional de predicación de Santiago era Hispania y los lugares occidentales. Véase Robert Plötz, «Der Apostel Jacobus», p. 19-145; Manuel C. Díaz y Díaz, «Literatura jacobea hasta el siglo XII», en Il Pellegrinaggio a Santiago de Compostela e la letteratura jacopea, ed. Giovanna Scalia, Perugia, 1985, p. 225-250.

26 Visunia en el Códice Compostelano. Cabría la identificación con Bretoña, mejor que Viseo, teniendo en cuenta que la forma Visunia reemplaza a Bretoña en algunas variantes de la División de Wamba. Véase Luis Vázquez de Parga, La división de Wamba. Contribución al estudio de la historia y geografía eclesiásticas de España en la Edad Media Española, Madrid, 1943. Para las identificaciones véase el estudio sistemático de José María Anguita Jaén, Estudios sobre el Liber Sancti Jacobi. La toponimia mayor hispana, Santiago, 2000. 
bra, Lugo, Ourense, Iria, Tui, Mondoñedo, Braga, Guimarães ${ }^{27}$, A Coruña y Compostela. Las diez primeras localidades habían sido en algún momento sedes episcopales.

Si en la relación de ca. 94 ciudades y villas mayores del resto de España seleccionamos las más occidentales por su situación geográfica, podremos fijar de modo aproximado el límite oriental de Galicia. Quedan fuera de Galicia: Oviedo, Ventosa, Astorga, León, Zamora, Salamanca, Trujillo, Badajoz, Talavera la Real y Mérida ${ }^{28}$.

La enumeración de los lugares conquistados en España da ocasión al autor para mencionar Guadix y poner de manifiesto que allí yace san Torcuato, discípulo de Santiago. Semejante concreción nos muestra otra de las reacciones que han provocado en Compostela, poco antes de 1095, las exigencias de Gregorio viI.

La primera versión de la translatio afirmaba que tres de los siete discípulos habían recibido sepultura junto al sepulcro de Santiago, empezando precisamente por Torcuato. Admitir que el sepulcro de Torcuato se hallaba en Guadix supone para Compostela un cambio de postura relevante, que probablemente está ya relacionado con el recurso a la puesta a punto de otros siete discípulos de Santiago alternativos. Aunque se insiste en presentarlo como un discípulo de Santiago, ya se había declarado al principio que los discípulos solo habían predicado en Galicia. En este contexto, la presencia del sepulcro en Guadix, sin la predicación previa del discípulo en la ciudad, concentra el objetivo del relato en el ámbito de esa Galicia donde está Braga, sin postular un estatuto primacial sobre toda Hispania, que entonces ostentaba el arzobispo de Toledo. Coincide en esto con el Iriense, que reivindica contemporáneamente la cabecera eclesiástica de la provincia bracarense, justamente cuando el obispo Pedro de Braga acababa de ser depuesto por procurar la restitución del rango metropolitano de su sede.

La definición territorial de Galicia se corresponde con el reino de García, entre los años 1065 y 1071, o, mejor aún, con el condado que Alfonso vi atribuyó a

27 «Ciuitas Sancte Marie Vimarana» en el códice, en el distrito de Braga (Portugal). Pierre David entiende que se enumeran dos núcleos diferentes: Santa María de Feria y Guimarães. Véanse sus «Études sur le livre de St-Jacques attribué au pape Calixte II», Bulletin des Études Portugaises, 10 (1945), p. 1-41; 11 (1947), p. 113-185; 12 (1948), p. 70-223; 13 (1949), p. 52-104, concretamente, 12 (1948), p. 91.

28 Anguita Jaén, Estudios, p. 20-37 explica la forma en que se agrupa la toponimia en diversas subrelaciones, de manera que Toledo aparece así desdibujada y privada de su antigua dignidad eclesiástica. 
Raimundo de Borgoña, es decir, entre los años 1093 y 1096, antes de que la concesión del condado de Portugal a Enrique amputase a su condado el territorio al sur del Miño. Es un indicio cronológico importante para fechar la composición del relato entre 1093 y 1095 y situar a su autor en la Compostela de Raimundo de Borgoña, circunstancia que le permite precisar que en tiempo de Carlomagno, cuando tuvo lugar la expedición, Compostela era todavía pequeña.

Otro indicio que relaciona el relato con el ambiente próximo a Raimundo de Borgoña es el vaticinio referido a propósito de la llave que tenía en sus manos el ídolo llamado Salam de Cádiz ${ }^{29}$. La llave solo caería de sus manos el año que naciese en la Galia el futuro rey que en los últimos tiempos subyugaría a las leyes cristianas toda la tierra española, arrebatándosela a los sarracenos. ¿A qué otro futuro rey nacido en la Galia se le podría presentar poco antes de 1095 como aspirante a heredar el trono de Alfonso vi, salvo Raimundo de Borgońa, en virtud de su matrimonio con la infanta Urraca? El Chronicon Compostellanum, escrito poco después de la muerte de la reina Urraca, registra esta misma tesis: en el matrimonio con la infanta Urraca Raimundo había recibido la promesa de la herencia del reino leonés.

Acabada la campaña, se explican sus consecuencias. Con el oro recibido de los musulmanes, Carlomagno reconoce y retribuye la ayuda recibida de Santiago, como contemporáneamente se planteaba en el voto de Santiago y como hacían los reyes leoneses al repartir el botín, según documenta la crónica Adefonsi imperatoris. El único lugar de la recién conquistada España que resulta beneficiado es la basílica de Santiago.

Carlomagno, no Alfonso II, es quien dota la iglesia, la enriquece con ornamentos y libros e instituye una sede episcopal con canónigos, que observan la regla de san Isidoro. Es el reflejo de la situación contemporánea hacia 1095. A pesar de que la concordia de Antealtares de 1077 preveía que la abadía mantendría sus tradicionales funciones litúrgicas supra corpus apostoli, la ampliación del número de canónigos a veinticuatro ha conformado un clero de canónigos regulares, que puede celebrar el culto en la iglesia catedral. La abadía, apartada del altar apostólico, ha culminado su plena benedictinización.

29 Apunta la relación de este pasaje con los derechos de la casa de Borgoña Marie de Menaca, Histoire de Saint Jacques et des ses miracles au Moyen-Age (VII ${ }^{\mathrm{ème}}$-XII ${ }^{\mathrm{ème}}$ siècles), Nantes, 1987, p. 192 ss. 
A finales del siglo xI, la confirmación canónica de la residencia de los obispos de Iria en Compostela solo podía venir de Roma, pero en este relato la pretensión se respalda con la autoridad, no ya de un rey cristiano hispano del siglo IX como Alfonso II, sino con la voluntad del primer emperador del Occidente medieval, uno de los dos poderes universales que contemporáneamente se disputaban la primacía sobre la Cristiandad occidental. Las «justas» aspiraciones de la sede compostelana se apoyan tanto en el poder temporal como en el espiritual.

Como el camino de Santiago que el Apóstol había revelado a Carlomagno principiaba en las orillas del mar de Frisia, la gratitud del emperador se manifiesta también en estas tierras del Occidente, levantando iglesias en honor del Apóstol. Con el oro obtenido fundó iglesias dedicadas a Santiago. Dos de ellas en París y Aquisgrán, es decir, en la vía más occidental que, por Tours, conducía a los peregrinos hasta Compostela. Otras dos en Toulouse y Béziers, lo que sugiere la vía más oriental o tolosana. La quinta en Gascuña, en una localidad existente entre Aix y San Juan de Sorde, que en este caso se dice expresamente que estaba «en el camino jacobeo", que viene a ser el más occidental o turonense, a poca distancia ya de los Pirineos.

En este relato las vicisitudes del reino astur-leonés, desde Alfonso II y sus sucesores, se trasponen legendariamente a la acción de Carlomagno y los suyos. Durante siglos los monarcas cristianos han combatido al Islam. La empresa estaba asociada con el culto y el auxilio del apóstol Santiago, evangelizador de un país, que había caído en manos de los musulmanes. Con este texto nace en Compostela la vinculación legendaria entre el culto del apóstol Santiago y el emperador Carlomagno, el más poderoso de todos los reyes, lo que permite ampliar al Occidente la irradiación de la acción del apóstol Santiago.

Esta asociación entre Carlomagno y Santiago solo puede ser obra de un clérigo de la catedral compostelana. En la afirmación del estatuto apostólico de la iglesia de Santiago se hace intervenir a un emperador franco y un arzobispo franco, justo en el momento en que el borgoñón Raimundo, en cuya curia figura Diego Gelmírez, acababa de llegar a Compostela. En Braga se había iniciado otra larga vacancia (1091-1097), tras la excomunión y deposición de su obispo Pedro en 1091. Urbano II y su legado Bernardo de Toledo tenían que avanzar en la organización de una provincia bracarense en la que pudiese progresar la reforma eclesiástica. Como había ocurrido en Toledo, promover a un monje cluniacense 
parecía la fórmula más segura. En tanto que conde de Galicia, Raimundo tenía autoridad sobre Braga y Compostela, pero todo sugiere que «el poder temporal», regio y condal, y Cluny detrás se habían decantado por la opción de Compostela.

La nueva postura de la sede compostelana en relación a Roma, y de Gelmírez en particular, facilita las cosas para que Dalmacio, un monje cluniacense francés, sea designado obispo de Santiago y no de Braga. Al igual que Diego Peláez y Pedro de Cardeńa, carecía de conexiones previas con la sede local. Pero la conducta final de Pedro de Braga respecto a Urbano in favoreció la opción favorable a un monje cluniacense, del que cabría esperar una actitud filial respecto a Roma y un respeto a su legado Bernardo de Toledo. Quizá por ello Urbano II respondió rápidamente con la concesión del 5 de diciembre de 1095. Roma reconocía plenamente la presencia sepulcral del Apóstol en Compostela y aceptaba la lejana decisión de Alfonso iI y sus sucesores, que habían fijado la residencia de los obispos de Iria junto al sepulcro apostólico, recientemente reinterpretada como la voluntad del emperador Carlomagno. La nueva sede compostelana fue declarada exenta de la autoridad de metropolitano y sujeta directamente a Roma, es decir, desvinculada de la eventual autoridad de un metropolitano bracarense y de la primacía de Bernardo de Toledo.

Nótese que este primer relato de una campaña de Carlomagno en Hispania, escrito en Santiago en plena época de Gelmírez, se incorporará a la forma definitiva de la compilación del Liber Sancti Jacobi, al igual que el Chronicon Iriense será completado y ampliamente renovado en sus planteamientos por la Historia Compostellana. Los alegatos compostelanos a favor de los justos derechos del apóstol Santiago habían sido eficaces tanto ante el poder eclesiástico, como ante el poder temporal. Diego Gelmírez no olvidaría esta lección.

La prematura muerte del obispo Dalmacio a principios del año 1096 resultó nefasta para la sede compostelana y complicó mucho las expectativas recientemente abiertas por la carta de Urbano II. La infanta Teresa contrajo matrimonio con Enrique de Borgońa, hermano del duque Eudes y sobrino de la reina Constanza. Ambos recibieron el gobierno de Portugal y Coimbra, que se segregaban así del distrito gobernado hasta entonces por el conde Raimundo. Braga y Compostela quedaban bajo el mando de distintos condes. Todo sugiere que se franqueaban así las puertas para que se resolviese por fin la vacancia de Braga, con la fórmula ensayada en Compostela: la promoción de un monje cluniacense. 
Sobre la nueva vacante compostelana recayeron las pretensiones del ex obispo Diego Peláez, que intentó que Urbano in lo repusiese en la sede exenta de Santiago, lo que, como sabemos, iba en contra de la línea pro cluniacense recién impuesta. El conde Enrique pudo ocuparse de la sede de Braga. En 1097, fue elegido el cluniacense Giraldo, procedente de Moissac. Mientras tanto, en 1096, Raimundo de Borgoña volvía a confiar en Diego Gelmírez como administrador del señorío compostelano.

Urbano II murió el 29 de julio de 1099, sin decantarse por Braga o por Compostela, por Enrique o por Raimundo. Para entonces el canónigo Diego Gelmírez, tras cuatro años de administración del señorío de Santiago, se había convertido en un firme candidato para ocupar la sede compostelana. Sin duda, contaba con el apoyo de Raimundo de Borgońa y del rey Alfonso vi, lo que le podía valer también el respaldo de Hugo de Cluny. El 13 de agosto fue elegido Pascual II, antiguo legado en Hispania, y el 29 de diciembre el papa zanjaba definitivamente las pretensiones de Diego Peláez y mandaba proceder a la elección de un nuevo obispo para Compostela. No es de extrañar que en tales circunstancias, Diego Gelmírez, alentado sin duda por Raimundo de Borgońa, decidiese viajar a Roma. Pascual II apostó por él y lo ordenó subdiácono de la Iglesia romana el 18 de marzo de 1100, en el entendimiento de que este respaldo papal era el primer paso para que fuese promovido a las sagradas órdenes, lo que en tales circunstancias solo podía significar que el mismo papa lo proponía como candidato pontificio para la sede compostelana.

\section{DIEGO GELMÍREZ, OBISPO: EL LIBRO DEL APÓSTOL SANTIAGO Y LA HISTORIA DE SU SEDE SEPULCRAL COMPOSTELANA}

Desde su elección y consagración como obispo en 1101 y hasta su muerte en 1140, Gelmírez no dejó de perseguir la exaltación de su sede. Giraldo de Braga se le adelantó en 1099-1100, cuando obtuvo el palio de Pascual ir y la restitución de la dignidad metropolitana. Ante cada nueva coyuntura, Gelmírez respondió con medios similares a los que se habían empleado en el siglo xI: el envío constante de legados y la elaboración de textos que expresasen, del modo más favorable, los fundamentos de sus pretensiones. 
Durante los diez primeros años de su episcopado, obtuvo de Pascual ir concesiones relevantes. Al ratificar en diciembre de 1101 la carta de Urbano II de 1095 sobre radicación, exención, derechos y extensión de la diócesis, Pascual II añadió la confirmación del voto hasta el Pisuerga (HC I, 12), tal como lo había descrito la Crónica de Iria-Compostela, pero la confirmación papal perdió buena parte de su interés desde el momento en que Braga recuperó su condición de metropolitana.

De mayor trascendencia para el estatuto de la sede compostelana fue la concesión del palio en diciembre de 1105, que Gelmírez recibió del papa en la basílica romana de San Lorenzo (HC I, 17). Importa también recordar que Pascual II aceptó las peticiones de Gelmírez en lo relativo a la organización del clero catedralicio y culto sobre el altar de Santiago «more romano», mediante la institución de siete cardenales presbíteros, que cubriesen sus cabezas con mitras preciosas a semejanza de los cardenales presbíteros o diáconos de la sede apostólica (HC I, 44). Los cardenales compostelanos serían los únicos, además de los legados romanos y los obispos, que podrían celebrar el culto sobre el nuevo altar de Santiago (HC I, 45). Al igual que en Roma, a los siete cardenales compostelanos Gelmírez les señaló otras siete iglesias parroquiales de la ciudad, a modo de tituli.

Tras la muerte de Raimundo de Borgońa en 1107 y de Alfonso vi en 1109 y la incertidumbre que esta suscitó, Gelmírez vio llegado el momento de elaborar una nueva crónica de la sede de Iria-Compostela, que actualizase adecuadamente el estatuto apostólico recientemente reconocido por Roma y apuntase cuáles eran sus aspiraciones futuras, y de enriquecer la forma en que la catedral compostelana debía celebrar la liturgia de las dos fiestas de Santiago el 25 julio y el 30 de diciembre.

\section{El Libro de Santiago}

Hemos visto cómo en la catedral compostelana se venían celebrando desde ca. 1080 una fiesta estival el 25 de julio para conmemorar la pasión de Santiago y otra invernal el 30 de diciembre su vocación apostólica.

Según la parte de la Historia Compostellana escrita hacia 1124 por Giraldo, Gelmírez introdujo las costumbres de las iglesias de Francia en la catedral com- 
postelana ${ }^{30}$. Pero debe advertirse que lo evocado en esta sección retrospectiva del capítulo (HC II, 3) se refiere a aspectos de la primera década del episcopado, que, por tanto, tendrían que haber sido narrados por Munio Alfonso. De hecho, Giraldo menciona aquí la ampliación del cabildo hasta los setenta y dos canónigos, efectiva en 1102, reforma de la que Munio Alfonso había dado cuenta oportunamente en la sección por él escrita.

En la liturgia que se había celebrado en la Catedral de Santiago hasta 1080, y en la nueva recién introducida, no había oficio propio de ningún santo para los días de la octava de su fiesta. Este tipo de liturgia solemne, conocida en Occidente antes del año 1000, no había existido en la liturgia hispánica, ni en su prolongación leonesa ${ }^{31}$. Diego Gelmírez implantó en Compostela una liturgia propia para la gran fiesta del 25 de julio y para los días de su octava. Probablemente aluden a ello las palabras de Giraldo en 1124 y, ciertamente, puede ser presentada como la introducción de una costumbre de Francia puesto que del sur de Francia procede la liturgia «romana», que se adopta en las iglesias del reino de León. Munio Alfonso no menciona la reforma litúrgica, quizá porque se realiza hacia 1109-1110, justo cuando el autor finaliza su relato.

En efecto, esta importante innovación debió tener lugar por esos años puesto que nunca se hubiera podido ultimar antes de la concesión del palio por Pascual ir a finales de 1105 . En esa carta, Pascual in admite por primera vez la translatio, lo que supone aceptar la autoría pontificia de la epístola de León. Declara que el cuerpo del apóstol Santiago había sido llevado a España y que, en consecuencia, sus restos descansaban en Compostela ${ }^{32}$, donde eran objeto de veneración por la Iglesia Occidental. Solo desde este momento quedaron franqueadas las puertas, para que la liturgia de la catedral compostelana pudiese incorporar el tema de la translatio apostólica. Por lo demás, ¿qué otra iglesia

30 Se le atribuye esta reforma en el sector de la Historia Compostellana escrito por Giraldo. HC II, 3.1, ed. Falque Rey, p. 222: «applicuit animum, ut consuetudines ecclesiarum Francie ibi plantaret».

31 En la liturgia hispánica la fiesta de Santiago nunca tuvo octava propia. Véase Pérez de Urbel, El Antifonario, p. 5-24.

32 Hс I, 17.2, ed. Falque Rey, p. 41-42. Véase Ludwig Vones, Die 'Historia Compostellana' und die Kirchenpolitik des nordwestspanischen Raumes 1070-1130. Ein Beitrag zur Geschichte der Beziehungen zwischen Spanien und dem Papsttum zu Beginn des 12. Jahrhundert, Köln-Wien, 1980, p. 40 ss. 
de Occidente podía tener más interés que la compostelana en introducir una fiesta dedicada a la translatio? ${ }^{33}$.

Es muy importante subrayar que en la forma que hoy reviste el Liber Sancti Jacobi en el códice compostelano no solo se aprecian las huellas de los cambios litúrgicos ocurridos en Santiago hacia 1080 y hacia 1109-1110, sino que también se conservan parte de los materiales utilizados en esos dos momentos ${ }^{34}$. Hasta aquí hemos identificado en el Liber tres piezas del leccionario, que con seguridad fueron seleccionadas en Compostela ca. 1080.

De la etapa de ca. 1109-1110, queda en el Liber la incorporación del tema de la translatio a la fiesta del 30 de diciembre, que pasa ahora a tener un carácter doble: junto a la vocación apostólica, se empieza a conmemorar el traslado del cuerpo de Santiago a Galicia por medio de varones apostólicos. Los discípulos y su actividad son la clave para situar el traslado en el siglo i y retrotraer el origen de la sede de Iria-Compostela a los tiempos apostólicos. Con tal motivo, se prepara un nuevo oficio para el 30 de diciembre y para el día de la octava, cuya celebración se adelanta al día 5 de enero, para evitar la coincidencia con la Epifanía.

De la fiesta del 30 de diciembre con su doble carácter (vocación-traslación) y de su octava se pueden identificar dos piezas en el leccionario del Calixtino. Para introducir la novedad (CC I, 19) de la celebración de la translatio en la festividad del 30 de diciembre, se selecciona el pasaje del Eclesiástico que narra el traslado de

33 En las discrepancias entre el leccionario y el misal José María Anguita Jaén («Notas sobre la liturgia y la composición del Liber Sancti Iacobi del Códice Calixtino», Compostellanum, 48 [2003], p. 427-447) encuentra razones para apuntar al origen compostelano de la compilación. En realidad, la forma de oficio monástico, más extensa y compleja, no es una objeción para relacionar la elaboración progresiva de la compilación con la catedral. Nótese que el objetivo declarado es que se lea en "todas» las iglesias de la cristiandad.

$34 \mathrm{La}$ forma adquirida finalmente por la parte litúrgica del Liber es el resultado de las vicisitudes por las que pasa la sede compostelana. Véase Fernando López Alsina, «La posición de la Iglesia de Santiago en el siglo XII a través del Códice Calixtino", en El Códice Calixtino y la música de su tiempo (Actas del simposio organizado por la Fundación Pedro Barrié de la Maza en A Coruña y Santiago de Compostela, 20-23 de septiembre de 1999), ed. José López-Calo y Carlos Villanueva, A Coruña, 2001, p. 23-42. Su elaboración parcial fuera de Santiago, en medios cluniacenses, o incluso en una parroquia rural (Saint-Jacques d'Asquins), como propone Bernard Gicquel (La Légende de Compostelle. Le Livre de saint Jacques, París, 2003, p. 177) tropieza con muchas dificultades y no tiene en cuenta estas características internas presentes en la compilación. 
Henoch al paraíso ${ }^{35}$, con la mínima adaptación de sustituir el nombre de Henoch por el de Santiago. El sermón Sollempnia sacra, propuesto para esta lectura, tuvo que ser redactado para la ocasión hacia 1109-1110, sin que para este estadio haya que hacer caso alguno de la atribución al papa Calixto II, epígrafe que le fue atribuido en una fase posterior de la historia del Liber. La pieza se estructura como una serie de ocho comentarios alegóricos a diferentes versículos del libro sagrado (Eccli. 44, 16-27; 45, 1).

El autor asocia los versículos con Henoch, Noé, Abraham, Jacob y Moisés y no deja de introducir ciertos paralelismos con el apóstol Santiago. La universalidad contemporánea del culto al apóstol Santiago y la peregrinación a Compostela es una idea central, que se expresa en dos momentos diferentes. En primer lugar, a propósito del paralelo con Abraham, tenido por padre de multitud de naciones, «así Santiago es venerado como padre piadoso de naciones de pueblos diversos, que vienen a Galicia a su santo sepulcro»; y, más adelante: «las naciones de peregrinos se aumentan todos los días en la tierra y sobre las estrellas del cielo son ensalzadas con él en la patria celestial» ${ }^{36}$. Y, en segundo lugar, al final del sermón. $\mathrm{Al}$ introducir la necesaria y oportuna referencia a la vocación apostólica y al traslado: «elegido en el día de hoy junto al mar de Galilea» ${ }^{37}$ fue "trasladado a la morada del paraíso celestial ${ }^{38}$ y coronado por sus méritos, entre los cuales se destaca que "es amado también en este mundo por los hombres, puesto que por los cuatro climas del mundo es amado, invocado, adorado y honrado por todos los fieles, y además en Galicia es visitado».

Es conveniente llamar la atención de esta analogía Santiago-Abraham, por las implicaciones que tiene con las piezas escultóricas que hoy vemos en el Portal de Platerías.

Para la fiesta de la octava, a celebrar el día 5 de enero, se propone la lectura del pasaje sobre la vocación de Santiago y Juan, según Mt 4, 21. Es extraordinariamente revelador de como han evolucionado los materiales en Compostela el hecho de que este capítulo (CC I, 20) lleve actualmente como única rúbrica: «5

35 Según el Eclesiástico 44, 16, y no el Libro de la Sabiduría, como apunta correctamente Moralejo, p. 239, n. 5.

36 Herbers / Santos Noia, p. 108-109; Moralejo, p. 244-245.

37 Herbers / Santos Noia, p. 110; Moralejo, p. 247.

38 Herbers / Santos Noia, p. 107; Moralejo, p. 241. 
de enero. Octava de la Traslación de Santiago». Vemos cómo se fue adaptando el significado de la fiesta del 30 de diciembre desde el ańo 1080. Primero se conmemoró exclusivamente la vocación; desde 1109-1110 se celebró el doble aspecto de la vocación-traslación; y, finalmente, cuando se cierra la compilación, la traslación había pasado a ser el aspecto central y único de la festividad, como lo sigue siendo todavía hoy en la Catedral de Santiago.

A propósito de esta lectura del Evangelio de San Mateo, se ofrece un comentario que se presenta como exposición a la lectura. El Festivitatem electionis se inicia también afirmando el doble carácter de la fiesta: «al celebrar la festividad de la elección y traslación de Santiago». La pieza fue compuesta en Santiago para esta ocasión. Se combinan fragmentos de Jerónimo, Agustín y Gregorio Magno, con otros atribuidos a "Calixto" en una fase posterior ${ }^{39}$. El responsable de la combinación de los materiales extraídos de estas homilías es el autor de las referencias a la doble solemnidad: elección y traslación de Santiago.

Su aportación más reveladora, por lo que sugiere en cuanto a su necesario origen compostelano, es la interpolación al pasaje de la homilía 24 de Gregorio Magno sobre la pesca milagrosa según Jn 21, 1-4. Afirmaba Gregorio Magno que la acción apostólica que los apóstoles realizaron en vida con epístolas o mediante la palabra la continuaban ejerciendo diariamente después de muertos mediante los milagros. Este tipo de acción apostólica es especialmente interesante en Compostela, donde la postura de Gregorio vir había obligado a prescindir de la noticia de la misión hispánica de un apóstol Santiago vivo y de la actividad de sus discípulos en una primitiva comunidad cristiana. A la altura de 1110 el autor comprende la importancia de este pasaje para Compostela, donde se hallaba el cuerpo de Santiago.

La interpolación precisa que los milagros de la acción apostólica se realizan «junto a los sepulcros» y enumera genéricamente estos signos que suponen la existencia de la peregrinación jacobea: «los enfermos vienen y son curados, los ciegos son iluminados, los cojos se levantan, los endemoniados se ven libres, se da consuelo a los tristes y, lo que es más, se escuchan las oraciones de los fieles y se quiebran las cadenas de los pecados» ${ }^{40}$. 
El autor es también el responsable de las alusiones al apóstol Santiago como «excelso patrono» y como "pastor y guía de las gentes de España y de Galicia».

En esta exposición, escrita hacia 1110, la Iglesia de Santiago se apoya otra vez en la nueva fundamentación de su posición como sede apostólica, que había habilitado la carta de Pascual in de 1105. Se trata de la acción apostólica de Santiago el Mayor, a través de los milagros que se realizan junto a su sepulcro de la basílica compostelana, en beneficio de los peregrinos que a él acuden de todas las partes del mundo. El recurso a este poderoso argumento era posible porque se había universalizado el culto a Santiago y su peregrinación, pero no sería plenamente eficaz si al mismo tiempo no se dejaba alguna constancia más precisa de cuáles eran los milagros operados por el Apóstol, es decir, si en esta oportunidad se dejaba de compilar un Libro de los Milagros de Santiago.

Para localizar dónde se fragua el Liber Sancti Jacobi es muy importante llamar la atención sobre el hecho de que, a pesar del nuevo cambio de naturaleza de la fiesta del 30 de diciembre, no por ello se desechó el material preparado en 1080 que solo conmemoraba la vocación de Santiago. Cuando adquiere la forma final, que hoy reconocemos en el Liber Sancti Jacobi del ejemplar compostelano, encontramos tanto el material preparado ca. 1080 (I, 18), como el de ca. 1110 (I, 19). Lo mismo ocurre con los antiguos materiales para los días 24 de julio (I, 1) y 25 de julio (I, 8), y con los preparados en esta segunda fase de ca. 1110: (I, 2) para el 24 y (I, VII) para el 25.

La yuxtaposición en el leccionario de materiales procedentes de distintas etapas es una característica que se mantuvo hasta el cierre de la compilación. La acumulación es especialmente densa para los días 24 y 25 de julio y para el 30 de diciembre. Para distinguir los materiales seleccionados hacia 1110 de los que fueron añadidos posteriormente, hemos de fijarnos en una característica que presentan las cinco piezas identificadas hasta aquí (CC I, 1, 8, 18, 19, 20). Las cinco

predicationis voce stabilitatem eterne patrie fidelibus ostenderunt. Hoc egerunt verbis, hoc epistolis, hoc agunt cotidie miraculorum signis. Ad eorum namque sepulcra creberrime miracula fiunt. Egri veniunt et sanantur, ceci illuminantur, claudi eriguntur, demoniaci liberantur, mestis consolacio datur et, quod maius est, fidelium preces exaudiuntur, peccatorum vincula resolvuntur. Quociens ergo per eorum predicamenta aut miracula ad amorem quietis eterne convertimur, quociens a terrenarum rerum tumultibus separamur, quid aliud quam missi intra rethe fidei quasi pisces ad litus traimur?». El texto interpolado figura en cursiva, por lo que, solo en parte, tiene razón Moralejo, p. 248, n. 7, que da el texto como no localizado. Véase, sin embargo, la identificación en Herbers / Santos Noia, p. 112, n. 379. 
constan de una lectura de las Sagradas Escrituras, seguida de una homilía. En cambio, las piezas incorporadas después de 1110 carecen de esta sencilla estructura. Veamos qué piezas del Liber pertenecen a la reforma de 1110.

Para el primer día, la vigilia del 24 de julio, se propone el pasaje del evangelio de Mc 3, 13-18, sobre la institución de los doce y se compone un largo sermón (CC I, 2). En su primera parte, el Vigilie noctis justifica la vigilia de Santiago y la celebración de la fiesta durante ocho días. Expone la forma en que debe celebrarse la vigilia de los mayores santos: ayuno, abstinencia, arrepentimiento, oraciones, salmodia y confesión, con velas encendidas desde la tarde hasta la terminación de la primera misa, en la que se debe comulgar. La basílica debe limpiarse y adornarse con tapices, paños, sedas y cortinas, además de esparcir juncos por el suelo. El propio Santiago se halla entonces entre los suyos y muchos afirman haberlo visto en figura de apóstol.

Tratándose de una novedad, es razonable que se justifique la celebración de la octava. Se recuerdan cinco prodigios memorables y las desgracias que padecieron ciertas personas, por no celebrar la fiesta de Santiago en Tudelonio (España), Albineto (Gascuña), Mayorra (Besançon) y San Damián (Montpellier).

En su segunda parte el sermón explica, pasaje por pasaje, la lectura del día. Entre otras consideraciones, desarrolla el modelo del buen sacerdote y denuesta diversos casos de simonía, entre los que menciona la mala costumbre, arraigada en Francia, de imponer falsas penitencias a peregrinos en el camino de Vézelay, de Saint-Gilles, de Roma o de Santiago. La exposición finaliza con una oportuna consideración sobre los doce apóstoles, en la que, interpolando unos dísticos de Venancio Fortunato, se pretende hacerle conocedor de la presencia del sepulcro de Santiago en Galicia en el siglo vi. En efecto, se sostiene que cada uno de los apóstoles resucitará de la ciudad en que predicó y fue sepultado, lo que, desde el punto de vista del lugar de predicación de Santiago, plantea cierta calculada ambigüedad.

Para el 25 de julio se toma como lección la muerte de Santiago, según los Hechos de los Apóstoles (Act. 11, 27-28) y se redacta el sermón Adest nobis (CC I, vII), quizá la pieza más importante de esta fase de 1109-1110. Como en el Vigilie noctis respecto a la vigilia y la octava, el autor de este sermón siente la misma necesidad de justificar las innovaciones litúrgicas y, en este caso, argumenta, con paralelos en las lecturas de las misas, la legitimidad de eliminar de los Hechos de 
los Apóstoles los elementos que no hacen al caso, como por ejemplo el versículo sobre la prisión de san Pedro.

Además del comentario simbólico de la lectura propuesta, el autor recuerda la Passio modica de Santiago, que solo en la etapa posterior de 1135-1139 se propondrá como lectura autónoma. Con una técnica idéntica a la del Vigilie noctis, se deja para el final el desarrollo específico sobre la actualidad del culto compostelano. Es la exposición más completa de cómo la acción apostólica de Santiago beneficia a la cristiandad desde su sepulcro compostelano. La clave explicativa es, como ya sabemos, el milagro. A partir de «in bonis iusti exaltabitur civitas» (Pro $11,10)$, el autor argumenta: el bien del justo se concreta en los milagros y la ciudad en la Iglesia. Al extenderse por el mundo la fama de los milagros de Santiago y la reputación de sus poderes, se engrandece en todas partes la Iglesia. Si la Passio modica testimonia que Santiago solo pudo convertir a Josías, sin embargo, por haber aceptado el martirio, convierte a Cristo, después de muerto, a las innumerables gentes que acuden a su sepulcro en Galicia.

El cuerpo de Santiago fue arrancado de Jerusalén y trasplantado a Galicia, para que crezca en gloria entre todas las gentes que a él acuden. La peregrinación a su sepulcro es ocasión de conversión y salvación futura para los que, atraídos por sus milagros, acuden a su basílica de los países y climas de todos los confines del orbe.

Los milagros, donde quiera que los haya realizado, o las gentes, que de tan diversos países confluyen en peregrinación a su sepulcro, son otros tantos testimonios de la fe de Cristo que Santiago da en la Iglesia. Lo que el Apóstol ganó antes de su muerte no es nada comparado con la enorme atracción que ejerce sobre todos los pueblos después de muerto. La acción apostólica que Santiago realizó en España y en Galicia «empezó» cuando, libre de la carne, fue trasladado de Jerusalén a Galicia y atrajo al culto de Dios a sus gentes con su llegada y sus milagros. Con el entrecomillado subrayo que el sermón Adest nobis del 25 de julio excluye expresamente la acción apostólica de Santiago en Occidente durante su vida.

La excelente reflexión, perfectamente adaptada a las circunstancias en que vive la sede compostelana hacia 1110, termina con la comprobación de la vitalidad de la acción apostólica de Santiago después de muerto y de su trasplante a Galicia: «muchos dan también testimonio de haber sentido su protección en los angustiosos peligros de los mares y los cautiverios y hasta de haberle visto liberándolos en hermosa figura corporal». Para hacerle justicia al mártir Santiago y dejar cons- 
tancia de su acción apostólica después de muerto, en esta segunda fase se hace preciso preparar una selección de sus milagros para su lectura en el oficio divino.

Nótese el impresionante avance entre las propuestas de Diego Peláez de ca. 1080 y las de Diego Gelmírez de ca. 1110 para la celebración del 24 y del 25 de julio, que, en último término, viene propiciado por el cambio de actitud de los papas hacia Compostela y el creciente respaldo a las justas pretensiones «del apóstol Santiago». Pero es también muy notable, como hemos subrayado, que Gelmírez haya querido que las principales aportaciones de ca. 1080 permaneciesen junto a las nuevas en el leccionario de ca. 1110.

Aunque para los días de la octava la reforma promovida por Gelmírez, para mayor gloria del Apóstol, no había el precedente de 1080, se utiliza ahora el mismo recurso a la homilética tradicional de tema apostólico y la misma sobriedad a la hora de hacer adaptaciones, como se había hecho en 1080. Se trata de cuatro piezas tomadas de la exegética de Jerónimo y Gregorio Magno. Salvo algún inevitable retoque, el respeto al modelo es una constante. Pero también, como es el caso de los textos preparados para los días 24 y 25 de julio y 30 de diciembre y 5 de enero, se advierte una contribución original.

Los tres comentarios de Jerónimo al evangelio de Mateo, para los días 26 (Apostolica sollempnia, sobre Mt 10, 1-15: CC I, 10), 27 (Quare Petrus, sobre Mt 17, 1-9, CC I, 11) y 29 de julio (In presenti capitulo, sobre Mt 26, 37-46: CC I, 13) ${ }^{41}$, y el de Gregorio Magno, para el día 30 de julio (Quia natalem, sobre Mc 19, 12-16: CC I, 14) ${ }^{42}$, están exentos de actualizaciones.

En cambio, en el comentario de Mt 20, 20-28 (Sollempnitatem hodiernam), previsto para el 31 de julio (CC I, 16), los clérigos compostelanos combinan textos de Jerónimo y de Juan Crisóstomo, y ańaden una nota característica de esta etapa, que hace de Santiago "patrono... venerado en todo el orbe de las tierras» ${ }^{43}$.

Finalmente, para el día 28 de julio, a propósito de Lc 9, 51-56, se prepara el sermón Preclara sollempnitas (CC I, 12). Si la pieza fuese de un exégeta anterior,

41 La pieza 20 (Apostolica sollempnia) sobre Mt 10, 1-15, en PL 26, col. 60-64; la pieza 22 (Quare Petrus) sobre Mt 17, 1-9, en PL 26, col. 121-124 y la pieza 26 (In presenti capitulo) sobre Mt 26, 37-46, en PL 26, col. 197-199; véase Moralejo, p. 134, n. 15.

42 La pieza 28 (Quia natalem), sobre Lc 21, 9-19 y no sobre Mc 10, 35-39, en PL 76, col. 1263-1265; véase Moralejo, p. 164, n. 9.

43 Herbers / Santos Noia, p. 83; Moralejo, p. 183. 
universalmente conocido, no hubiesen dejado de consignarlo en 1109 y, como ocurre con los sermones de Jerónimo, Beda o Gregorio Magno, hacia 1135-1139 habrían respetado su nombre, en lugar de cambiarlo por el de Calixto II.

Además de tres sermones completos, los liturgistas compostelanos de ca. 1110 hicieron otras aportaciones: pequeñas, pero significativas, interpolaciones; combinación inteligente de textos diferentes en una sola pieza y redacción de comentarios parciales más amplios.

El hecho de que tres de estos ocho sermones - los de los días 24, 25 y 28 de julio- se hayan atribuido hacia 1135-1139 al papa Calixto II nos garantiza que fueron escritos por colaboradores de Gelmírez hacia 1109-1110.

El resultado de esta reforma, en la medida en que ha llegado hasta nosotros, sería un homiliario-leccionario con las diez piezas ultimadas bajo la iniciativa del obispo Diego Gelmírez. Las del 24 y 25 de julio y 30 de diciembre podrían haber sustituido a las que, para esas mismas fechas, se habían previsto bajo Diego Peláez y, sin embargo, no fue así. Como hemos apuntado, en el homiliario que abre el Códice Calixtino, las diez lecciones organizadas bajo Gelmírez hacia 1109 figuran al lado de las tres piezas preparadas bajo Peláez para los días 24 y 25 de julio y 30 de diciembre. También en este aspecto verificamos una misma forma de proceder, característica de Diego Gelmírez: construir sobre lo construido.

La iniciativa del obispo compostelano puso al apóstol Santiago a la altura de los más grandes santos de la Iglesia con su nueva liturgia «romana» para sus dos fiestas, después de que lo permitiera la carta de Pascual in de 1105. Se seleccionaron pasajes apropiados de las Sagradas Escrituras, siempre en función de la figura del Apóstol, se buscaron los comentarios más adecuados para cada lección, tomados de la homilética de mayor autoridad, adaptando las exposiciones a las nuevas circunstancias de la sede apostólica compostelana, y se compusieron los textos que ilustrasen la idea central: la acción apostólica universal de Santiago sobre todo el orbe, a través de los milagros operados sobre aquellos que acuden a su sepulcro compostelano.

Es importante advertir que en el leccionario que hoy vemos en el Libro i del Liber Sancti Jacobi está tan latente la impronta de la reforma litúrgica promovida hacia 1109-1110 por el obispo Diego Gelmírez, como la de la reforma de Diego Peláez, prueba evidente de las vinculaciones de toda la compilación con Compostela, como no podía ser de otro modo. Obsérvese que ninguna de las piezas 
hasta ahora analizadas puede guardar relación alguna con el papa Calixto II. La presencia de las referencias a este papa en el material de 1109-1110 es un eslabón de la cadena que une el material litúrgico compostelano de ca. 1080 con el de 1110 y con la compilación "calixtina» de 1135-1139.

El necesario sacrificio del tema de la predicación de Santiago en Hispania se compensa con la acción apostólica llevada a cabo por Santiago después de muerto a través de los milagros, de los que son beneficiarios no solo los peregrinos que acuden a su sepulcro, sino también los fieles que lo invocan en cualquier lugar del orbe. Gelmírez siempre aspiró a que Roma reconociese a la sede compostelana un estatuto preeminente sobre las iglesias occidentales, apoyándose en la dimensión universal del culto apostólico y de la diversidad real de los lugares de procedencia de los peregrinos beneficiados por la acción apostólica de Santiago. Mostrar eficazmente la acción apostólica de un Santiago muerto requería elaborar una colección de milagros.

De nuevo en el Liber Sancti Jacobi encontramos las huellas de este nivel cronológico, correspondiente al año 1110, en el desarrollo de la compilación. Una docena de los veintidós milagros de Santiago del Libro II se datan con precisión en un año determinado. Sus fechas respectivas se concentran precisamente en los ańos de la primera década del siglo XII, a razón de uno por año, hasta que la serie de milagros fechados se cierra justamente en el año 1110. Esta observación nos sugiere que se compuso una primera colección de milagros en plena sintonía y coordinación con los objetivos de la reforma litúrgica. La colección expresaba la universalidad de la acción apostólica de un Santiago cuyo cuerpo sin vida yacía en su sepulcro compostelano.

Pero a la compilación litúrgica le faltaba todavía un tercer componente decisivo: un relato "autorizado» de la translatio, respetuoso con la postura de Roma. Desde nuestro punto de vista, esta versión «autorizada», reflejo de las circunstancias de los años 1109-1110, que expresa los puntos de vista oficiales, que entonces sostenía el obispo Diego Gelmírez, puede ser la versión que figura en el CC III, 2, como carta del papa León ${ }^{44}$. 
Los puntos esenciales de esta versión oficial son los siguientes: León no puede elegir unos destinatarios más universales «dilectísimos rectores de toda la cristiandad»; no hay predicación del apóstol Santiago en Hispania, como exigía la tesis pontificia del origen petrino de la Iglesia hispánica; se traslada el cuerpo «entero", contra la pretensión de que la cabeza pudiese estar en otro lugar distinto de Compostela; fue sepultado en Liberum donum, topónimo que permite silenciar definitivamente el incómodo Arcis Marmoricis altomedieval; descripción de la fundación de una pequeña iglesia sobre el cuerpo apostólico, centro de la primera comunidad cristiana de tiempos apostólicos; no se concreta el número de los discípulos, para diferenciarlos de siete varones apostólicos romanos; en contraste con versiones anteriores, solo dos discípulos permanecen junto al sepulcro, cuyos nombres - Teodoro y Atanasio- son los únicos mencionados; el resto se dispersa para evangelizar Hispania, mientras que Teodoro y Atanasio permanecieron junto al sepulcro y fueron enterrados junto a su maestro.

Diego Gelmírez quiere respaldar con la autoridad pontificia de un PseudoLeón esta versión oficial de la translatio, una vez que Pascual in la había aceptado en 1105. La epístola constituye un fundamento de la reivindicación por la iglesia de Santiago de la primacía sobre todas las iglesias de Espańa. Es exactamente la misma aspiración que en 1110 expresa la Historia Compostellana (I, 1), fundamentada también en la epístola del papa León, que allí solo se cita y que aquí se nos presenta por extenso.

Hemos propuesto que el conjunto de las lecturas y los sermones, una colección de milagros de Santiago y la carta del Pseudo-León integraban un libro que, hacia 1110, recogía la versión oficial que Gelmírez quería que sus canónigos leyesen en el oficio divino de las fiestas de Santiago del 25 julio y del 30 de diciembre. De hecho, la combinación escrita de la translatio y los milagros era demandada por los propios peregrinos, que, como es natural, estarían menos interesados en copiar los sermones. La práctica no debía de ser excepcional: «cierto clérigo conocido mío, devoto y peregrino de Santiago [...] queriendo llevar consigo a su patria esta traslación con algunos otros milagros del Apóstol, encargó en la misma ciudad de Santiago que se los escribiese a un copista llamado Fernando y pagó como precio veinte rotomagenses» ${ }^{45}$.

45 CC III, «Prólogo», Herbers / Santos Noia, p. 185, y Moralejo, p. 385; véase Díaz y Díaz, Códice, p. 40, n. 
La naturaleza de este Libro de Santiago de 1109-1110 se ajusta a la perfección al códice que posteriormente describe el sermón Veneranda dies ${ }^{46}$. Desde la perspectiva abierta por la carta de Pascual in de 1105, el libro tenía como objetivo ofrecer una versión oficial sobre la translatio, que desautorizase y pusiese coto a versiones anteriores: «debemos narrar y corregir las invenciones apócrifas que muchos insensatos y otros que torpemente cayeron en la herejía, de nuestro Santiago y de su traslación se han atrevido a inventar y, aun lo que es peor, que han consignado por escrito» ${ }^{47}$. En sus contenidos, este libro autorizado sobre Santiago no defendía la predicación de Santiago en Hispania, de manera que, desde el momento de su misma existencia, los desarrollos literarios anteriores sobre ese primer viaje y la predicación en Hispania podían ser calificados de fábulas. Semejante libro, el «codex qui dicitur lacobus», no podía ser una obra definitiva y acabada: por una parte, el Apóstol seguiría realizando milagros en el futuro; por otra, se seguirían investigando «sus gloriosas gestas»" ${ }^{48}$. Desde el momento de su concepción y realización hacia 1110 , estaba previsto que la compilación pudiese ser actualizada.

Una misma versión oficial de los fundamentos de la sede compostelana se recoge por las mismas fechas en la segunda empresa promovida por el obispo Diego Gelmírez: la Historia Compostellana. Como en el Libro de Santiago, por mandato del obispo se expurgan cuidadosamente las versiones apócrifas, para presentar una "doctrina jacobea» ajustada a las exigencias de Roma, que dejase abiertas las puertas para futuras reivindicaciones.

29.

$46 \mathrm{Me}$ refiero al sermón Veneranda dies, CC I, 17, ed. Herbers / Santos Noia, p. 85-104, y más concretamente al pasaje de p. 87, traducido así por Moralejo, p. 194: «llega nuestro furor a su colmo prohibiendo bajo anatema que nadie se atreva a escribir algo acerca de él, a no ser lo auténtico, que se contiene en el libro llamado Jacobo. Pues éste contiene lo necesario para leer, o cantar en las fiestas de Santiago, lo cual está sacado de libros auténticos como consta en él». El sermón Veneranda dies niega explícitamente la predicación de Santiago en España, como lo hace el libro llamado Jacobo, y es, por tanto, anterior en su composición a la fase en que la Iglesia de Santiago se decide a recuperarla, invocando la autoridad de Calixto II.

47 CC I, 17, ed. Herbers / Santos Noia, p. 86 y Moralejo, p. 192.

48 Herbers / Santos Noia, p. 87 y Moralejo, p. 194: «los milagros, sin embargo, que el mismo Santo haya de realizar en adelante, que tengan la comprobación de dos o tres testigos, permitimos que se escriban para edificación de los fieles». 


\section{La Historia Compostellana}

Como ocurre con el Libro de Santiago respecto a la primera liturgia, la Historia Compostellana se presenta también como un desarrollo actualizador del Chronicon Iriense, escrito poco antes de 1095. Su autor principal, el tesorero Nuño Alfonso, con sus colaboradores, entre ellos un franco, el arcediano Hugo, y el capellán Pedro, escribió, entre 1109 y 1110, los primeros 45 capítulos del actual Libro I.

La doctrina oficial sobre la figura del apóstol Santiago y su culto en Compostela se complementa con la doctrina oficial sobre la historia de su sede compostelana. Muerto Alfonso vi en 1109, en el marco del nuevo estatuto que ha propiciado Pascual II a finales de 1105, Diego Gelmírez cree llegado el momento oportuno para adaptar el relato del Iriense a la nueva realidad, que ya se antojaba timorato en exceso. La iglesia de Santiago ha fortalecido su posición y puede elaborar una memoria histórica más densa y ambiciosa, acorde con el nuevo giro en la concepción de la apostolicidad.

Basta comparar el Iriense con los dos primeros capítulos de la Historia Compostellana para advertir el nuevo punto de vista. Admitido por Roma el traslado del cuerpo de Santiago, la historia oficial de la sede episcopal puede, de nuevo, remontarse a la época apostólica, aunque a base de pulir, depurar y censurar los contenidos que ahora se consideran apócrifos, molestos e inconvenientes.

Frente a un Chronicon Iriense que arranca con la fundación de Iria en el siglo vI, Gelmírez y sus colaboradores inician el relato, como no podía ser menos, con la translatio en los tiempos apostólicos: «En nombre de nuestro señor Jesucristo. Empieza el traslado de Santiago». Como desde Gregorio vir había exigido Roma, se silencia su actividad en Occidente y se subraya que, en la asignación de provincias a los apóstoles, Santiago, el hermano de Juan, permaneció en Jerusalén. Al igual que en el Libro de Santiago, la fuente de autoridad en cuanto a las circunstancias del traslado es una epístola del papa León. No se traslada su texto íntegro pero se cita su contenido, de forma que quede claro que la cabeza fue trasladada con el cuerpo hasta el lugar llamado Liberum donum.

Condicionado por el relato del Chronicon Iriense, al autor le resulta imposible explicar por qué en el siglo vi Miro fundó la sede episcopal en Iria, en lugar de hacerlo en Liberum donum. El sepulcro cayó en el olvido, aunque no se sepa muy bien cuándo. En cualquier caso, queda constancia de que no ha habido 
continuidad en la sucesión episcopal. Aun así Compostela reivindica la primacía hispánica. El tratamiento de la fundación de la sede refleja muy bien hasta qué punto había mejorado la posición de la sede de Santiago entre 1093-1094 y 1110. Ahora Compostela afirma que Iria fue la primera de las sedes episcopales de Hispania constituida «según la norma de la iglesia romana». En el nuevo orden «romano» introducido con la reforma gregoriana, la iglesia de Santiago debe ostentar la primacía.

El tratamiento de la inventio muestra también el avance respecto al siglo XI al menos en tres puntos. En primer lugar, se potencia al máximo el papel del obispo y del cabildo, en la medida en que se borra todo rastro de la intervención de la comunidad de Antealtares, que ahora ha sido sustituida en la celebración del culto «supra corpus apostoli» por los siete cardenales presbíteros, «more romano». En segundo lugar, se conjuga hábilmente la intervención de los dos poderes en los que Santiago se quiere apoyar. Si la fundación de la sede de Iria se hizo con arreglo a «la norma de la iglesia romana», el traslado subsiguiente de la sede episcopal desde Iria a la recién «restaurada» iglesia de Santiago se llevó a cabo por el rey Alfonso II, con privilegio real y con la autoridad de muchos obispos, en tiempos de Carlomagno. En tercer lugar, la nueva clave de la acción apostólica de Santiago el Mayor a través de los milagros aparece inmediatamente puesto que, desde tiempos del obispo Teodemiro, «Santiago resplandecía con milagros y prodigios después que se erigió la basílica en su honor». De nuevo plena congruencia con las tesis subyacentes en el Libro de Santiago de ca. 1110, cuyo milagro más antiguo se remite precisamente al tiempo del obispo Teodemiro ${ }^{49}$.

Finalmente, resta otra diferencia bien significativa. La concesión de un voto de Santiago por el rey Ramiro, a percibir exclusivamente desde el río Pisuerga hasta el mar, era todavía relevante para la iglesia compostelana en 1101, por su implicación en la primacía frente a Braga dentro del espacio provincial bracarense, hasta el punto que se obtiene la confirmación de Pascual ir. Pero después de que el papa reconociese los derechos metropolitanos de Braga, el voto hasta el Pisuerga deja de tener interés. Por eso la Historia Compostellana, a diferencia del Iriense, omite toda referencia al mismo. En 1110, Diego Gelmírez y su iglesia aspiran a una primacía más ambiciosa.

49 CC II, 2, ed. Herbers / Santos Noia, p. 161-162 y Moralejo, p. 340-314. 
Es posible que el Iriense llevase su relato hasta finales del siglo XI. La primera Historia Compostellana llega hasta el año 1110 y su autor subraya el papel de Diego Gelmírez al estructurar la historia de la sede en dos grandes secciones: antes y después de la primera administración de Gelmírez en 1094. Toda la segunda parte se escribe, pues, sin la necesidad de actualizar el relato del Iriense y adopta la forma de una crónica-cartulario, al copiar, más o menos íntegramente, treinta y seis documentos. De ellos, treinta son cartas pontificias: una de Urbano II y veintinueve de Pascual II. Con este criterio se pretende trazar una clara división entre el período anterior y posterior al reconocimiento papal del sepulcro de Santiago y de la apostolicidad de la sede compostelana en $1095^{50}$.

Esta primera Historia Compostellana, escrita por mandato de Diego Gelmírez, hemos de evaluarla también por otros aspectos que silencia a propósito. La poda es especialmente notable en relación con las «fábulas» relativas a la translatio frente a la versión canónica del Libro de Santiago. Se impone ahora una constante para el futuro: la historia oficial de la sede compostelana será siempre mucho más sobria y consecuente que las amplificaciones efectuadas en el complejo hagiográfico del Libro de Santiago, que se habían iniciado con el relato sobre Carlomagno.

La Historia Compostellana, como el Iriense, no menciona ni el número ni los nombres de ninguno de los discípulos del Apóstol. Su actividad finaliza al dar sepultura al cuerpo de Santiago. Nada se dice de lo que hicieron después, ni si alguno de ellos fue o no sepultado junto a su maestro. Sin embargo, sabemos que, como reacción a las exigencias de Roma, ya se había propuesto un cambio de identidad de los siete discípulos. Incluso la imagen de la inventio, que con toda probabilidad figuraba en el códice original de ca. 1110 y que en el siglo XIII reproduce el manuscrito de Salamanca, subraya el hallazgo del sepulcro de Santiago, flanqueado por dos de sus discípulos. La parte textual de la Historia Compostellana no explica quiénes son, pero sí lo hace el Libro de Santiago: Teodoro y Atanasio.

Está claro que en Compostela circulaban desde hacía tiempo versiones de la translatio mucho más explícitas e incluso podemos afirmar que muchas de las innovaciones procedían, como no podía ser de otro modo, de ambientes compos-

50 Véase Fernando López Alsina, «Los Tumbos de Santiago de Compostela y las relaciones con el Pontificado», en Erinnerung, Niederschrift, Nutzung - Das Papsttum und die Schriftlichkeit im westeuropäischen Mittelalter, ed. Klaus Herbers, Ingo Fleisch, Akademie der Wissenschaften zu Göttingen, NF 11, Berlin-New York, 2011, p. 137-170. 
telanos. En las diversas actividades atribuidas a los siete discípulos de Santiago en el complejo hagiográfico jacobeo, se venía incluyendo la construcción del edículo sepulcral de Santiago. A propósito de la liturgia de consagración de las tres iglesias de Santiago, Antealtares y San Juan Bautista en el año 899, se afirmaba que nadie se había atrevido a tocar el altar de Santiago, porque había sido consagrado por sus discípulos.

Lógicamente, este elemento fue eliminado de las versiones oficiales desde finales del siglo XI. Sin embargo afloró inesperadamente en la pluma de Nuño Alfonso al narrar lo acontecido en Compostela, cuando Gelmírez organizó el nuevo altar románico y se encontró antes de 1107 con la oposición de buena parte de los canónigos, con el argumento de que las obras afectaban al edifico construido por los discípulos del Apóstol51.

Por debajo de las versiones oficiales, estas creencias, tan arraigadas en Compostela desde mucho tiempo atrás, seguían latentes y vigorosas. Por ello, cuando en el siglo XI empezó a ser comprometedora para Santiago la translatio efectuada por los varones apostólicos ya «romanos», fue la propia sede compostelana la que, al proponer el cambio de identidad de los siete varones apostólicos, adjudicó a los siete nuevos varones apostólicos la edificación del edículo. La novedad circuló rápidamente, como circulaban ampliamente los distintos relatos relativos a Santiago, y fuera de Compostela no podía actuar la censura impuesta en Santiago sobre estas versiones «apócrifas».

La novedad llegó a Oviedo, donde la recogió su obispo Pelayo ${ }^{52}$, que se valió de ella para redactar la interpolación a la crónica de Sampiro e introducir la noticia del concilio de Oviedo. Al tratar el tema de la consagración de la basílica de Santiago en el ańo 899, Pelayo atribuye la consagración del altar de Santiago a estos siete nuevos discípulos del Apóstol y nos proporciona sus nombres: Calo-

51 нс I, 18, ed. Falque, p. 43-44.

52 Acta pseudo-original en «letra gótica» que Mauro Castellá Ferrer vio y copió en el Archivo de la Catedral de Oviedo. Véase Historia del Apóstol de Jesucristo Santiago Cebedeo, patrón y Capitán General de las Españas, Madrid, 1610, f. 460r. Cf. Justo Pérez de Urbel, Sampiro, su crónica y la monarquía leonesa en el siglo X, Madrid, 1952, p. 278-279, 284-305; Manuel Rubén García Álvarez, «El monasterio de San Sebastián del Picosacro», Compostellanum, 6 (1961), p. 5-48; Eduardo López Pereira, José Manuel Díaz de Bustamante, "El "Acta instaurationis ecclesie beati Iacobi": texto y pretexto", en Actas del I Congreso de la Asociación Hispánica de Literatura Medieval, Santiago de Compostela, 2-6 de diciembre de 1985, ed. Vicente Beltrán, Barcelona, 1988, p. 247-262. 
cerus, Basilius, Pius, Grisogonus, Theodorus, Atanasius, Maximus ${ }^{53}$. A Teodoro y Atanasio ya los conocíamos por el Libro de Santiago y por la miniatura de la Historia Compostellana, pero los otros cinco nombres nunca llegaron a figurar en las fuentes «canónicas» compostelanas.

Las dos empresas promovidas por Diego Gelmírez, el primer Libro de Santiago y la primera Historia Compostellana, insisten por primera vez en que el cuerpo del Apóstol no fue enterrado en Jerusalén, sino que fue trasladado a Hispania juntamente con la cabeza. Este planteamiento niega la posibilidad de que se hubiese podido desarrollar otro culto sepulcral a Santiago en ningún lugar que no fuese Compostela, incluida Jerusalén, la propia ciudad del martirio. La cabeza estaba en Occidente desde el primer momento, aseveración que neutralizaba las pretensiones del obispo Mauricio de Coimbra, que acababa de regresar de Jerusalén con una cabeza de Santiago el Mayor y que deseaba abortar el incipiente culto tributado a la cabeza de Santiago en la misma Jerusalén.

\section{DIEGO GELMÍREZ, ARZOBISPO: LA ACTUALIZACIÓN DE LA HISTORIA DE LA SEDE EPISCOPAL COMPOSTELANA, EL CHRONICON COMPOSTELANO, EL TUMBO $A$ Y LA AMPLIACIÓN DEL LIBRO DE SANTIAGO}

En la complicada coyuntura política que sobrevino tras la muerte de Alfonso vi, Diego Gelmírez nunca descuidó la opción de Alfonso Raimúndez, hijo de la reina Urraca y de su difunto marido, Raimundo Borgońa, a quien el obispo había bautizado en Santiago hacia 1106. Raimundo fue sepultado en Compostela y su hermano Guido, arzobispo de Vienne, futuro Calixto II, había acudido a León, a finales de 1107, para defender la posición de su sobrino, el joven Alfonso Raimúndez, cuya tutela quedó encomendada al obispo Gelmírez y al conde Pedro Froilaz. Tan pronto como se vislumbró que el matrimonio de Urraca y Alfonso I de Aragón podría no tener futuro, Gelmírez y Pedro Froilaz apostaron por el

53 Pérez de Urbel, Sampiro, p. 292-293: «In altare quoque quod est super corpus beati Iacobi apostoli, quod consecratum fuerat a septem discipuli eius, quorum nomina sunt hec: Calocerus, Basilius, Pius, Grisogonus, Theodorus, Atanasius, Maximus. Tamen nemo, ex iam dictis episcopis, ausus fuit aliquid in eo agere». 
infante de cinco años y, en septiembre de 1111, Gelmírez lo ungía rey de León en la Catedral de Santiago e, inmediatamente, conde y obispo lo condujeron a León para que tomara posesión de su reino. Pero la expedición quedó bloqueada poco antes de llegar a León, en Viadangos, por los partidarios de Alfonso de Aragón.

La tesis defendida por Gelmírez es que la fórmula legítima no debía ser el rey Alfonso el Batallador y la reina Urraca, sino el rey Alfonso Raimúndez y su madre Urraca, detentando el poder durante su minoría de edad ${ }^{54}$. Al crecer el joven rey, se le exige a Urraca que el nińo empiece a gobernar alguna parte del reino, pensando en primer lugar en la Galicia, de la que su padre había muerto como conde. En el pacto de 1107, se había previsto que el niño Alfonso heredase el mismo gobierno de Galicia que había tenido su padre, pero solo en el caso de que su madre, Urraca, contrajese nuevo matrimonio. Este pacto no contemplaba que Urraca pudiese llegar a suceder a Alfonso vi en calidad de reina y, menos aún, que ese eventual segundo matrimonio regio fuese con el rey Alfonso de Aragón.

Gelmírez siempre tuvo claro que su objetivo último era alcanzar un patriarcado para Compostela, porque «en todo lugar de la tierra donde descansaba el cuerpo de algún apóstol, allí existía o el Papado o un patriarcado o al menos un arzobispado, excepto en la Iglesia de Santiago " 55 . Occidente era el ámbito que iluminaba el apóstol Santiago con su acción y el Patriarcado de Occidente, mejor que una primacía hispánica en poder de Toledo, sería la dignidad apropiada para una iglesia que «con la presencia del apóstol Santiago iluminaba todo el Occidente». En efecto, convenía alcanzar «el arzobispado o algo mayor» ${ }^{56}$.

Pero el obispo compostelano sabía también que el objetivo final solo se alcanzaría gradualmente. El pontificado de Pascual II abrió esperanzas, pero el papa acabaría por mantener inalterable un mismo esquema - metropolitano en Braga (Giraldo y Mauricio) y primacía en Toledo (Bernardo) — y dejaría a Diego Gelmírez con la dignidad del palio, que le había concedido en 1105 , porque nunca accedió a reconocerle las sufragáneas propias de un obispo metropolitano.

Probablemente, la misma crisis política del reino, que impedía a Gelmírez contar con un apoyo regio sólido y estable, aconsejaba a Pascual II no introducir

$54 \mathrm{HC}$ I, 107, ed. Falque, p. 180-184.

55 HC II, 107.3, ed. Falque, p. 223.

56 Hс I, 81.1, ed. Falque, p. 127, y I, 117, p. 218. 
modificación alguna. Pero el prelado compostelano ideó una nueva estrategia para extender su influencia sobre un ámbito más amplio que el de su diócesis exenta y paliar, de algún modo, la imposibilidad de contar con el apoyo papal o el regio.

El programa de estructuración provincial de la Iglesia hispánica, que se venía promoviendo desde el siglo XI, acabó afectando inevitablemente a la necesaria estructuración territorial compacta de cada una de las diócesis, sujeta a la jurisdicción del obispo respectivo. Las circunstancias históricas de los siglos IX al XI habían introducido una extraordinaria desarticulación de los antiguos espacios diocesanos compactos de cada sede episcopal. Por otra parte, el señorío que la iglesia de Santiago había acumulado desde el siglo ix era muy extenso. Muchos de sus elementos se hallaban situados fuera del antiguo espacio diocesano de Iria, a gran distancia de la iglesia de Santiago, dentro y fuera de Galicia. Sobre los bienes eclesiásticos de ese señorío, que radicaban fuera de la diócesis de Iria-Compostela, los obispos compostelanos podían ejercer la jurisdicción episcopal. El proceso de reintegración territorial compacta de los espacios diocesanos acabaría cuestionando la jurisdicción de la iglesia de Santiago sobre personas y bienes eclesiásticos ubicados fuera de los límites estrictos de la diócesis compostelana.

Diego Gelmírez acudió muy pronto a Pascual in para asegurarse la jurisdicción sobre personas y bienes eclesiásticos del señorío de la Iglesia de Santiago, con independencia de donde radicasen. En mayo de 1103, Pascual II declaraba que la protección de la sede romana, que desde 1095 disfrutaba la sede compostelana, se extendía a «las restantes iglesias de su jurisdicción, constituidas en diversas parroquias, que pertenecen a la mencionada iglesia por donaciones de fieles». El resultado era que «todos los bienes y todas las posesiones que se sabe pertenecen a las mismas iglesias [...] se conserven para ti firmes e íntegros». Finalmente, Pascual II añade la clave: «que no tengan facultad los obispos, ni los ministros de los obispos, en las mismas iglesias para imponer nuevas costumbres, ni excomulgar o prohibir a los clérigos de las mismas o a las mismas iglesias sin tu examen y el conocimiento de una culpa segura, sino que permanezcan ellas íntegra y tranquilamente en tu dominio y en el de la iglesia compostelana» ${ }^{57}$.

57 нс I, 14.2, ed. Falque, p. 30-31. 
Con esta concesión, Gelmírez mantuvo y potenció una red de vínculos personales de amistad especial con otros obispos. Gelmírez los nombraba canónigos de Santiago, en un cabildo ampliado a 72 miembros, y, aparte de los derechos propios de la canonjía, les cedía en préstamo, a título personal, los bienes de la iglesia de Santiago radicados en su respectiva diócesis, con lo que el obispo-canónigo podía ejercer la jurisdicción sobre esos bienes, en tanto que agente de la Iglesia de Santiago ${ }^{58}$. No es de extrańar que, entre los primeros obispos en ser incorporados a esta red, encontremos al arzobispo Giraldo de Braga y a los obispos Diego de Ourense y Alfonso de Tui ${ }^{59}$, los obispados organizados con espacio diocesano compacto en una misma operación ente 1069 y 1071.

Conocemos la renovación de este acuerdo y el documento correspondiente con los sucesores de Giraldo. Mauricio de Braga, canónigo de Santiago, recibía en préstamo en 1109 nada menos que la mitad de Braga y la mitad de Correlhá, "que es de derecho real y pertenece al obispo de Santiago», tan solo la mitad, porque la otra mitad era de los canónigos de Santiago ${ }^{60}$. Lo mismo ocurrió con Pelayo de Braga, nombrado canónigo de Santiago en idénticos términos hacia $1121^{61}$.

La red se ampliaba también cada vez que un canónigo de Santiago era elegido obispo, como ocurrió en 1112 con Hugo, electo de Oporto, y con Munio, electo de Mondoñedo. En 1113, tres de los cuatro obispos gallegos sufragáneos de Braga — los de Tui, Ourense y Mondoñedo- eran canónigos de Santiago, además de dos de los tres obispos de Portugal: el arzobispo Mauricio de Braga y el obispo Hugo de Oporto. El rango y la influencia que Gelmírez no alcanzaba de Pascual II, lo preparaba el obispo compostelano por esta vía.

En 1114, fue rechazada por el papa Pascual la última gestión de Gelmírez para trasladar a Compostela la dignidad metropolitana de Mérida y la jurisdicción sobre sus sufragáneas ${ }^{62}$. Con la muerte de Pascual II en 1118, se abrían de nuevo las esperanzas, sobre todo al saber que en marzo de 1118 le había sucedido el

\footnotetext{
58 Sobre el cabildo bajo Gelmírez véase Francisco Javier Pérez Rodríguez, La Iglesia de Santiago de Compostela en la Edad Media: el cabildo catedralicio (1100-1400), Santiago, 1996, p. 23-32.

59 нс г, 20.6, ed. Falque, p. 48.

$60 \mathrm{HC} \mathrm{I}, 81.3$, ed. Falque, p. 128.

$61 \mathrm{HC}$ II, 46.1-3, ed. Falque, p. 297-298.

$62 \mathrm{HC} \mathrm{I}, 101.3$, ed. Falque, p. 171.
} 
canciller de la sede romana, el cardenal Juan de Gaeta, que tomó el nombre de Gelasio II. Prueba de que el año 1118 sería visto por Diego Gelmírez como una inflexión es que esta fecha, y no el año 1120, es la que tomó como referencia el maestro Giraldo para dar por concluido el Libro I de la Historia Compostellana, dedicado a los hechos ocurridos durante el obispado, e iniciar el Libro II, que aborda los hechos del arzobispado. El privilegio de Calixto II sobre el traslado de la metrópoli de Mérida es de 1120.

La red de amistades funcionaba con eficacia y Gelmírez podía enviar agentes a Roma que eran obispos de sedes hispánicas. Muerto Pascual II, el arzobispo Mauricio de Braga fue el candidato de Enrique V para oponerse a Gelasio II. La debilidad de la sede de Braga era, en ese momento, extrema y Gelmírez envió a un sufragáneo de Braga, el obispo Diego de Ourense, canónigo compostelano, junto con el maestro Giraldo, como nuncios ante el papa Gelasio II, y, dando un salto cualitativo en la composición de la red, nombró canónigo compostelano al mismísimo cardenal Deusdedit, legado de Gelasio $\mathrm{II}^{63}$. La red de hermanos de la iglesia de Santiago se extendía, así, hasta el mismo colegio cardenalicio.

Pero los acontecimientos tomaron un giro inesperado. Gelasio II moría el 28 de enero de 1119 y el 1 de febrero era elegido el arzobispo Guido de Vienne, que tomó el nombre de Calixto II. De pronto, Gelmírez vio como simultáneamente se rehabilitaban las dos vías posibles para apoyar sus pretensiones: la vía pontificia y la vía regia, puesto que el apoyo papal sería decisivo para despejar definitivamente la situación de su sobrino Alfonso Raimúndez respecto al trono leonés. De hecho, Calixto II se puso inmediatamente en contacto con Gelmírez mediante una carta del 2 de marzo, que le envió por medio de su cuñado, que partía en peregrinación a Santiago.

Gelmírez presentó su primera petición a Calixto II a través del maestro Giraldo: el traslado del arzobispado de Braga a Compostela. Pero entonces Braga ya tenía al frente al arzobispo Pelayo. Calixto in se opuso. Gelmírez envió entonces al obispo Hugo de Oporto, canónigo de Santiago, cuya sede se hallaba precisamente en Portugal. Finalmente, en marzo de 1120 Calixto II no solo concedió a Gelmírez el traslado de la sede metropolitana de Mérida a Compostela, sino la legacía pontificia sobre las provincias de Braga y Mérida. El resultado para el 
arzobispo de Santiago era óptimo, porque la primacía de Bernardo de Toledo parecía quedar reducida al mínimo. Para Calixto II, para Poncio de Cluny y, probablemente también para Hugo de Oporto, fue la ocasión para apuntalar al otro miembro de la familia, Alfonso Enríquez, que entonces debía contar unos once años, cuyo padre, el conde Enrique de Portugal, había muerto en 1112. Es verdaderamente significativo que Calixto II otorgue a su madre, la infanta Teresa, el tratamiento de reina. Para Calixto II, Portugal había pasado de condado a reino, en claro beneficio del infante y de su madre, lo que lógicamente encontraría la oposición de Urraca, que en 1121 encarceló momentáneamente al arzobispo de Santiago.

Gelmírez pudo ejercer la legacía, no sin dificultades y oposiciones, hasta la muerte de Calixto II el 13 de diciembre de 1124. Como arzobispo y legado, el 25 de mayo de 1124 armó caballero a Alfonso vir, que debía contar por entonces unos dieciocho años, ante el altar de Santiago, en la iglesia donde yacía el cuerpo de su padre Raimundo ${ }^{64}$.

La concesión de Calixto ir elevaba el rango de la iglesia de Santiago, lo ponía por encima de un simple arzobispado y lo aproximaba al deseado patriarcado. Diego Gelmírez procedió como cabía esperar en él y ordenó a uno de sus más directos colaboradores que actualizase, una vez más, la historia de la sede de Santiago. El maestro y canónigo Giraldo debió empezar su tarea a principios de 1122 y la concluyó hacia 1124. Giraldo, probablemente natural de Beauvais, respetó al máximo el texto de Munio Alfonso y se amoldó a él. Mantuvo intacto el fragmento "Palabras del autor»" ${ }^{65}$, donde su predecesor en la narración afirmaba escribir por mandato del «obispo» Diego Gelmírez.

Al respetar el texto de Munio Alfonso, la aportación de Giraldo queda circunscrita a la figura de Diego Gelmírez y a los acontecimientos posteriores a 1109. Sin embargo, el resultado de su trabajo no deja de ser un producto nuevo, al que hay que dotar de la necesaria unidad, que hoy es difícil de reconocer en el conjunto de la historia, porque volvió a ser ampliada después de 1124. Quizá la posición actual del capítulo 61 del Libro II podría sugerir que este punto del Libro II marca el final del texto de Giraldo y el comienzo de la última ampliación. 
El capítulo 61 tiene todo el aspecto de haber sido el prólogo general, que abría la Historia Compostellana, cuando la acabó Giraldo hacia 1124. Como tal prólogo, no es de Giraldo, sino de Gelmírez: «los que por el cuidado pastoral debemos instruir a los demás». Solo puede ser Gelmírez quien afirma: «si algo digno de memoria ha acaecido durante el episcopado o después durante el arzobispado, en nuestro tiempo o en el de nuestros antecesores, y también cuanto hemos ayudado cada uno a la iglesia que presidimos, para que no quede cubierto por el hollín del olvido, hemos considerado adecuado recogerlo en la redacción de este libro para edificación de los que han de seguirnos». El nuevo libro, que explica la historia de la sede hasta 1124, se define a sí mismo en este prólogo como un Registrum, porque recoge las cosas hechas en el pasado (retrogestae y res gestae). A este prólogo de Gelmírez seguiría de forma prácticamente literal la parte escrita hacia 1110 por Munio Alfonso, lógicamente con la imagen de la inventio. Cuando llegó el momento de la segunda y última ampliación de la Historia Compostellana, el prólogo de Gelmírez fue desplazado a su ubicación actual ${ }^{66}$.

Giraldo compuso el actual prólogo al Libro II, donde explica cuál ha sido su papel en el Registrum, que ha dejado dividido en dos libros. Al haber respetado el texto de sus predecesores y presentándose como su continuador, describe su papel personal, asume que la obra nació en último término del mandato de Gelmírez, cuando era obispo, y que narra cuanto había ocurrido antes y después de su acceso al episcopado: «obedeciendo la exhortación de tu santidad, reverendísimo padre Diego, obispo de Santiago, hemos procurado componer parte del libro precedente, pues lo que antecede a este libro lo habían escrito los obispos Nuño de Mondoñedo y Hugo de Oporto».

Giraldo completó aquel primer mandato episcopal y «acomodando la chispa de mi ingenio a la pluma de éstos», afirma que ha procurado manifestar "por escrito qué y de qué manera habéis trabajado en la mencionada iglesia [...] y de qué modo la habéis gobernado antes de ser obispo y durante el episcopado». A partir de aquí anuncia el comienzo del Libro II: «en adelante nos proponemos contar de qué manera la misma iglesia del Apóstol, con la ayuda de Dios y el esfuerzo de vuestra dedicación, fue nombrada metropolitana». Como Giraldo no ha querido alterar el texto de sus predecesores, no se abstiene de hacer referencias 
a lo ocurrido antes de 1110, cada vez que lo considera oportuno, dando así su punto de vista sobre hechos narrados u omitidos por Munio Alfonso.

Naturalmente, al concentrarse en la narración de los hechos de Gelmírez, precisamente en el momento de sus más sonoros éxitos, Giraldo no se puede sustraer a la tentación de subrayar cómo sus pasos fueron guiados por el patrocinio del apóstol Santiago y la diestra del poder de Dios, hasta el punto de «traer a la memoria en un único capítulo» ${ }^{67}$ siete episodios en los que Gelmírez salvó milagrosamente la vida. Estos episodios o bien no se habían mencionado en el lugar del Registrum, que le correspondería por su cronología, o, si se habían relatado, no se habían enfocado desde esta perspectiva providencialista. Este tono apoteósico, que inspira el relato de Giraldo, refleja las circunstancias en que escribió, los momentos de apogeo triunfal de Diego Gelmírez.

Se quiere mostrar también la eficacia universal del patrocinio del Apóstol a través de los milagros, que se extiende al arzobispo, a los cristianos de Francia, Inglaterra, Italia y Alemania e incluso a los sarracenos que visitan Santiago ${ }^{68}$. De nuevo intuimos la estrecha relación entre ampliación de la narración histórica en el "Registrum» y la ampliación en Compostela de aquel «Libro de Santiago», que anunciaba la futura recopilación de los milagros que el Apóstol seguiría realizando.

En los últimos dieciséis años de su arzobispado, Gelmírez no encontró acogida a sus pretensiones patriarcales, ni en Honorio II, ni en Inocencio II. Es más, con la muerte de Calixto II, en diciembre de 1124, perdió definitivamente la legacía para las dos provincias.

En poco más de un año, además de Calixto II, murieron Bernardo de Toledo (abril de 1125) y la reina Urraca (marzo de 1126), y Gelmírez, infatigable, empezó una vez más a jugar sus cartas ante los nuevos actores: Honorio II, Raimundo de Toledo (desde 1125) y Alfonso vir. Maestro como nadie en el recurso a los dos poderes - ecclesiastica atque seculari potentia magis suffulta-, explotó, hasta donde pudo, las nuevas posibilidades que se le abrían con Alfonso vir al frente del reino de León. Ahora el arzobispo se cuida de hacer ver que fue él quien «bautizó, ungió rey y armó caballero» a Alfonso y empieza a identificar el ámbito político 
sobre el que Alfonso viI debe ejercer su autoridad, como el que mejor se ajusta a la extensión geográfica que debía corresponder al patriarcado compostelano.

Había llegado el momento esperado desde 1109. Por primera vez Gelmírez podría acudir a Roma con el respaldo explícito del rey que ostentaba la «secularis potentia». Nada más oportuno que exaltar el papel que los reyes cristianos desde Alfonso Ir habían tenido en la fundación y engrandecimiento de la sede apostólica. Para encauzar adecuadamente el reinado de Alfonso VII, convenía acceder a instituciones próximas al rey, vincularlas institucionalmente con el titular del arzobispado compostelano y marcar pautas de gobierno inspiradas por el apóstol Santiago y su patrocinio.

En Compostela se redacta el llamado Chronicon Compostellanum, una breve relación de los monarcas astures y leoneses hasta Urraca, escrito desde una perspectiva sutilmente favorable a las pretensiones de Gelmírez, al señalar toda Hispania como el espacio político que le debe corresponder a Alfonso VII ${ }^{69}$.

En noviembre de 1127, Gelmírez consigue que Alfonso viI vincule al titular de la sede compostelana la cancillería y la capellanía regia. Los principales asuntos del reino tendrían que pasar por Gelmírez o por los clérigos por él designados. Encomienda la cancillería regia al tesorero Bernardo y se reserva personalmente la capellanía regia y el control de sus clérigos. Como capellán regio, el arzobispo es el principal responsable de la salud espiritual del rey y de su salvación eterna, lógicamente condicionada por el ejercicio de un recto gobierno.

La mejor forma de alcanzar este objetivo es hacer al rey partícipe de las oraciones elevadas al Apóstol y los beneficios de él obtenidos en la basílica compostelana, asiento natural de la capellanía regia. La fórmula elegida era bien conocida: ampliar la red de canónigos y recibir al propio rey en el oficio y el beneficio correspondiente. La canonjía le garantiza al joven Alfonso viI, todavía soltero, los beneficios espirituales en vida. Para después de su muerte se instituye un aniversario para impetrar su salvación eterna, que solo puede celebrarse en la capilla regia, porque Alfonso viI se ha comprometido a que su cuerpo sin vida descanse en Compostela, como el de su padre Raimundo, en un panteón regio junto al sepulcro apostólico.

69Ed. Henrique Flórez, «Chronicon ex Historiæ Compostellanæ Codice. Nunc primum editum», España Sagrada, xx, Madrid, 1765, p. 608-613. 
Es entonces, a finales de 1127, cuando el capellán regio ordena compilar en un único códice la serie de diplomas otorgados por reyes y personas reales a la iglesia de Santiago ${ }^{70}$. Lógicamente, la selección documental es inteligente y ajustada a esa visión oficial promovida desde la cátedra arzobispal. Al igual que, poco antes de 1095, el relato de la campaña de Carlomagno había dado la versión más adecuada de la fundación de la iglesia de Santiago y, hacia 1110, se habían excluido de la reproducción en la Historia Compostellana las cartas papales anteriores a la de Urbano II de 1095, tampoco ahora interesa copiar ciertos documentos obsoletos. El primero que se sacrifica es el de la propia fundación de la iglesia de Santiago por el rey Alfonso II, diploma que en 1127-1129 recordaría unas funciones litúrgicas de Antealtares, al abad Ildefredo y a sus monjes, que ahora eran ejercidas por los cardenales compostelanos. El segundo que tampoco tenía ya el más mínimo interés era un diploma real que concedía el derecho a percibir los votos, únicamente en el espacio comprendido desde el Pisuerga al océano.

La serie documental se agrupó por otorgantes y cada serie se hizo preceder de la imagen del respectivo donante, con una única excepción, la misma imagen que hacia 1110 figuraba en la Historia de la sede y desde 1124 en el Registrum: la inventio del sepulcro bajo Teodomiro y Alfonso II, siempre con dos sepulcros, los de Teodoro y Atanasio, el fundamento de la apostolicidad de la sede, yuxtapuesta al fundamento regio de su posición en el reino.

Honorio ir nunca accedió a confirmar la legacía de Gelmírez sobre las provincias de Braga y Mérida, que era tanto como devolver a Raimundo de Toledo el estatuto de primado hispánico, que había tenido su predecesor, el arzobispo Bernardo. Desde noviembre de 1127, Gelmírez puede utilizar los nuevos cauces que acababa de abrir. En las cartas reales preparadas bajo el nuevo canciller se afirma la condición de Alfonso vir como emperador hispano. A esta nueva dimensión contribuye el matrimonio regio de Alfonso con Berenguela en noviembre de 1128, que era hija del conde de Barcelona Ramón Berenguer III $^{71}$.

70 Fernando López Alsina, «El Tumbo A y sus relaciones con otros cartularios del escritorio compostelano», en Manuel C. Díaz y Díaz, Fernando López Alsina, Rocío Sánchez Ameijeiras, Índice de los Privilegios Reales que contiene este Libro intitulado de la Letra A, Colección Scriptorium 31, Madrid, 2008, p. 47-141.

71 Sobre Alfonso vir véase el estudio reciente de Manuel Recuero Astray, Alfonso VII (1126-1157), Burgos, 2003. 
En 1129, después de la celebración del concilio de Palencia (marzo 1129), presidido por el arzobispo Raimundo de Toledo, primado y legado pontificio, Gelmírez, ahora con el apoyo de Alfonso vir, solicitó a Honorio II la legacía sobre toda España ${ }^{72}$. El papa justificó al arzobispo y al «ilustre rey de las Españas» el principal impedimento: acababa de confiársela al cardenal Humberto ${ }^{73}$.

Si Alfonso vir aspiraba a gobernar un imperio hispánico, la acción pontificia desde finales del siglo xi había hecho progresos en la implantación cada vez más visible de una ordenación provincial de ese mismo espacio en el plano eclesiástico, bajo la autoridad de Roma y sus legados. Es muy significativo que Humberto, el legado papal para el ámbito hispánico, hubiese presidido en febrero de 1130 el concilio de Carrión, al que además del arzobispo Gelmírez asistió el «arzobispo de Tarragona», es decir, el obispo Olegario de Barcelona.

La dignidad imperial había cobrado nuevo valor desde la conquista de Toledo en 1085, hasta el punto de que el control de la ciudad estaba directamente asociado con el uso del título ${ }^{74}$. Después de 1109 buena parte del reino de León estuvo en poder de Alfonso I de Aragón. Urraca primero y Alfonso vir después fueron reduciendo el ámbito territorial en manos de Alfonso I. Alfonso vir emplea el título imperial para subrayar esa deseada supremacía peninsular, vinculada al gobierno de Toledo, cuyo arzobispo ostenta la primacía hispánica. Aun cuando se intitule emperador, Alfonso vir es el primer monarca que utiliza el león en el sello regio, emblema heráldico de su reino. El título imperial expresa una supremacía compatible con la existencia de otros poderes peninsulares, incluso con el título regio. La muerte de Alfonso I de Aragón en 1134 franqueaba las puertas para la coronación imperial de Alfonso vir en León en 1135. El vasallaje del rey de Navarra y del conde de Barcelona podían dar la impresión de que, como afirma la Chronica Adefonsi imperatoris, el imperio de Alfonso vir se extendía desde el océano, donde está el Padrón de Santiago, hasta el río Ródano ${ }^{75}$.

72 HC III, 7.4, ed. Falque, p. 431.

73 HC III, 10.2, ed. Falque, p. $435-436$ (JL 7382), III, 10.3, p. 436 (JL 7383).

74 Andrés Gambra Gutiérrez, Alfonso VI. Cancillería, Curia e Imperio, I: Estudio, León, 1997, p. 692-694.

75 Chronica Adefonsi Imperatoris I, 68, ed. Antonio Maya Sánchez, en Chronica Hispana saeculi XII, Corpus Christianorum, Continuatio Medievalis 71, Turnhout, 1990, p. 109-248: «Et facti sunt termini regni Adefonsi regis Legionis a mari magno Oceano, quod est a Patrono Sancti Iacobi, usque ad fluuium Rodani». 
En esta última década de su arzobispado, Diego Gelmírez, canciller y capellán regio, contempla ese imperio como el ámbito de su deseado patriarcado de Occidente. Tras la muerte de Honorio iI, en febrero de 1130, Gelmírez obtiene de Inocencio II el 2 de agosto de ese mismo año la confirmación de un «voto», que ya nada tiene que ver con el que confirmara Pascual $\mathrm{II}^{76}$. El límite occidental en el río Pisuerga ha desaparecido y el papa manda a los arzobispos y obispos de España que no pongan impedimento para que sean pagados. Estamos en el camino que conducirá abiertamente a la reivindicación de un voto sobre toda "Hispania».

Como lo había sido el emperador Carlomagno poco antes de 1095, ahora será el papa Calixto II la figura pontificia adecuada para autorizar las tesis con las que respaldar las viejas aspiraciones compostelanas. En 1123, durante la celebración del I Concilio de Letrán, el papa había equiparado la reconquista ibérica con la cruzada oriental. Dándole la vuelta a la iniciativa pontificia, Diego Gelmírez, amparado en su legacía romana, concedía el 18 de enero de 1125 desde Compostela la indulgencia plenaria a todos cuantos participasen en la cruzada hispánica, por la autoridad de Dios y de los santos apóstoles Pedro, Pablo, «Santiago» y de todos los santos ${ }^{77}$.

Si el obispo León, autor de la carta sobre la traslación, había pasado en el siglo XI a ser un papa León, de todos los papas posibles, Calixto II, tío de Alfonso viI y generoso benefactor de la sede compostelana, era la figura adecuada para atribuirle, con cierto grado de credibilidad, la autoría de cualquier iniciativa tendente a presentar la basílica compostelana como la sede del patriarcado de Occidente. La muerte de Alfonso el Batallador en 1134 acabó de facilitar las cosas.

La coronación imperial de Alfonso vir en 1135 induce a Gelmírez a poner en marcha una profunda ampliación del Libro de Santiago y, sobre todo, a atribuir al papa Calixto in no solo muchos de los nuevos elementos ahora incorporados, sino la autoría de toda la compilación. Es seguro que la ampliación se realiza en las tres secciones ya existentes y con la adición de otras dos nuevas, que acabarán siendo los Libros IV y v del Códice Calixtino.

76 HC III, 22.3, ed. Falque, p. 453 (JL 7417).

77 HC II, 78.2, ed. Falque, p. 378-379. Sobre esta «apoteosis de Gelmírez» véase Ayala Martínez, Sacerdocio, p. $413-415$. 
El gran objetivo que ahora persigue el arzobispo es recuperar el tema de la predicación de Santiago en Espańa con todas sus consecuencias, motivo que entra en diversos lugares de la compilación. Es especialmente revelador que el relato de una segunda campaña de Carlomagno en España, que culmina en la concesión a Compostela de un ambicioso estatuto patriarcal, se adjudique al arzobispo Turpín, compañero del emperador y testigo ocular de la expedición. Al atribuir la autoría del conjunto del Liber Sancti Jacobi al papa Calixto II, la decisión imperial queda ratificada por la autoridad pontificia: Compostela, columna de justicia, apoyada por ambos poderes. El resultado es una amplia reflexión sobre la cultura y la espiritualidad de la peregrinación jacobea y su camino. Alguno de los elementos ahora admitidos en el Libro de Santiago aporta indicios claros de la cronología de la revisión. Veamos las cinco grandes incorporaciones a lo que pasará a ser el Códice Calixtino del Libro de Santiago.

El primer elemento que se puso a punto para ampliar el Libro de Santiago es una actualización del relato de finales del siglo XI sobre la expedición hispánica de Carlomagno. A partir del escueto relato anónimo, que atribuía al emperador la decisión de que Santiago fuese sede episcopal, estatuto que hacia 1135 no podía tener ningún interés para la sede compostelana, se recurre a una reacción musulmana que, al arruinar los resultados de la primera expedición de Carlomagno, hace necesaria la segunda campaña. Son muchos los elementos y los materiales integrantes de lo que será el Libro IV en el actual Códice Calixtino. Interesa subrayar aquí solo los aspectos relacionados con la coyuntura de su incorporación a la compilación jacobea. Adviértase que, una vez más, el modo de operar es el conocido: a partir del relato de la primera campańa se construye un relato unitario más amplio, que sea la suma de los dos. El autor es un testigo ocular de los acontecimientos, el arzobispo Turpín de Reims, participante en la expedición.

Se trata de acentuar, una vez más, el papel que han tenido los reyes en la fundación de la iglesia de Santiago, en la configuración de las vías de peregrinación y en la dilatación por las armas del espacio de la Cristiandad frente al Islam en una contienda plurisecular. El emperador Carlomagno es el trasunto de ese poder temporal, que históricamente le había correspondido a los reyes representados en el Tumbo A, desde Alfonso II hasta Alfonso viI, desde 1135 emperador hispánico.

En el relato de la segunda campaña, mucho más largo y pormenorizado que el de la primera, se advierten muchos más nexos con Santiago. Hay una voluntad 
manifiesta de ubicar el escenario concreto de varios episodios en diversos lugares, que el Libro $\mathrm{v}$ nos indica enseguida que son puntos por los que transcurre el Camino de Santiago: Sahagún, Pamplona, Burdeos, Puente Arga, Monjardín, Nájera, Roncesvalles, Valcarlos, Ostabat.

La vinculación del tema de la evangelización con el de la defensa o expansión armada de la cristiandad, que ha hecho del evangelizador Santiago el auxiliador en las batallas, se aplica al viejo tema de los siete varones apostólicos de la Galia desde una perspectiva sutilmente favorable a Compostela ${ }^{78}$. Para empezar, no se dice que estos siete santos obispos hubiesen operado a escala de la Galia, ni que hubiesen sido enviados a ella por Pedro y Pablo o por sus sucesores. Al contrario, las sedes de estos siete varones se sitúan en la parte meridional de la Galia, siempre al sur del Loira y al este del Ródano: Maximino en Aix, Trófimo en Arlés, Paulo en Narbona, Saturnino en Toulouse, Frontón en Périgueux, Marcial en Limoges y Eutropio en Saintes ${ }^{79}$. Se trata del mismo espacio ultrapirenaico que el Libro v presenta como el territorio atravesado por los Caminos de Santiago, lo que explica la ausencia en la lista de san Dionisio de París.

Los siete santos obispos son traídos a colación para atribuirles la consagración de dos cementerios considerados, por ello, más sagrados que los demás, uno en Burdeos, el otro en Arlés, ciudades por las que pasan esos mismos caminos. Si en 1127 Alfonso viI, el emperador cristiano que dirigía las campañas hispánicas contra el Islam, había prometido enterrarse en Compostela, junto al sepulcro del Apóstol, ciertos combatientes caídos en la campaña de Carlomagno en España, verdaderos mártires de la fe, tenían que ser sepultados en estos dos cementerios del espacio jacobeo del sur de Francia. Otros lo fueron en Belin, lugar de paso del

\footnotetext{
78 cc IV, 21, Herbers / Santos Noia, p. 222 [Iv, 28]: «et erant tunc temporis bina cementeria precipua sacrosancta, alterum quod apud Arelatem in Ailis Campis, alterum apud Burdegalem, que Dominus per manus sanctorum viI antistinum, scilicet Maximi Aquensis, Trophimi Arelatensis, Pauli Narbonensis, Saturnini Tolosanensis, Frontonis Petragoricensis, Marcialis Lemovicensis, Eutropii Sanctonensis, consecravit, in quibus máxima pars illorum sepelitur».

79 Nótese el desplazamiento hacia el sur de los siete varones apostólicos. En la Historia Francorum, Gregorio de Tours, invocando la pasión de san Saturnino, nos presenta a estos siete obispos: Catiano de Tours, Trófimo de Arlés, Pablo de Narbona, Saturnino de Toulouse, Dionisio de París, Stremonio de Clermont y Marcial de Limoges: siete obispos ordenados ad praedicandum in Galliis, enviados desde Roma en el siglo III, en tiempos del emperador Decio. Historia Francorum I, 30: Gregorii Episcopi Turonensis Libri Historiarum X, ed. B. Krisch, W. Levison, MGH, ss rer. Mer. 1/1, 2a ed., Hannover, 1951, p. 22-23.
} 
camino turonense. Roldán, el héroe de la Chanson y del Pseudo-Turpín, recibe sepultura en Blaye, también en el camino turonense.

Las ciudades de Blaye y Compostela, las iglesias de San Román y de Santiago, quedan de nuevo unidas por la voluntad de los príncipes cristianos, porque se cuenta que Carlomagno concedió en alodio a la iglesia de San Román toda la tierra que se extendía en seis millas a la redonda de la iglesia de San Román y toda la ciudad de Blaye, justamente las mismas seis millas del Giro de Santiago que Alfonso II y sus sucesores habían concedido a la iglesia compostelana.

Además, Carlomagno instituye un aniversario en la iglesia de San Román, que se celebrará el día 16 de junio, fecha de la muerte de Roldán, por las almas de su sobrino, sus compañeros y todos los que en España hubiesen padecido el martirio o lo recibiesen en adelante. El sepulcro del mártir Roldán y la iglesia, donde se celebra el aniversario por los mártires caídos en España, se ubican en el Camino del apóstol mártir, que ha inspirado la campaña de Carlomagno y que le ha auxiliado en el combate.

La eficacia del patrocinio de Santiago en la salvación de las almas de quienes defienden con las armas su sepulcro, su campo de actividad evangelizadora y sus caminos se pone de manifiesto en la visión del arzobispo Turpín, quien contempla cómo las almas de los caídos en Roncesvalles son transportadas el mismo día directamente al cielo. Sin embargo, Carlomagno no había caído en la campaña y había regresado felizmente a Aquisgrán. Aun así, también a él le ayudó Santiago, "un gallego descabezado», en el trance del peso de las almas, y le alcanzó la corona de los mártires, que le había prometido cuando se le apareció en Aquisgrán.

El relato unificado de las dos campañas de Carlomagno tiene como principal objetivo destacar la potestad que le corresponde al rey o al emperador, en el caso de Alfonso vir ambas cosas, frente a la autoridad pontificia, sobre la iglesia de su reino o de su imperio, sobre todo en aquellos ámbitos fronterizos con el Islam contemplados en la reciente iniciativa pontificia de la cruzada.

La primera campańa finalizaba con la concesión de un modesto estatuto episcopal para Compostela, vital para la sede a la altura de 1095. En el relato de la segunda, tal como se concibe hacia 1135, es Carlomagno quien pone en pie la iglesia hispánica sobre el territorio recién conquistado. Frente a las pretensiones pontificias de exclusividad, el emperador establece sesenta obispados en las ciuda- 
des conquistadas y convoca en Compostela el primer gran concilio de esta nueva iglesia, que decreta la primacía apostólica de la sede compostelana ${ }^{80}$.

La consagración de la iglesia recién fundada y su dotación inicial no se deben a Teodomiro de Iria y a Alfonso II, sino al arzobispo de Reims y al emperador Carlomagno. La dote, acorde con el estatuto primacial, consiste en un censo anual de cuatro monedas sobre todas las casas de Espańa. Es el resultado de la nueva interpretación del voto que, a instancias de Gelmírez, había confirmado en 1130 Inocencio II, y que suprimía el límite occidental en el Pisuerga. Los efectos se harán sentir muy pronto. Alfonso viı concederá el voto de Toledo, con el beneplácito del arzobispo Raimundo ${ }^{81}$, y el canónigo Pedro Marcio ultimará el «Privilegio de los Votos» basado en la campaña de Clavijo ${ }^{82}$.

Con todo, la novedad de mayor calado es la revisión del concepto de sede apostólica. Gelmírez había conseguido de Pascual ir la aceptación de la translatio y la incorporó al Libro de Santiago hacia 1110, pero había sacrificado la misión apostólica en vida y la había compensado mediante la acumulación de milagros póstumos. Hacia 1135, al incorporar este relato al Libro de Santiago, propone abiertamente un estatuto de sede apostólica, basado en la combinación de ambas: la recuperada predicación en Hispania durante su vida y su actividad apostólica póstuma en todo Occidente mediante los milagros.

En virtud de este estatuto de sede apostólica, se celebrarán en Santiago los concilios de la iglesia hispánica de esos sesenta obispados, una iglesia sin provincias y sin metropolitanos. A pesar de los acuerdos que Gelmírez alcanzó en 1127 con un Alfonso vir al que había coronado rey y de las ordenaciones episcopales hechas por el prelado en la Catedral de Santiago, las competencias reclamadas en 1135 estaban todavía muy lejos de la realidad contemporánea: al titular de la sede apostólica de Santiago se le concede la facultad de otorgar — per manum — los báculos episcopales y las coronas reales.

El fundamento del estatuto se asienta en el mismo pasaje evangélico (Mt 20, 20 ss.) que había inspirado el himno O Dei Verbum en el siglo viII, pieza clave de

80 Véase Klaus Herbers, Política y veneración de santos en la Península Ibérica. Desarrollo del «Santiago político», 2a ed., Pontevedra, 2006, p. 57-65.

81 Edita Manuel Lucas Álvarez, Tumbo A de la Catedral de Santiago. Estudio y edición, Santiago, 1988, p. 258-261, n. 106.

82 Herbers, Política y veneración..., p. 66-71. 
la liturgia del 30 de diciembre desde el siglo vin hasta 1080, proscrito en la nueva liturgia romana de la sede compostelana. Ahora se retoman los viejos argumentos: «de la misma manera que por san Juan Evangelista, hermano de Santiago, se estableció en Oriente la fe en Cristo y una sede apostólica en Éfeso, así también en la parte occidental del reino de Dios fue establecida por Santiago la misma fe y una sede apostólica en Galicia».

El mismo pasaje se aduce para justificar la apostolicidad de la sede compostelana, lo que no se había podido concretar en un himno escrito unas décadas antes de la inventio del sepulcro: «estas son sin duda las sedes apostólicas: Éfeso, que está a la derecha en el reino de Cristo, y Compostela, que está a la izquierda, sedes que en la división de las provincias correspondieron a estos dos hijos de Zebedeo». Como veremos, el himno O Dei Verbum no es el único material litúrgico altomedieval recuperado por estas fechas en Compostela.

Consciente de que aun cuando la forma fuese una ficción carolingia, los argumentos expuestos tendrían que ser eficaces en el segundo tercio del siglo XII, el relato que hace Turpín de las legendarias medidas de Carlomagno tiene que ser legitimado por Roma, que es lo que se consigue atribuyendo todo el Libro de Santiago y sus materiales al papa Calixto II. Solo de Roma podría llegarle a Gelmírez la dignidad de patriarca de Occidente. Por eso se argumenta la teoría de las tres sedes, con Roma ostentando la primacía, la única sede ante la que debe ceder la de Santiago: «tres sedes apostólicas principales sobre todas suele con razón la cristiandad venerar especialmente en el mundo, a saber, la romana, la gallega y la de Éfeso».

El mismo Cristo, que distinguió a Pedro, Santiago y Juan con mayor dignidad que a los demás apóstoles, quiso que estas tres sedes fuesen reverenciadas sobre todas las demás. Y explícitamente se introduce la predicación de Santiago: «los sacrosantos lugares donde predicaron y fueron enterrados».

De las tres sedes, la primacía le corresponde a Roma. Pedro es el príncipe de los apóstoles y en Roma predicó, padeció el martirio y está sepultado. ¿Y Compostela? Santiago es el segundo de los apóstoles y Compostela la segunda sede, pues Santiago la santificó con su predicación, la consagró con su sepultura y la ilustra con sus milagros y permanentes beneficios.

La interpretación que hace Gelmírez y su sede compostelana es toda una propuesta sobre cómo debía organizarse una cristiandad dividida entre Inocencio 
II y Anacleto ir. Roma es el centro de la iglesia universal, pero existe una región occidental y un emperador. Santiago, lo quiso Carlomagno, es la única sede apostólica de Occidente y su camino se extiende hasta el mar de Frisia. Pero en este amplio marco de la Cristiandad occidental, la autoridad pontificia está matizada por la del emperador y los reyes cristianos en sus respectivos ámbitos políticos.

Se trata de un Occidente plural. Ante todo Alfonso viI, como emperador, y el ámbito de su imperio, que se extiende hasta el otro lado de los Pirineos, como sugieren los caminos de Santiago descritos en el Libro v. Pero en el Occidente, por el que transita el Camino, que sigue Carlomagno desde Aquisgrán y que arranca en el mar de Frisia, se halla el propio emperador germano y su imperio y el reino de Francia con su monarquía capeta. El Libro IV tendría que interesar a Lotario II (1133-1137) y, desde luego, en la siguiente dinastía, a Conrado III (1138-1152) y a Federico II, y, en Francia, a Luis vi (1108-1137) y a su consejero Suger, abad de Saint-Denis, donde el rey recibió sepultura, y a su sucesor Luis vII (1137-1180).

La implicación de París y la monarquía capeta en el universo explicativo de los dos poderes, espiritual y temporal, se consigue cuando Carlomagno, en París de regreso de España, reúne un concilio en la abadía de Saint-Denis ${ }^{83}$ y otorga a la abadía un estatuto sobre Francia similar al que había concedido a la sede de Santiago sobre España. La justificación es el apostolado de Dionisio sobre toda Francia, que le había sido encomendada por san Pablo y el papa Clemente. Sin el consejo del abad de Saint-Denis, no debían ser coronados los reyes, ni ordenados los obispos. El emperador concedió a la abadía un censo sobre toda Francia semejante al que había concedido a Santiago sobre toda Espańa. Ahora reaparece el varón apostólico que faltaba, este ciertamente enviado desde Roma, con un papel restringido a la Francia del norte, la Francia capeta.

Con las concesiones a Saint-Denis, el Pseudo-Turpín pretende reforzar la lógica de la concesión de Carlomagno a Compostela. Hacía siglos que la abadía parisina pretendía que el mártir Dionisio, personaje histórico del siglo III, era un varón apostólico enviado a la Galia desde Roma en el siglo i. Las iglesias que guardan los cuerpos - y, desde luego, las cabezas - de los evangelizadores apostólicos de los francos y de los hispanos deben aspirar a un mismo estatuto y a unas 
mismas prerrogativas, aunque la abadía de Saint-Denis nunca hubiera formulado sus aspiraciones en estos términos.

Las relaciones internas entre el Pseudo-Turpín y el Libro v quedan de nuevo en evidencia en el tratamiento dado a Dionisio de París y a los siete varones apostólicos meridionales. Según el Libro v, la vía tolosana incluye Arlés y el sepulcro de Trófimo en el ámbito apostólico de los caminos de Santiago. En cambio, la vía más occidental arranca en Tours y se cuida de no mencionar París. El Loira marca el límite de los caminos jacobeos, con lo que la basílica de Saint-Denis puede ser el centro de su propio ámbito de apostolicidad en la Francia del norte, apostolicidad ahora claramente romana.

El nexo de Compostela con Aquisgrán se establece a través de Reims. El deán Liutprando de Aquisgrán escribe al arzobispo de Reims pidiéndole que le narre con todo detalle las hazañas de Carlomagno en España, que no encuentra suficientemente expuestas en las crónicas. Según la epístola introductoria del Libro IV, Turpín ha escrito todas estas hazañas por encargo de Aquisgrán. En Santiago, hacia 1135 , no se tenía ninguna duda del interés que semejante relato iba a suscitar en Aquisgrán y en el círculo imperial.

El obispo Gelmírez había coronado en Santiago al rey Alfonso vir en 1111 y este había prometido en 1127 que su cuerpo descansaría en Compostela. El estatuto que Gelmírez pretende para Santiago hacia 1135 ponía a Compostela en el mismo plano que Reims, Saint-Denis, Aquisgrán, lugares donde se coronaba a reyes y emperadores de las regiones Occidentales de la Cristiandad o se acogían sus sepulcros.

Si Carlomagno representa a Alfonso viI, Calixto ir es el trasunto de Diego Gelmírez. El sagaz arzobispo compostelano sirve al apóstol Santiago y a su rey Alfonso vII, del que es capellán y canciller, sentando las bases para neutralizar la reciente mutación de la reconquista en cruzada hispánica pontificia y devolver al emperador la iniciativa frente a las aspiraciones papales.

Gelmírez y su iglesia compostelana y Alfonso vir y su imperio son los grandes beneficiados al aceptar como mártires de la fe a los caídos en la lucha contra los almorávides, pero bajo la bendición del apóstol Santiago, no solo de Pedro y de Pablo. Por eso se amplían las tesis de Gelmírez en su carta de enero de 1125 sobre la cruzada hispánica y se ponen en boca del Pseudo-Calixto II, en la epístola que 
cierra la narración del Pseudo-Turpín, que pretende ser una carta papal de 25 de marzo de 1123, dada ante cien obispos, reunidos en el I Concilio de Letrán ${ }^{84}$.

Según esta versión de la carta papal, la cruzada en España la estableció Carlomagno con sus campañas y su compañero, el arzobispo Turpín de Reims, al conceder indulgencia plenaria a los combatientes en España durante la celebración de un concilio de todos los obispos de la Galia y de Lorena, reunido en Reims. La cruzada a Jerusalén, convocada por Urbano II en Clermont, no fue otra cosa que la confirmación de esa cruzada «imperial», que en 1095, como novedad, se dirigiría hacia Jerusalén. Ahora el Pseudo-Calixto confirma y equipara la cruzada hispánica y la jerosolimitana, como hiciera realmente Calixto II en 1123, bajo la bendición de los apóstoles Pedro y Pablo, pero, como quiso Gelmírez en 1125, en la carta se añade «Santiago».

¿En qué otro lugar de Occidente, salvo en Compostela, se iba a fraguar esta carta? ¿Dónde mejor que en Compostela se podía recordar la cruzada predicada por Gelmírez en enero de 1125 bajo la protección de Santiago? ¿Qué otro obispo, que no sea Diego Gelmírez, iba a asumir las tesis jacobeas por él predicadas en 1125 sobre la cruzada hispánica? Es el arzobispo Diego Gelmírez, en la Compostela de ca. 1135, quien recurre a la figura del papa Calixto II, para dar autoridad al relato del Pseudo-Turpín, en primera instancia y, después, a toda la compilación del Libro de Santiago, que lo acoge.

En el caso del Pseudo-Turpín, su integración en la compilación se realiza mediante una técnica que se usará ampliamente en otras partes del Libro de Santiago, consistente en la adjudicación de capítulos concretos a la autoría de Calixto II, en este caso, además de la epístola, los dos que la preceden ${ }^{85}$. En el antepenúltimo capítulo del Pseudo-Turpín hábilmente se hace hincapié en que el arzobispo, al regreso de la expedición hispánica, no volvió a Reims, como cabría esperar, sino que permaneció en Vienne. Allí tuvo noticia de la muerte de Carlomagno y desde allí escribía al deán Liutprando de Aquisgrán ${ }^{86}$.

Vienne es el nexo necesario con el arzobispo Guy, futuro Calixto II. Nada más lógico que sea Calixto II quien tome la palabra, para informarnos de que

84 CC Iv, 26, Herbers / Santos Noia, p. 228-229 (Appendix D).

85 CC IV, 24-25, Herbers / Santos Noia, p. 227-228 (Appendix A, B).

86 cC rv, 24, Herbers / Santos Noia, p. 227 (Appendix A). 
el sepulcro del arzobispo Turpín, que había fallecido y había sido enterrado en Vienne, fue encontrado incorrupto en un sarcófago «en nuestra época». Siendo, pues, Calixto arzobispo de Vienne, tuvo lugar la invención del cuerpo de Turpín y fue trasladado a la iglesia donde era venerado como mártir, por haber participado en la cruzada de España.

La segunda ampliación de la compilación es una presentación de los diversos Caminos de Santiago y la detallada descripción de la basílica a la que conducen. Su incorporación, como Libro v del Códice Calixtino, parece perfectamente razonable y, desde luego, es una consecuencia lógica, derivada de la decisión de añadir al Libro de Santiago los relatos de las dos campañas de Carlomagno, fundidas en el Pseudo-Turpín ${ }^{87}$. En el Libro iv las vías de peregrinación jacobeas se plantean desde varios puntos de vista. Por una parte, es el largo Camino desde el mar de Frisia de la visión de Carlomagno; por otra, las vías más concretas del territorio del sur de Francia y del norte peninsular. El Libro v se decanta por el segundo punto de vista, hace hincapié en un espacio más reducido, limitado por el Ródano al oeste y el Loira al norte, y desarrolla las tesis apuntadas en el Pseudo-Turpín. Por evidencias internas, el Libro $\mathrm{v}$ tiene que ser posterior a la muerte de Luis vI de Francia, ocurrida en agosto de 1137.

La cronología conocida de la expansión de los caminos de Santiago y la de sus afluentes presta un cierto aval a la presentación del Libro v. En este sentido, es muy significativa la mención del año 1132 de la via publica Sancti Jacobi, a su paso por Montpellier, a más de $1200 \mathrm{~km}$ de distancia de Compostela. Más difícil sería poder documentar la misma fijación geográfica y denominativa del Camino de Santiago en los puntos de las otras vías más alejados de los Pirineos ${ }^{88}$.

En la descripción pormenorizada de los caminos no podía estar ausente la cultura de la peregrinación jacobea, nacida de la dilatada experiencia de varias

\footnotetext{
87 Del Libro v disponemos de un estudio, edición crítica y traducción inglesa de Paula Gerson, ed., The Pilgrim's Guide to Santiago de Compostela: A Critical Edition, t. I: The Manuscripts. Their Creation, Production and Reception, por Alison Stones, Jeanne Krochalis, Paula Gerson, Annie Shaver-Crandell, t. II: The Text: Annotated English Translation, por Paula Gerson, Annie Shaver-Crandell, Alison Stones, con asistencia de Jeanne Krochalis. Texto latino cotejado, editado y anotado pr Jeanne Krochalis y Alison Stones, Londres, 1998.

88 Fernando López Alsina, «El Camino de Santiago: realidad histórica y tema historiográfico», en IV Semana de Estudios Medievales (Nájera, 2-6 agosto 1993), ed. José I. de la Iglesia Duarte, Logroño, 1994, p. 89-104, concretamente p. 103.
} 
generaciones de peregrinos, que se había ido depositando en Compostela. Ningún otro lugar de la cristiandad había acumulado mejor esa experiencia, relatada por los peregrinos, pero vivida también directamente por Diego Gelmírez en sus viajes y por muchos de sus clérigos, enviados a estudiar a Francia o en legacías casi anuales a la curia pontificia.

El autor describe cuántas jornadas y por cuántos pueblos se pasa, desde la falda de la vertiente norte de los Pirineos hasta Santiago, para que el peregrino pueda calcular los gastos necesarios. Alaba tres grandes hospitales para peregrinos y evoca a las personas que repararon tramos del camino. Enumera los buenos y malos ríos, para seguridad de los peregrinos a la hora de calmar su sed. Caracteriza las tierras y sus gentes por las que pasan los caminos, principalmente el camino turonense, lo que nos sugiere que el autor podría ser del Poitou. En sus notas ha hecho alusión a propósito de Sahagún, la Cruz de Carlomagno, Valcarlos y Roncesvalles a episodios narrados en el Pseudo-Turpín.

La relación del Libro $v$ con el IV y la identidad de objetivos se aprecia en el capítulo 8: «De los cuerpos santos que descansan en el camino de Santiago y que deben ser visitados por sus peregrinos». Cada peregrino jacobeo partía desde su lugar de residencia y, antes o después, acababa incorporándose al camino, o a uno de los ramales existentes, antes de llegar a su unificación en Puente la Reina. En los territorios por los que transitaba había numerosas iglesias famosas por sus relicarios o por la presencia de diversos cuerpos santos, focos autónomos de devoción, que pocos peregrinos dejaban de frecuentar y visitar a la ida o a la vuelta. Al ubicar los sepulcros de estos cuerpos santos, se completa la definición del territorio que atraviesan los caminos. Con la identificación de los santos se refuerza la novedad interpretativa del Libro IV.

Uno de los colaboradores de Gelmírez, en este caso un franco, como lo fueron Hugo o Giraldo en la Historia Compostellana, definió el territorio desde las claves contemporáneas: un camino peninsular, organizado en etapas, y cuatro vías en el sur de la Galia — turonense, lemosina, podiense y tolosana. Son las vías internas de un espacio lingüístico, bien perfilado de lengua de oc, distinto de la Francia del norte propiamente dicha. Las estaciones o puntos de paso llegan por el norte hasta Tours y por el este hasta el Ródano. Un ámbito que se quiere relacionar con ese espacio del Ródano al «Padrón» jacobeo de Galicia, donde Carlomagno clavará su lanza. Como vimos más arriba, la referencia al ámbito del imperio de 
Alfonso vir indica la amplitud espacial que cabría esperar del patriarcado occidental de los obispos de Santiago.

Para el peregrino jacobeo los centros intermedios por los que transitaba eran ciertamente focos de devoción, pero su meta era el sepulcro de Santiago. La descripción de una treintena de lugares de las vías de peregrinación, donde se veneraban cuerpos santos, podía presentarlos como elementos complementarios y hasta subordinados al gran foco que era el sepulcro de un apóstol. La principal descripción y el centro de la atención debía ser, lógicamente, la basílica apostólica, sede del patriarcado de Occidente, pero las noticias hagiográficas sobre cada uno de estos santos, con indicación del día de su festividad, constituye a pequeńa escala un retablo en el que destaca mejor el gran corpus litúrgico-hagiográfico que es el Libro de Santiago. Un camino donde reposan los evangelizadores de la primera hora, avala la misión evangelizadora de Santiago en Espańa, la gran novedad de la ampliación del Liber Sancti Jacobi a partir de ca. 1135. Un camino donde reposan los mártires de la cruzada subraya el sentido que desde Santiago se quiere dar a la cruzada hispánica.

En ese retablo de evangelización y cruzada comparecen los varones apostólicos y los héroes del Libro iv. En el punto más oriental de la vía tolosana, en Arlés, junto al Ródano: san Trófimo, ordenado obispo por san Pablo, y el cementerio de Aliscamps, cuerpos de muchos santos mártires y confesores; y en Toulouse, san Saturnino.

En la vía lemosina, se evita a san Marcial; pero en Vézelay se menciona a la Magdalena, cuyo cuerpo había sido enterrado primeramente en Aix por su compañero san Maximino, discípulo de Cristo, primer obispo de Aix, para ser después trasladado a Vézelay. En Périgueux, san Frontón, obispo consagrado en Roma por san Pedro,

En la vía turonense, en Saintes, san Eutropio, ordenado obispo por el papa Clemente. En este punto, el componente litúrgico-hagiográfico de esta sección se desequilibra definitivamente al transcribir íntegramente su pasión, de la que se hace autor a su compañero san Dionisio, obispo de París. Finalmente, en Blaye se venera el cuerpo del mártir Roldán y en Belin los cuerpos de Oliveros, Gandelbodo, Ogier, Arestiano, Garín y otros. Los sepulcros de los varones apostólicos y de los mártires de la cruzada se concentran en este espacio del sur de la Galia, vinculado al apóstol Santiago por sus Caminos. 
La ampliación del Liber, llevada a cabo con la elaboración de los Libros IV y V entre ca. 1135 y ca. 1139, y las nuevas tesis que exponía explican que también se actualice el Liber de 1110, se dé entrada a los nuevos postulados, se ańadan nuevos materiales y se asuma en muchas de sus piezas la nueva autoría del papa Calixto II.

En el actual Libro III se aíslan con facilidad los materiales nuevamente incorporados. Recuperada oficialmente en Compostela la tesis de la predicación en Hispania, como se afirma en el Libro Iv, el nuevo relato de la traslación ${ }^{89}$ combina predicación y traslado, cosa que nunca había hecho la epístola de León en sus diferentes versiones, que se limitaba a dar cuenta de la traslación, sin mencionar la predicación. El nuevo relato empieza con la dispersión de los apóstoles, la llegada de Santiago a Hispania y la elección de los siete varones apostólicos, que ahora son, de nuevo, Torcuato y sus seis compañeros, como en las versiones más antiguas, para intentar conciliarlas con los reparos puestos por Gregorio viI. Pero a partir de este punto, estos siete varones apostólicos pasan a un discreto segundo plano. Santiago regresa a Jerusalén, aparentemente sin los siete discípulos, y allí padece el martirio.

El traslado a Galicia lo realizan unos discípulos, cuya identidad no se desvela. Ya en Galicia, entran en escena muchos de los detalles que habían ido enriqueciendo el relato de la traslación: Lupa, el rey de Duio, el hundimiento del puente, los toros amansados, el dragón del Monte Sacro, la cristianización del palacio y templo pagano de Lupa y la sustitución del mismo por la iglesia con el sepulcro. Mientras los discípulos continúan la evangelización, dos de ellos permanecen allí y son enterrados junto a su maestro, no los tres de las versiones más antiguas de la carta de León. Los matices son sutiles. El relato no concreta qué pudo haber sido de Torcuato y sus compañeros y, por tanto, no cuestiona la versión antagónica, ni tampoco que hubieran podido ser ordenados obispos en Roma por Pedro y Pablo o que el cuerpo de Torcuato descansase en Guadix, como afirma el Pseudo-Turpín.

Nótese que la versión de la translatio, que se corresponde con el nivel del Liber a la altura de 1110 , es decir, la carta del papa León ${ }^{90}$, no se elimina de la 
compilación. De hecho, el relato propuesto a la altura de ca. 1135-1139 confirma la novedad de la carta de 1110: que habían sido dos y no tres los discípulos enterrados junto a Santiago. Sutilísimamente se quieren hacer compatibles las tesis de Gregorio vir sobre los varones apostólicos con la predicación de Santiago en España.

Para defender la misión hispánica, explicar a fondo la compatibilidad con las tesis papales y la coherencia básica entre la carta del papa León y el nuevo relato más ambicioso, que incluye la predicación, se prepara un prólogo justificativo y aclaratorio ${ }^{91}$. Los principales discípulos de Santiago fueron doce. Tres fueron elegidos en Jerusalén — Hermógenes, Fileto y Josías - y nueve en Galicia. Son Teodoro y Atanasio y Torcuato y los otros seis varones apostólicos. De ellos, siete acompañaron a Santiago a Jerusalén y trajeron su cuerpo a Galicia, mientras dos continuaban la evangelización en Galicia.

Este prólogo certifica que Compostela ha prescindido definitivamente de Calocero y los otros cuatro varones apostólicos compañeros de Teodoro y Atanasio. Efectivamente, el prólogo da por hecho que los otros siete, es decir, Torcuato y sus seis compañeros, después de que Santiago recibiese sepultura, fueron ordenados obispos en Roma por Pedro y por Pablo y fueron enviados a predicar a España, aceptando así la muy antigua versión, recordada por Gregorio viI, que los identificaba como discípulos de Pedro y Pablo. Naturalmente, de este modo Diego Gelmírez reconocía hacia 1135, como no podía ser de otro modo, que la iglesia hispánica era en origen romana, si bien este origen podía, y para el arzobispo debía, ser compatible con la predicación directa de otro apóstol.

El prólogo se apoya en la carta del papa León para identificar a Teodoro y Atanasio como los discípulos que descansaron junto a Santiago. En cambio, Torcuato y sus compañeros fueron finalmente enterrados donde señalaban los textos litúrgicos altomedievales. Torcuato ciertamente en Guadix, como sostiene el Libro IV.

Otro capítulo importante, incorporado ahora al Libro de Santiago, es la reinterpretación del sentido de las fiestas de Santiago y la institución de la fiesta de los milagros, a celebrar el 3 de octubre ${ }^{92}$. Los milagros eran la clave de la acción 
apostólica de Santiago, de ahí el interés en instituir tercera festividad. La fiesta del 30 de diciembre, que en 1080 conmemoraba la vocación apostólica, celebraba desde 1110 la vocación y la traslación. El largo camino recorrido desde 1080 se pone de manifiesto en este capítulo. A las fiestas se le quiere dar una justificación particular, en función del culto sepulcral compostelano. El martirio de Santiago ocurrió un 25 de marzo, como le fue revelado a un conocido del papa Calixto. La razón para celebrarlo el 25 de julio, fecha señalada por el martirologio atribuido a san Jerónimo, supuestamente ratificada por un papa Alejandro y, posteriormente, por Beda el Venerable, es que el cuerpo de Santiago fue llevado de Iria a Compostela ese mismo día.

Justificada así la fiesta del 25 de julio, la del 30 de diciembre tiene también una fácil explicación: el traslado a Compostela se hizo el 25 de julio, pero la obra del sepulcro duró desde agosto a diciembre. El autor prosigue su argumento y acepta que «la fiesta de la traslación y elección» de Santiago fue instituida en el día 30 de diciembre por un famoso emperador hispano, Alfonso, porque «la traslación no era menos insigne que la muerte», y, en consecuencia, el Pseudo-Calixto la confirma.

Adviértase de que el fundamento de la fiesta del 30 de diciembre era en 1080 la vocación apostólica y en 1110 la vocación y traslación. Ahora, poco antes de 1140, la clave para ambas festividades es la traslación en sus diversas fases, que históricamente se habría completado un 30 de diciembre, una vez finalizada la construcción del sepulcro en Compostela. La vocación apostólica ha pasado a un segundo plano, en beneficio de la traslación, según lo ratifica el Pseudo-Calixto. La descripción de la pomposa procesión del 30 de diciembre, en la que participaba el venerable rey Alfonso, parece casar bien con Alfonso vi. Pero algún detalle sugiere que, aunque se aluda a Alfonso vi, no se excluye el protagonismo de Alfonso vir. Las mitras con las que se ataviaba parte del clero compostelano dependen de una concesión de Pascual II, datada en el último o el penúltimo año del reinado de Alfonso vi. En cualquier caso, se trata de ensalzar los símbolos imperiales, como «el admirable cetro de plata del imperio hispano» o la «espada de doble filo, que era llevada desnuda delante del rey», que el Pseudo-Turpín, a propósito de Carlomagno, nos recuerda que era un símbolo imperial. Ya fuese Alfonso vi o su nieto Alfonso viI, el «obispo» que 
delante de él marchaba dignamente solo puede ser Diego Gelmírez, puesto que en la procesión participaban también los setenta y dos canónigos.

Como acabamos de comprobar, es posible aislar en el actual Libro III la parte que había sido escrita hacia 1110 y los materiales añadidos poco antes de 1140 . Lo mismo ocurre con el actual Libro is, en el que la colección de milagros de 1110 subsiste intacta, salvo en lo tocante a la masiva atribución de los milagros a la autoría de Calixto ir. En efecto, el Libro de Santiago, tal como había quedado organizado por Diego Gelmírez en la Compostela de hacia 1110, es la base sobre la que se opera también en Compostela poco antes de 1140, para ultimar esta especie de Gesta Beati Jacobi, atribuidos al papa Calixto II. La adición de un milagro datado en 1135 (II, 13), incompatible con la cronología del papa, es un indicio muy importante para datar la ampliación del Liber ${ }^{93}$.

Los cambios afectaron de lleno al actual Libro I. Otro de los grandes objetivos de Gelmírez a la altura de 1135 fue revisar la liturgia del 25 de julio y 30 de diciembre, cuyo alcance no se limitó a introducir la fiesta de san Josías del 26 de julio. Para las dos fiestas de Santiago se prepararon los textos del oficio divino y se compusieron unas misas, cuidadosamente elaboradas, adecuadas para un apóstol y mártir, que recogiesen la importancia del martirio y de la predicación en Hispania, para presentar la nueva liturgia como obra autorizada, en la medida en que se atribuía al papa Calixto II $^{94}$. Como en el caso de la tesis de la predicación y del himno $O$ Dei Verbum, empleado en el Pseudo-Turpín, a la altura de 1135 Diego Gelmírez estaba igualmente decidido a recuperar materiales de la liturgia propia de la festividad del 30 de diciembre, tal como se había celebrado antes de la introducción del rito romano hacia 1080. El nuevo oficio divino y el misal con nuevos textos atribuidos a la autoría de Calixto van acompañados de partituras y piezas atribuidas a otros autores contemporáneos. En las anáforas figuran antífonas tomadas de la Passio magna.

Al leccionario de 1109-1110 se le añadieron seis nuevas piezas, con las que este adquiere su forma actual. Fueron pensadas para introducir la nueva perspectiva

93 CC II, 13, Herbers / Santos Noia, p. 169.

94 Adalbert Hämel (Überlieferung und Bedeutung des Liber Sancti Jacobi und des Pseudo-Turpin, München, 1959, p. 49-50) entiende que las misas proceden de los usos litúrgicos de Compostela. De hecho, la incorporación de la pasión de Santiago según la Historia Eclesiástica como lectura, de la que luego se nutre el oficio, supone una nueva etapa de la transformación del oficio romano propio de Santiago. 
compostelana de los años 1135-1139 en los días más importantes: cuatro como lecturas para el día 25 de julio, una pieza para la octava de la pasión, en el día 31 de julio, y la última para el 30 de diciembre. Pero no se eliminan del leccionario las piezas de 1080, ni las de 1109-1110. La acumulación de materiales para las lecturas de estos tres días se justifica porque son los únicos con nueve lecciones, frente a las tres de los restantes días.

El caso de la Passio modica y de la Passio magna es muy particular. La recuperación de estos antiguos textos y sus personajes en 1135-1139 sintoniza con las reflexiones contemporáneas sobre cuántos fueron los discípulos de Santiago, introducidas en el Libro III (CC III, 3), en los que se menciona a Josías, Hermógenes y Fileto. Hasta este momento la estructura del leccionario era clara y constante: el sermón siempre va precedido de la correspondiente perícopa de las Escrituras. Con las pasiones ocurre al revés. En ambos casos van precedidas de sendos prólogos, atribuidos al papa Calixto ir. La Passio modica coincide con el relato de Eusebio de Cesarea ${ }^{95}$. El prólogo de la Passio magna refuta la opinión de quienes la tienen por apócrifa ${ }^{96}$. Su incorporación al leccionario está estrechamente relacionada con las preocupaciones de este momento, como por ejemplo la identificación de los discípulos de Santiago.

La atención a los discípulos pone en el punto central al mártir Josías, para el que se habilita una fiesta a celebrar el 26 de julio. Por lo demás, en el texto de la Passio magna se introducen ciertas interpolaciones, comprensibles desde la perspectiva compostelana de 1135-1139. Así, en la oración de Santiago se introduce la predicación en Hispania al poner en sus labios las siguientes palabras: «he sido testigo de tus milagros hasta en los pueblos de Occidente, entre los que padecí mucho por Ti, infamias, blasfemias, burlas y contiendas». Ocurre de nuevo al relatar el martirio: «la cabeza no cayó a tierra, sino que el santo apóstol, lleno de la virtud de Dios, la recogió en sus brazos elevados al cielo y así permaneció de rodillas y sosteniéndola entre ellos, hasta que llegó la noche y recogieron el cuerpo sus discípulos. Entre tanto, algunos, enviados por Herodes, intentaron arrancarle la cabeza, mas no pudieron, porque se les agarrotaban las manos sobre 
el preciosísimo cuerpo de Santiago». Esta interpolación está claramente enfocada a desautorizar el incipiente culto a la cabeza de Santiago el Mayor en Jerusalén.

Finalmente, como cabría esperar, se le incorpora también la translatio: sus discípulos «le encontraron, como hemos dicho, de rodillas y sosteniendo la cabeza con los brazos; colocaron su cuerpo y cabeza en un zurrón de piel de ciervo con preciosos aromas y le transportaron de Jerusalén a Galicia por el mar, acompañándolos un ángel del Señor, y le sepultaron donde se le venera hasta el día de hoy».

Los cuatro sermones, añadidos al leccionario hacia 1135-1139, presentan como rasgo común la carencia de la pertinente perícopa. Como hemos visto más arriba, los tres más antiguos remiten a la recepción del día 25 de julio y el giro dado a la festividad del 30 de diciembre, con ocasión de la introducción de la liturgia romana en la catedral compostelana hacia 1080. Otros diez constituyen el armazón que sustenta el oficio propio de Santiago, puesto en pie por Gelmírez hacia 1110. En cambio, los cuatro sermones de ca. 1135-1139 juegan un papel claramente diferente. A ninguno de ellos le precede la pertinente perícopa bíblica. Ninguno fue concebido como explanación de un texto sagrado concreto, sino que los cuatro fueron escritos con la finalidad de introducir, en un leccionario de Santiago ya articulado, los nuevos y audaces puntos de vista, cuidadosamente evitados en los textos de las fases precedentes. Los cuatro fueron escritos ad hoc, como muy tarde entre 1135-1139. Se autorizan mediante la atribución a un papa: tres a Calixto II y uno a un papa León. Al modo de pequeños tratados, carentes de perícopas previas, gozan de una mayor libertad para incorporar al cuerpo del comentario cuantos pasajes de las Sagradas Escrituras parezcan más oportunos.

El Celebritatis sacratissime, propuesto como lectura para el día 25 de julio ${ }^{97}$, defiende la primacía de Santiago sobre el colegio apostólico, si bien concediendo que solo la tiene en el cielo, pues en la tierra le corresponde a Pedro. En consecuencia, en una línea que recuerda el estatuto de la iglesia de Santiago, según el concilio de Compostela presidido por Carlomagno, el Pseudo-Calixto manda que las fiestas de Santiago se celebren en toda la iglesia universal, no solo en las iglesias de Galicia: el 25 de julio con vigilia, ayuno y octava; y el 30 de diciembre se conmemorará su elección y traslado de Jerusalén a Galicia. Como corresponde a un sermón escrito en esta tercera fase, aparece la innovación de la tercera fiesta

97 CC I, 5, Herbers / Santos Noia, p. 29-33. 
del 3 de octubre, dedicada a los milagros de Santiago, que se justifica también en la contemporánea ampliación del Libro III. El papa, en nombre de Dios «y del Apóstol», levanta cualquier posible entredicho puesto sobre cualquier iglesia, para que en ella se pueda celebrar el oficio divino con maitines y horas propias. Las tres fiestas de Santiago se celebrarán en toda la iglesia universal, del mismo modo que se festejan las de los apóstoles Pedro y Pablo.

El sermón Spiritali igitur iocunditate, propuesto como lectura para el 25 de julio ${ }^{98}$, no se limita a justificar la acción apostólica de Santiago mediante los milagros, como en 1109-1110, sino que introduce abiertamente la predicación occidental, tema característico de las preocupaciones de la etapa 1135-1139. La innumerable cantidad de sus milagros la defiende el autor con un notable conocimiento de los tratados médicos. Afirma que la medicina divina, que administró Santiago, curó a enfermos de más de una treintena de enfermedades diferentes, mejor de lo que médicos famosos, como Hipócrates, Dioscórides, Galeno, Macro, Vindiciano, Sereno o Tuli, lo hubieran podido hacer con una docena de recetas concretas. Al leer estos párrafos, conviene recordar la presencia en Compostela del médico Roberto de Salerno, que acompañaba a Gelmírez en sus viajes. La predicación queda también expresamente defendida: «desde Jerusalén hasta Galicia divulgó el nombre del Señor»; "fue salvación hasta el extremo de la tierra, porque dio a conocer con su palabra hasta en las últimas islas del mar a Aquél que es su salvación en todo el mundo» y «desde Judea hasta el mar Mediterráneo u occidental propagó las doctrinas evangélicas».

El tercer sermón, Exultemus in Domino, está propuesto como lectura para la octava de la pasión, el 31 de julio ${ }^{99}$. Para autorizarlo, y al mismo tiempo disimular la composición en Compostela hacia 1135-1139, se atribuye a un papa León. Como en el Pseudo-Turpín, resuena en este sermón la teoría de las tres sedes ${ }^{100}$. El autor aplica a Santiago el Mayor la afirmación de san Pablo referida a Santiago el Menor: Pedro, Santiago y Juan fueron constituidos en príncipes y columnas de los demás. Su intención es subrayar la superioridad de Santiago: «es digno de

98 cC I, 6, Herbers / Santos Noia, p. 34-41.

99 CC I, 15, Herbers / Santos Noia, p. 78-82.

100 La trascendencia de esta teoría la puso de manifiesto Klaus Herbers, Der Jakobuskult des 12. Jahrhunderts und der "Liber Sancti Jacobi». Studien zum Verhältnis zwischen Religion und Gesellschaft im hohen Mittelalter, (Historische Forschungen 7), Wiesbaden, 1984, p. 72-81. 
alabanza S. Pedro, porque dejó sus bienes ante el llamamiento del Señor. Pero aún es mayor la alabanza que debemos a Santiago», porque Pedro "poco, o casi nada, dejó en comparación de Santiago».

También le aplica a Santiago el Mayor el pasaje de las Disposiciones de Clemente de Alejandría: «Pedro, Santiago y Juan, después de la Ascensión del Salvador, aunque a todos por Él hubieran sido antepuestos, sin embargo ninguno se apropia la gloria de serlo, sino que Santiago, a quien llamaban el Justo, fue nombrado Obispo de los Apóstoles». Con estos argumentos el Pseudo-León cree haber justificado que Santiago fue antepuesto a san Pedro.

Si en el concilio de Santiago Carlomagno había invocado el himno $O$ Dei verbum, aquí menciona el himno un supuesto papa León con idéntica finalidad: fundamentar la primacía hispánica de la sede compostelana. En efecto, la petición de María Salomé de una sede especial para su hijo encuentra respuesta, porque Santiago fue trasladado después de su martirio "por sus discípulos a España y en la extremidad de Galicia, que ahora se llama Compostela, fue honoríficamente sepultado, no solo para regir con su patrocinio a los españoles que le habían tocado en suerte, sino para confortarlos con el tesoro de su cuerpo». España se apoyó en otro tiempo en las columnas de Hércules, pero ahora se apoya en «la firmísima columna de Santiago». Primero el papa León I, después el emperador Carlomagno, pero siempre en un Libro de Santiago gelmiriano: «Compostellana ecclesia, columna iustitie et ecclesiastica atque seculari potentia magis suffulta».

En el Exultemus in Domino no faltan otros motivos, característicos del momento en que se incorpora a la compilación, que, puestos bajo la autoría de un papa León, le daban al culto de Santiago una antigüedad insólita. Es el caso de la peregrinación al sepulcro de Santiago desde todas las partes del mundo o los asaltos a los peregrinos y las estafas en los albergues.

El cuarto sermón, el Veneranda dies, está previsto como lectura para el 30 de diciembre ${ }^{101}$. Se trata de una de las piezas más interesantes y completas, un verdadero tratado centrado en la peregrinación y su espiritualidad hacia 1135-1139. En este sentido refleja preocupaciones muy similares a las que afloran en el Libro v. Con profundidad, originalidad y conocimiento directo de la peregrinación aborda diversos motivos: vocación y traslación; Libro de Santiago; virtud apos- 
tólica mediante la predicación y los milagros desde el sepulcro; coros de peregrinos procedentes de más de setenta pueblos y naciones, reunidos devotamente durante las fiestas de Santiago en la basílica compostelana como el fruto de la obra apostólica de Santiago; diversidad de dones concedidos a los occidentales por la peregrinación y a los orientales mediante los milagros; el camino ascético del peregrino, el báculo, el morral y la concha; modelos de peregrinos a imitar desde Adán a Cristo y los apóstoles; denuncia de abusos y fraudes a peregrinos y exhortación a los responsables: mesoneros, albergueros, estafadores, falsos penitenciarios, enfermos fingidos, vendedoras de velas y de alimentos, cambiadores, especieros, médicos, negociantes de paños y pieles, cobradores de portazgos; la dicha de Galicia es el tesoro del sepulcro de Santiago; Santiago, custodio del alma y abogado universal en el día de la muerte; invocación a Santiago para que ore por la salvación de sus peregrinos, «que hacen el camino desde la Dacia y desde la Etiopía».

Respecto a la fecha de composición, los abusos descritos con tanto realismo en el Veneranda Dies son un indicio complementario sobre su cronología. Para atajar los desmanes cometidos en Compostela en la venta del vino, la sidra, la carne, el pescado, el pan, la cera, las especies, las herraduras, el calzado, los cueros, las pieles por parte de taberneros, carniceros, pescaderos, panaderas, albergueros, monederos, cambiadores, herreros o zapateros, tanto con los ciudadanos, como con los forasteros, los canónigos, jueces y ciudadanos de Compostela, con autorización de Alfonso vil y del arzobispo Gelmírez, aprobaron en 1133 un decreto en el que se establecen normas de venta, precios máximos y veedores designados por el concejo ${ }^{102}$.

Los numerosos puntos de contacto del Veneranda dies con el Libro v ratifican cuanto sabemos sobre la ampliación del Libro de Santiago hacia 1135-1139. El autor del Veneranda dies da por hecho que ya existía un Libro de Santiago, que es el que estimamos ultimado hacia 1110. Rechaza un largo catálogo de fábulas que se decían o se habían escrito sobre Santiago y prohíbe que nadie se atreva a escribir algo, a no ser lo auténtico «que se contiene en el códice llamado Jacobus. Pues éste contiene lo necesario para leer, o cantar en las fiestas de Santiago, lo cual está sacado de libros auténticos, como consta en él». Por un momento el autor nos 
desvela que su sermón aún no figura en ese Libro de Santiago, cuyo contenido y finalidad nos describe con exactitud. Pero, al mismo tiempo, el Pseudo-Calixto afirma en el sermón que se está procediendo a ampliar el Libro, con el mismo criterio de evitar los errores: «estamos investigando sus gloriosas gestas».

A propósito de las fábulas rechazadas, tiene gran interés la atención prestada al Petronum. Se censura tanto a quienes afirman que Santiago, cumpliendo el mandato de Cristo, vino a predicar a Galicia sentado sobre un Petronum, en medio de las olas del mar, sin barca alguna, y que un pedazo del mismo peńasco quedó en Jafa, como a quienes sostienen que este peñasco lo trajeron en la nave con el cuerpo muerto. Para el Pseudo-Calixto ambas versiones son falsas, porque ha examinado personalmente el peńasco en Padrón y pudo comprobar que es piedra del país. En cambio, acepta dos tradiciones: al desembarcar los discípulos el cuerpo del Apóstol en el puerto de Iria lo colocaron sobre él y sobre él se celebró devotamente la Eucaristía.

Por las mismas fechas Diego Gelmírez mostraba parejo interés por el Petronum. En 1134, el arzobispo completaba una completa reconstrucción de la iglesia de Santiago del Padrón, según la inscripción de la era 1171 o 1172, que se conserva en el muro meridional de la iglesia actual ${ }^{103}$. Se trata de un hecho realmente extraordinario, puesto que, entre 1101 y 1109, Gelmírez ya había reedificado «desde los cimientos hasta el techo la iglesia de Santiago de Padrón con ayuda de un presbítero de buena memoria llamado Pelayo» ${ }^{104}$.

El templo había sido fundado por el obispo Gundesindo a principios del siglo $\mathrm{x}$, en el lugar donde se creía que había sido depositado el cuerpo sin vida de Santiago ${ }^{105}$. Solo con la fábrica de 1134 adquirió la iglesita cierta prestancia, que nunca había tenido, como demuestra el relato del tercer autor de la Historia Compostellana: «la iglesita pequeña y pobrísima levantada a orillas del Sar, donde había sido colocado el cuerpo del glorioso Apóstol Santiago, cuando lo sacaron de la nave», fue sustituida por otra de «tres ábsides, para construir y colocar allí con afecto de santa devoción tres altares: el de en medio en honor del gloriosísimo

\footnotetext{
103 Antonio López Ferreiro, Historia de la Santa A.M. Iglesia, I, 1898, p. 231: «D(idacus) · c(om) $\mathrm{P}($ ostellane $) \cdot \operatorname{ECC}\left(\right.$ lessi) $\mathrm{E} \cdot \mathrm{PRIMUS} \cdot \mathrm{A}($ rchiepiscopus $) / \mathrm{IN} \cdot \mathrm{ERA} \cdot \mathrm{I} \cdot \mathrm{C}^{\mathrm{a}} \cdot \mathrm{LX}^{\mathrm{a}} \mathrm{X} \cdot \mathrm{I}^{\mathrm{a}}{ }^{\prime}$.

104 En la sección redactada por Munio Alfonso, HC I, 22, Falque, p. 50-51. Lo corrobora el maestro Giraldo, HC I, 100.1, p. 164: «edificó el obispo varias iglesias, a saber: la de Santiago de Padrón».

105 López Alsina, La ciudad..., p. 189-190.
} 
apóstol Santiago, cuyo cuerpo se había hospedado en aquel sitio, y los otros dos de los lados, uno en honor de su madre santa María y el otro en honor de su hermano san Juan apóstol y Evangelista» ${ }^{106}$. La elección de los titulares de los altares refleja, una vez más, la importancia que para Compostela tiene hacia 1135-1139 el pasaje evangélico que fundamenta la teoría de las tres sedes, columnas de la Iglesia.

Diego Gelmírez mostraba ahora la nueva relevancia que había adquirido el Petronum, que en 1134, como hoy, era un ara romana dedicada a Júpiter, colocada bajo el altar principal de la iglesia. Con razón interpretaba el autor del Veneranda dies que se había utilizado como ara.

Como ha sugerido Serafín Moralejo, el Petronum, cátedra de Santiago en su misión apostólica, tenía un componente relevante para la iglesia hispánica, que se asentaba así sobre su propia y específica piedra angular. Sin embargo, la misión hispánica y la primacía ya han sido recuperadas en esta fase de ca. 1135-1139. No es tanto esa interpretación la que rechaza el Veneranda dies, cuanto la relación de Santiago con Jerusalén que en ella subyace. El Petronum está íntegro en Galicia y ningún fragmento podía haber quedado en Jafa.

Una vez más vuelve a preocupar en Compostela la cabeza de Santiago el Mayor. Una de las interpolaciones, incorporadas ahora a la Passio magna, va precisamente en esa dirección. Por primera vez aflora el motivo de que la cabeza de Santiago quedó sujeta entre sus brazos. Munio Alfonso, el primer autor de la Historia Compostellana, había añadido hacia 1110 que el cuerpo había sido trasladado «cum capite». No obstante, en 1124 el segundo autor, el maestro Giraldo, narra cómo Gelmírez adquirió la cabeza de Santiago y relata la entrada triunfal, verdadero «adventus», de la reliquia en la ciudad en 1117, hecho del que Giraldo fue testigo ocular. Y, sin embargo, la interpolación de la Passio magna recalca el matiz señalado, porque pretende desmentir cualquier posibilidad de que la cabeza se hallase todavía en Jerusalén, precisamente cuando se insiste en negar que una parte del Petronum pudiese estar en Jafa.

106 HC III, 36.3, Falque, p. 484-485. Cf. Fernando López Alsina, «De Santa Eulalia de Iria Flavia a Santiago de Padrón: la transformación medieval», en Escritos dedicados a José María Fernández Catón, coord. Manuel C. Díaz y Díaz, León, 2004, II, p. 819-868. 
La coherencia de esta ampliación del leccionario compostelano, mediante la adición de seis nuevas piezas, hecha hacia 1135-1139, se pone también de manifiesto por el hecho de que los nuevos textos se incorporan como material de lectura obligatoria justo para aquellos mismos días que una de estas seis piezas, el sermón Celebritatis sacratissime, manda que se celebren en todas las iglesias de la cristiandad.

Hacia 1135-1139 este mandato universal iba especialmente dirigido a Jerusalén. Uno de los principales objetivos de la compilación de 1135-1139 es deslegitimar desde Compostela la nueva veneración al apóstol Santiago el Mayor, surgida en la ciudad de Jerusalén.

Poco antes de la primera cruzada, tuvo lugar en Jerusalén la inventio milagrosa de la cabeza de Santiago el Mayor, precisamente en el lugar que se presentaba como el escenario del martirio del Apóstol. El culto en Jerusalén a la parte más noble del cuerpo de Santiago se hizo más popular a raíz de la primera cruzada y, lógicamente, preocupó en Compostela. Cruzados y peregrinos occidentales, como Mauricio de Coimbra, conocieron directamente este nuevo culto y entre ellos, o por medio de ellos, empezaron a circular diversas «fábulas», cuando no reliquias, que acabaron por llegar a Occidente. En Santiago estos relatos se conocieron mucho antes de que los peregrinos y cruzados de la segunda mitad del siglo XII empiecen a documentarlas en sus escritos. Téngase en cuenta que en Compostela existía desde el siglo XI una iglesia dedicada al Santo Sepulcro ${ }^{107}$.

Según el relato de un clérigo alemán, Juan de Würzburg, que viajó a Palestina hacia 1165, en el lugar del martirio de Santiago, es decir, en el oratorio de los armenios, se veneraba la cabeza del Apóstol. Allí fue informado el peregrino de que el cuerpo de Santiago el Mayor «discipuli sui in Joppe navi impositum in Galiciam detulerunt», pero «capite suo in Palestina remanente». Y añade: «eadem testa adhuc in eadem ecclesia peregrinis advenientibus ostenditur» ${ }^{108}$.

Un relato anónimo, escrito hacia 1180 , recoge las noticias sobre el «Petronum» de Galicia y el Petronum de Jafa, escenario ya de frecuentes milagros ${ }^{109}$.

107 HC I, 15.5, Falque, p. 36. La iglesia cambió de advocación al recibir el cuerpo de la mártir Susana en 1103 .

108 Titus Tobler, Descriptiones Terrae Sanctae ex saeculo VIII, IX, XII et XV, Leipzig, 1874, p. 108-192, concretamente, 161.

109 Véase el De locis sanctis et populis et bestiis in Palaestina vitam degentibus vi.2, según Sabino 
La misma coherencia que presenta el conjunto de materiales ańadidos hacia 1135-1139 como lecturas se aprecia también entre el Veneranda dies y el Libro $\mathrm{v}$, no solo por la atención prestada al camino, a los peregrinos, a la cultura y a la espiritualidad de la peregrinación, sino también en ciertos puntos de contacto, característicos de una misma fase redaccional. Detalles como la impiedad atribuida a los navarros, las referencias a los cobradores de portazgos en Ostabat, San Juan y San Miguel del Pie del Puerto de Cize y a ciertos santuarios de peregrinación se abordan tanto en el Veneranda dies como en el Libro v.

\section{Después de Gelmírez: el destino del Libro de Santiago}

Al final de la década de 1130, siempre después de la coronación imperial de Alfonso vir en 1135 y en pleno pontificado de Inocencio II (1130-1143), culminaba la ampliación del Libro de Santiago. El nuevo Liber puede entenderse como una especie de Gesta Beati Jacobi, complementaria de la que el propio Gelmírez promovía en paralelo como Gesta episcopi et archiepiscopi compostellani. La obra se dio por formalmente concluida y, en consecuencia, se confeccionaron las piezas inicial y final, en las que se desarrollan las ficciones sobre la autoría y la génesis del libro.

La primera pieza justifica el nombre oficial de la compilación. La obra se bautiza por la materia que trata y, por ello, el libro se llama Iacobus ${ }^{110}$. La epístola introductoria, atribuida al papa Calixto II, acredita la autoría pontificia y el acopio de materiales durante catorce años ${ }^{111}$. Hay que reconocer que parecía plausible que Guido de Vienne se hubiese interesado por el culto a Santiago desde

de Sandoli, Itinera Hierosolymitana crucesignatorum (saec XII-XIII): textus latini cum versione italica, III, [Jerusalén] 1988, p. 29 y 42: «Nunc autem tacendum non est inter cetera miracula, quod apud Jopen in litore maris lapis est quidam, ad quem maxima multitudo et infinitas piscium more peregrinantium in estate conveniunt qui salue vocatur, habentes lineas ex longo super dorsum croceas et deosculantem lapidem, quasi sanctuarium aliquod cito recedunt. Piscatores illius terre referunt, quod cum Dominus preciperet beato Jacobo, ut in Galitiam iret, respondit beatus Jacobus: Cum lapis iste uenerit mecum, et ego ueniam; et tunc lapis diuisus est per medium et medietas delata est in Galiticiam, vbi hodie a peregrinis uisitatur et dicitur pecerius S. Jacobi; et alia medietas ibi remansit». Creemos que donde se lee "pecerius S. Jacobi» ha de interpretarse «Patronum S. Jacobi».

110 Herbers / Santos Noia, p. 7: «Ex re signatur, Iacobus liber iste uocatur».

111 Id., p. 7-8. 
que su hermano Raimundo fuese nombrado conde de Galicia. Había estado en el reino de León tras la muerte de Raimundo para defender los derechos de su joven sobrino, el futuro Alfonso viI, y mantuvo estrechas relaciones con Gelmírez, que había bautizado y ungido rey al niño que se educaba en Galicia. En el colofón el autor explica que escribió el libro en siete lugares — Roma, Jerusalén, la Galia, Italia, Alemania, Frisia y, principalmente (precipue), Cluny- ${ }^{112}$. Según la epístola, Calixto II sometió el libro al juicio de la comunidad de Cluny, del patriarca Guillermo de Jerusalén y del arzobispo Diego de Compostela, para que lo corrigiesen, si lo estimaban necesario, por ser los varones más excelentes en dignidad y honor. Como Gelmírez aspiraba a que Roma le reconociese el estatuto de patriarca de Occidente, nada más lógico desde el punto de vista compostelano que el papa consultase con el patriarca latino de Jerusalén, instituido por Roma tras la primera cruzada, y con el arzobispo de Santiago. Una vez hecha esta consulta, el colofón nos dice que la iglesia romana fue la primera en recibir el libro, lo que resulta normal puesto que el libro había de leerse a lo largo del año litúrgico en todas las iglesias.

La autoría, la duración de la empresa, los lugares donde se escribió y la entrega a la curia romana forman parte de la misma ficción: presentar a la iglesia de sepulcral del apóstol Santiago como columna iustitie et ecclesiastica atque seculari potentia magis suffulta y ocultar que ha sido elaborado en Santiago, por inspiración del arzobispo Gelmírez, canciller y capellán del emperador Alfonso vII. El estatuto que merece la sede apostólica compostelana se lo ha concedido el emperador Carlomagno, pero lo ha ratificado la autoridad pontificia de Calixto II. El Libro de Santiago, atribuido al papa Calixto, pero ultimado en Compostela en los últimos ańos de la cuarta década del siglo XII, recoge los puntos de vista y el arsenal de argumentos que el arzobispo Gelmírez estaba dispuesto a utilizar para alcanzar de Inocencio II, el quinto papa al que enviaba legados, la concesión del patriarcado de Occidente. Gelmírez murió en marzo de 1140, tres años antes que Inocencio II, sin haber alcanzado su objetivo.

$\mathrm{Al}$ igual que otras empresas institucionales iniciadas o promovidas por Diego Gelmírez, como el Tumbo A, la Historia Compostellana, la fábrica de la iglesia 
románica, también el Libro de Santiago fue objeto de posteriores modificaciones que pretendían perfeccionarlo.

No existe un manuscrito que refleje única y exclusivamente el estado original del Códice Calixtino, tal como quedó ultimado en los últimos años de la vida de Gelmírez. El ejemplar que posee la Catedral de Santiago es una copia posterior ${ }^{113}$, en la que se advierte alguna novedad, ajena a la compilación original. Tres de ellas merecen aquí nuestra atención, porque constituyen otros tantos indicios acerca de la fecha en que se pudo haber efectuado la copia conservada.

La primera innovación llevada a cabo en Compostela respecto al Liber de Gelmírez es la carta del papa Inocencio $\mathrm{II}^{\mathrm{II} 4}$ y el milagro relatado del año 1139 , escrito por Alberico. Según la ficción del colofón del libro de Calixto II, el códice había sido entregado a la iglesia romana. En algún momento pareció oportuno completar la ficción y dar cuenta de la forma en que el Códice Calixtino había llegado a la catedral compostelana. Según esta carta pontificia, un ejemplar de aquel códice, compuesto "primeramente» por el papa Calixto, fue donado a Santiago de Galicia por Aimerico Picaud y sus compañeros. Lógicamente la ficción sugiere que, a partir del ejemplar romano que poseía Inocencio II, se hizo la copia, de bellísima ejecución, que la carta papal afirma que iba a ser llevada a Compostela. El papa confirma la veracidad del libro, que es ajeno a toda malicia herética y apócrifa y que debe ser tenido por un códice eclesiástico auténtico y estimable.

$\mathrm{Al}$ igual que la atribución del Liber a Calixto II no se hizo hasta unos quince años después de la muerte del papa, tampoco parece posible que se haya inventado esta carta en vida de Inocencio II (1130-1143). Por tanto, la carta se ha fraguado en la misma Compostela, como muy pronto durante el arzobispado de Pedro Helías (1143-1149), etapa en la que, con toda probabilidad, se escribe la tercera y última parte de la Historia Compostellana, que relataba los hechos de Diego Gelmírez entre los años 1124 y 1140, y que describe los últimos esfuerzos

113 Díaz y Díaz, El Códice, p. 314: «cuando se decidió copiar la copia que poseemos ya existía un modelo, bien estructurado y limpio. La existencia de tal manuscrito modelo queda firmemente establecida por la corrección general del ejemplar presente, por la disposición y elaboración de algunos elementos decorativos y la presencia en el Códice de capitulaciones, no organizadas en el mismo, sino ya en ejemplar anterior, donde se habían confeccionado después de efectuada la preparación, ordenación y disposición de los textos».

114 Cc f. 221, Herbers / Santos Noia, p. 268. 
del arzobispo por obtener de Inocencio II el estatuto patriarcal. De alguna manera, para la Iglesia de Santiago la falsa bula de Inocencio II contenida en el Liber viene a reemplazar la auténtica que nunca llegó.

Nótese que, en último término, la carta de Inocencio II viene a ser el certificado papal de la autenticidad de un nuevo ejemplar del Liber, lo que, al mismo tiempo, legitima cualquier innovación que se haya querido introducir respecto al supuesto modelo romano de Calixto II, que servía de modelo a la copia. Es decir, la ficción de la carta pontificia permite que con facilidad se puedan introducir en el contenido del Liber de Diego Gelmírez los elementos necesarios para dar credibilidad a la falsa llegada del libro a Santiago.

Con toda intención, la carta papal relaciona a los portadores con el Poitou y con Santa María Magdalena de Vézelay. Como el Libro v describía con mayor detalle la vía turonense, que pasa por el Poitou, y en ciertos pasajes se refería a hechos y circunstancias posteriores al papa Calixto II, resultaba así perfectamente lógico que esos pasajes del Libro v se debiesen a la pluma del poitevino Aimerico. Para ello solo había que introducir en las rúbricas de algunos capítulos del Libro v la autoría de Aimerico, como es el caso de los capítulos 5 y 9.

El milagro escrito por Alberico, abad de Vézelay, obispo de Ostia y legado pontificio, forma parte del mismo artificio. Con toda intención, se data en el año 1139, con el complemento sincrónico del reinado de Luis rey de los francos y «el pontificado de Inocencio II» ${ }^{115}$. La autoría por un abad de Vézelay hace verosímil que Aimerico haya podido tener acceso al mismo. La condición de legado pontificio, en tiempos de Inocencio II, le da al milagro una autoridad similar a la que recibe la copia del Liber a través de la carta pontificia. La conexión con el artificio de la epístola papal queda subrayada todavía más por otro recurso: el legado Alberico, obispo de Ostia, es el último de los ocho confirmantes de la carta papal. En realidad, mediante tales procedimientos la sede compostelana pretende presentar esta versión ampliada, ligeramente retocada respecto al Liber de Gelmírez, como la única realmente existente en Compostela, que acabaría por reemplazar al Liber original. La inclusión de las dos piezas, carta papal y milagro, tenían como finalidad hacer verosímil que la copia de bellísima ejecución ya había sido entregada en Compostela en vida del arzobispo Gelmírez, que había muerto en 1140. Desde 
ahora el Liber compostelano conserva su estructura, que se inicia con la epístola introductoria y finaliza con el colofón, pero tras el colofón se copian la carta de Inocencio ir y del milagro de 1139.

La nueva versión del Liber, en la que Aimerico comparte autoría con Calixto II, resuelve también el grave problema que para la credibilidad de la autoría exclusiva de Calixto in planteaban la datación del milagro del año 1135 y las precisiones cronológicas relativas al comienzo de la catedral románica, primero mediante una referencia absoluta, por lo demás errónea, que lo sitúa en el año $1078^{116} \mathrm{y}$, en segundo lugar, indirectamente mediante el tiempo transcurrido desde la colocación de la primera piedra hasta la muerte de tres reyes: cincuenta y nueve años para Alfonso I de Aragón (m. 1134), sesenta y dos para Enrique I de Inglaterra (m. 1135) y sesenta y tres para Luis vi de Francia (m. 1137). Una supuesta intervención de Aimerico en el texto del Liber, llevada a cabo en tiempos del papa Inocencio II, solventaba estas dificultades.

Una segunda innovación en el texto del Liber, introducida al mismo tiempo que la carta de Inocencio ir y el milagro relatado por Alberico, se refiere a la conclusión de la obra de la catedral. El Liber, ultimado en los ańos finales del arzobispado de Gelmírez, cuando no podía dar por acabada la construcción de obra románica, entonces todavía en curso. Semejante acontecimiento no habría dejado de relatarse en la Historia Compostellana. De hecho, en el curso de la detallada descripción de la iglesia, como no podía ser menos, el Liber afirma explícitamente que de todo lo que se ha descrito parte está completamente terminado y parte por terminar ${ }^{117}$.

Cuando en Compostela se lleva a cabo esta revisión del Liber, una vez muerto Gelmírez, ya había finalizado la obra de la catedral y se había concluido su cierre occidental. Por eso en la rúbrica que daba cuenta del inicio de las obras «De lapicidibus ecclesie et de primordio (et fine) operis eius» se intercalan las dos palabras entre paréntesis y en el texto referente a la colocación de la primera piedra se añade la siguiente frase relativa a la colocación de la última: «et ab anno quo primus lapis in fundamento eius ponitur, usque ad illum quo ultimus mittitur

116 CC V, Ix, Herbers / Santos Noia, p. 256.

117 CC v, Ix, Herbers / Santos Noia, p. 254: «sed ex his que diximus alia sunt iam omnino adimpleta, aliaque adimplenda». 
XLIIII anni habentur». La fecha ante quem se puede dar por finalizada la catedral románica, y por tanto la intervención en el Liber de Gelmírez, es el año 1168, data de la concesión de Fernando ir al maestro Mateo.

Como hemos visto, esta adición no se limita a alterar las rúbricas, sino que modifica el texto, lo que abre la posibilidad de que haya habido otras intervenciones puntuales en otros lugares de la obra, problema interesante acerca de su nivelación final. En cualquier caso, la falsa noticia, al situar la colocación de la última piedra dentro del arzobispado de Gelmírez — poco importa que realmente se quiera datar cuarenta y cuatro años después de 1078, es decir, en 1124_, una vez más demuestra la voluntad de ocultar todo lo posible que la manipulación del texto es posterior a Gelmírez.

La tercera de las innovaciones realizadas en Santiago sobre el Liber de Gelmírez es la adición de un complemento con himnos y música, constituido por el cuaternión 27 y correspondiente a los folios 212-219. Como explica Díaz y Díaz, el cuaderno se preparó completo, al mismo tiempo que los cuadernos precedentes, aun sabiendo que el texto a copiar del original solo ocuparía dos folios más. Como no se habría planeado dejar en blanco seis folios, «resulta obvio concluir que, en el momento de la confección del cuaderno, ya se contaba con el Complemento al que irían destinados» ${ }^{118}$. La novedad musical de estas piezas consiste en el canto a dos voces, frente a las composiciones musicales del Libro i en canto «gregoriano» monódico con los neumas escritos sobre una pauta de cuatro líneas. Como advirtió López-Calo, el escriba que copia aquí la música monódica del libro primero es el mismo que copió la polifonía del complemento ${ }^{119}$. Es más, después de haber transcrito la polifonía en el complemento, se «actualizaron» dos piezas musicales del Libro I para convertirlas en polifónicas. Al parecer, el estilo musical de la polifonía del complemento, que lo aproxima a las corrientes musicales parisinas, no debe ser anterior a 1175 , lo que podría constituir un indicio valioso para datar la copia y, por tanto, la fecha de ejecución del ejemplar compostelano del Calixtino.

118 Id., p. 154.

119 José López-Calo, La música en la Catedral de Santiago, vol. v: La Edad Media, La Coruña, 1994, p. 90. 
Conviene subrayar que esta segunda intervención en el Liber de Gelmírez se atiene al mismo principio que la primera, realizada antes del año 1168, con resultados idénticos. No es casualidad que la última pieza musical del complemento, el himno Ad honorem Regis summi, sea atribuido a Aimerico Picaud, presbítero de Parthenay ${ }^{120}$. Con esta atribución, se puede seguir manteniendo tanto la ficción de su coautoría con el papa Calixto II, como la cronología de la intervención en el pontificado de Inocencio ir y en vida de Gelmírez. Es decir, también en este caso se pretende hacer creer al lector que el libro que tiene entre las manos es el que se trajo a Compostela en vida de Gelmírez. Reforzando la ficción, las dos primeras piezas que figuran en el apéndice que sigue al complemento son precisamente la carta de Inocencio II y el milagro narrado por Alberico. Las dos primeras intervenciones, operadas en Compostela sobre el Liber de Gelmírez tras la muerte del arzobispo, pretenden ocultar la fecha en que se realizaron para hacer creer que el códice así ampliado se había ultimado en vida del arzobispo. Tal era el respeto a su memoria.

Esta segunda intervención, cuyo resultado es el códice actualmente conservado en la Catedral de Santiago, tuvo que realizarse después de la primera. No se puede descartar que la segunda intervención pueda ser anterior a 1173, fecha de la copia de Arnaldo del Monte. López-Calo sospecha que Arnaldo llegó a saber de la existencia del Liber a través de la música que oyó ejecutar en la catedral compostelana. Como su copia no refleja el conocimiento de la ampliación polifónica, el año 1173 sería en una data post quem para la elaboración del ejemplar compostelano del Calixtino.

A modo de conclusión, creo que han quedado suficientemente expuestas las razones por las cuales el Códice Calixtino es una obra netamente compostelana, por su génesis, sus planteamientos y sus objetivos finales, que coinciden plenamente con la dinámica de las relaciones de Santiago con la curia romana durante la primera mitad del siglo XII. También se comprenden los motivos por los cuales se recurrió a la ficción de presentarlo como una obra ajena a la sede jacobea. En la Compostela inmediatamente posterior a Diego Gelmírez, siempre se consideró al arzobispo como su responsable último. El eclesiástico, que por su cargo de can$97-101$. 
ciller y capellán regio más podía influir en las decisiones del emperador Alfonso vII y que aspiraba a obtener de Inocencio iI el estatuto patriarcal para su sede, expone ampliamente en el Liber la epopeya de la acción apostólica de Santiago el Mayor, tanto mediante su predicación en España, como mediante los milagros operados desde su sepulcro y la atracción universal de los peregrinos. Según el pensamiento de Gelmírez a la altura de 1135-1140, el estatuto patriarcal de Occidente, que le corresponde como sede apostólica, una vez que se ha constituido el Patriarcado latino en Jerusalén, solo se puede alcanzar mediante el respaldo de las autoridades regia y pontificia. La Iglesia de Santiago reformulaba, una vez más, el concepto de su apostolicidad, recuperando audazmente la idea de la predicación de Santiago en Hispania, ahora en el seno de las sedes episcopales de un imperio como el de Alfonso viI, que desde 1135 se extendía desde el Ródano hasta el Padrón de Galicia, el territorio por el que transitaban los peregrinos y los caminos jacobeos. Los clérigos compostelanos sabían muy bien cual era el valor del Calixtino, como lo resumía el autor de la nota marginal del f. 200: «erubescant igitut toletani qui superbiuntur corpus beati iacobi zebedei apostoli penes se retinere cum per testimonium summi pontificis calixti pateat compostelle in gallecia quiescere in propia baselica» ${ }^{121}$. trabajo. 